Aus dem Institut für Klinische Pharmakologie (Prof. Dr. med. J. Brockmöller) im Zentrum Pharmakologie und Toxikologie der Medizinischen Fakultät der Universität Göttingen

\title{
Molecular mechanisms of the TGF $\beta 1$ Arg25Pro polymorphism related to acute radiotherapy-induced toxicity
}

\author{
INAUGURAL-DISSERTATION \\ zur Erlangung des Doktorgrades \\ der Medizinischen Fakultät \\ der Georg-August-Universität zu Göttingen \\ vorgelegt von \\ Kateryna Filonenko \\ aus Lugansk, Ukraine
}

Göttingen 2014 
Dean:

Prof. Dr. med. H.K. Kroemer

I. Referee:

Prof. Dr. med. J. Brockmöller

II. Referee: $\quad$ Prof. Dr. rer. nat. M. Bohnsack

III. Referee: $\quad$ Prof. Dr. hum. biol. M. Schön

Day of oral examination: $\quad$ 25.03.2015 


\section{Table of Contents}

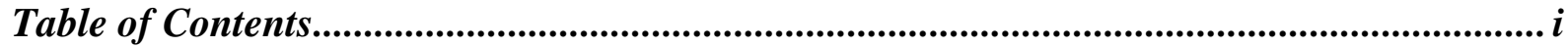

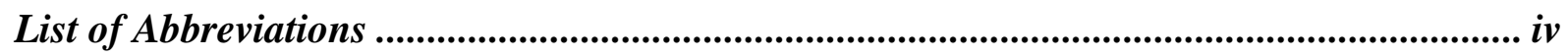

List of Figures ................................................................................................................. vii

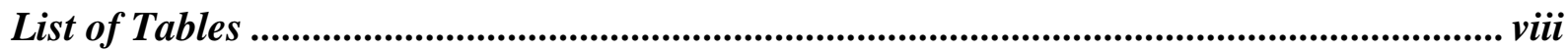

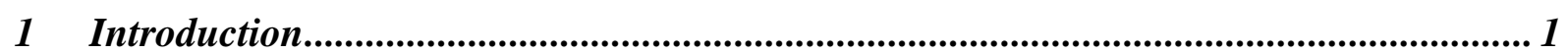

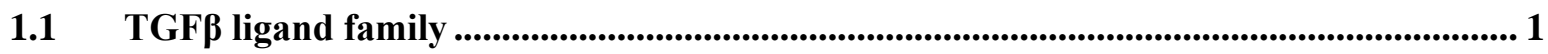

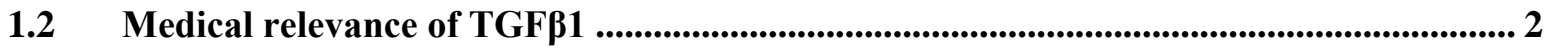

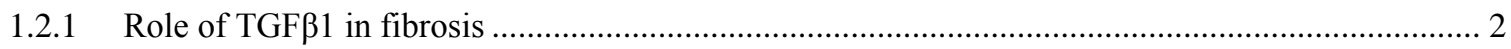

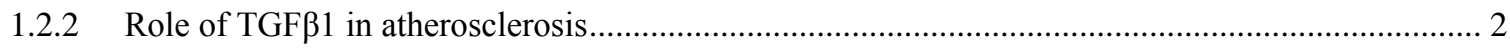

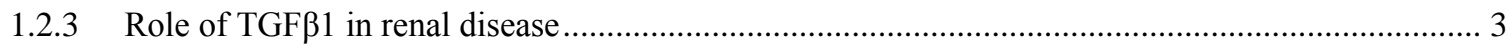

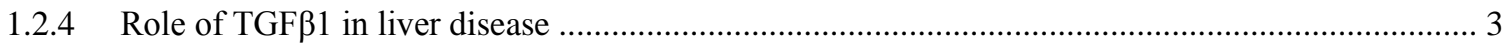

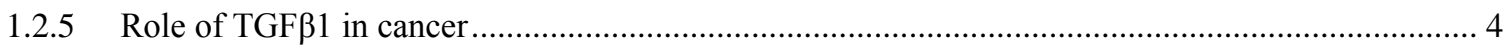

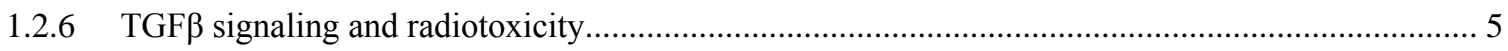

1.3 From transcription to activation and signaling of TGF $1 \ldots \ldots \ldots \ldots$

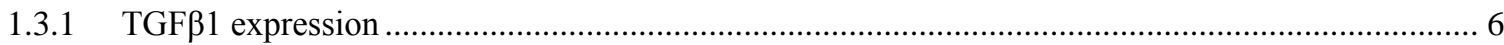

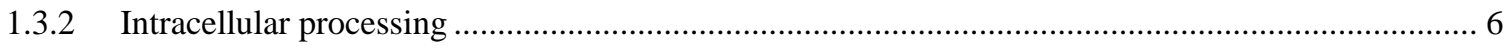

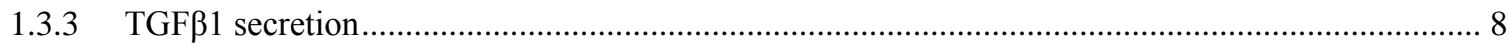

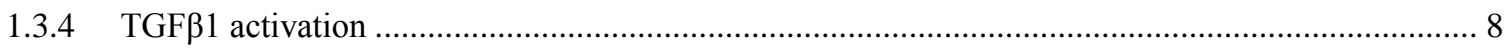

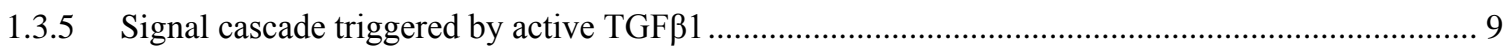

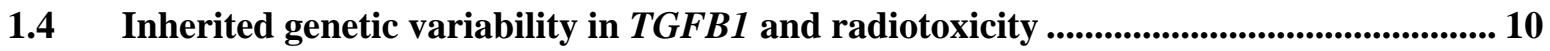

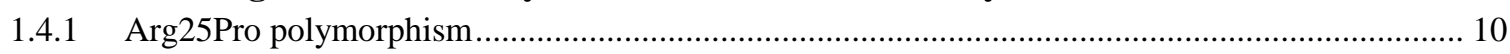

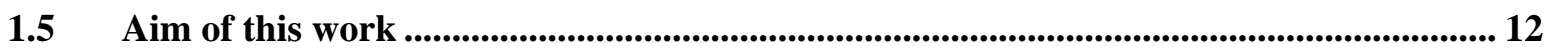

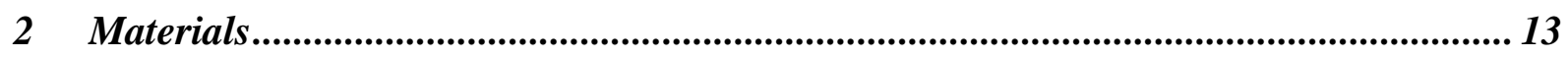

$2.1 \quad$ Equipment .............................................................................................................................................. 13

2.2 Used laboratory materials ................................................................................................................... 15

$2.3 \quad$ Reagents, kits, media .............................................................................................................................. 16

2.4 Antibodies...................................................................................................................................... 19

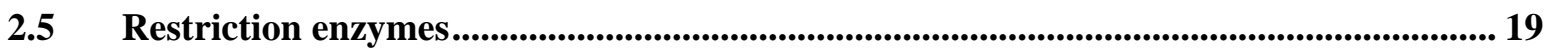

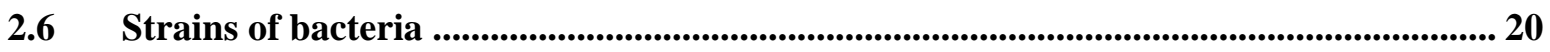

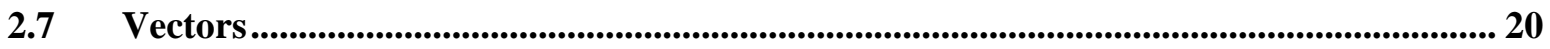

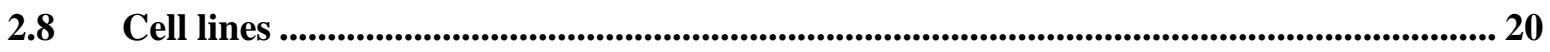

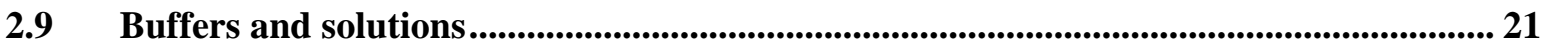

2.10 Primers ................................................................................................................................................ 24

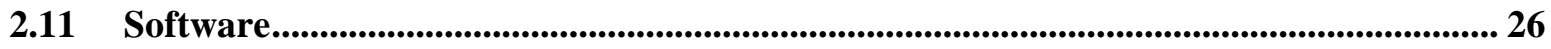

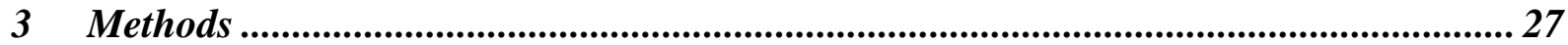

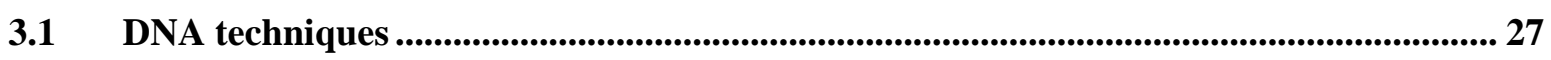

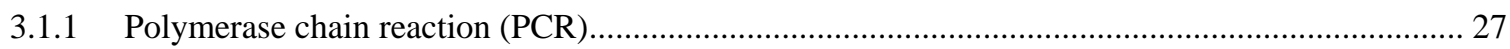




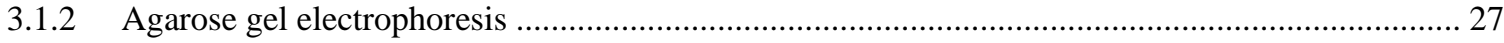

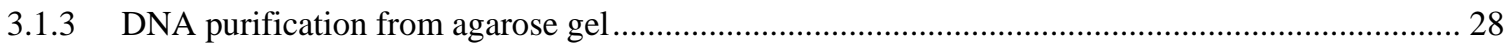

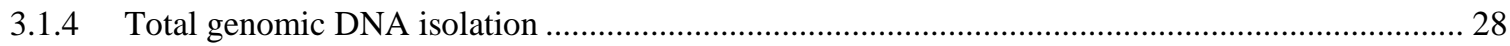

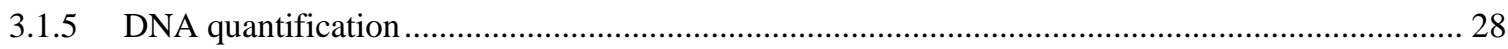

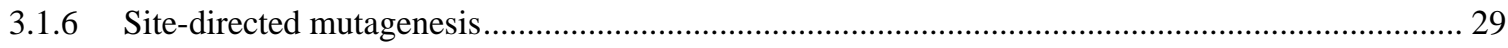

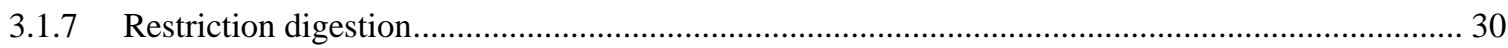

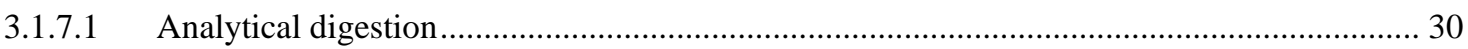

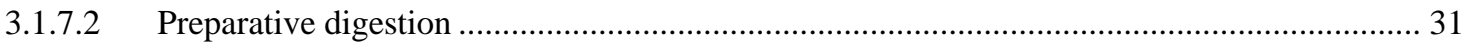

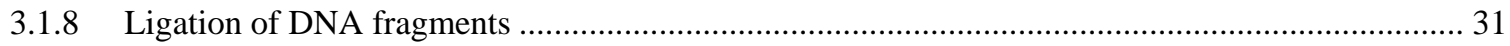

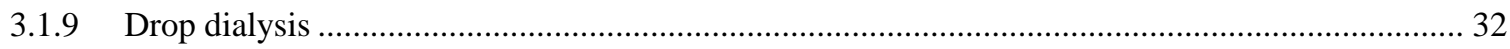

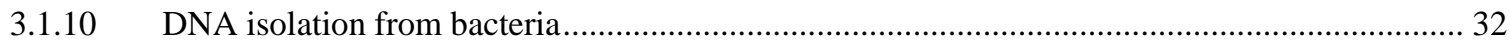

3.1.10.1 Isolation of plasmid DNA by chloroform extraction (plasmid mini-preparation) ................ 32

3.1.10.2 Isolation of plasmid DNA by solid extraction (plasmid midi-preparation) ......................... 33

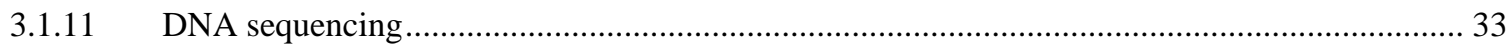

3.1.12 Genotyping by single base primer extension method $\left(\mathrm{SNaPshot}{ }^{\mathrm{TM}}\right)$............................. 35

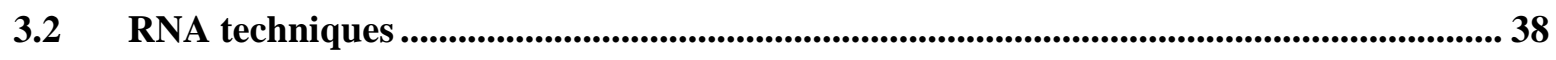

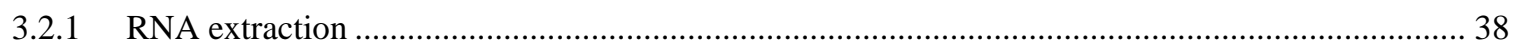

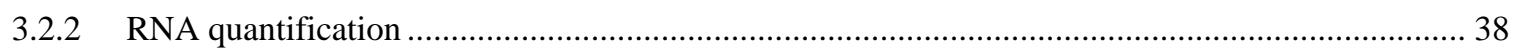

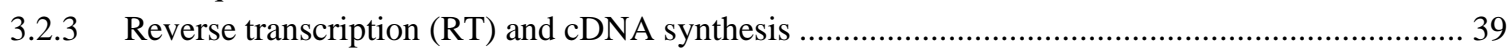

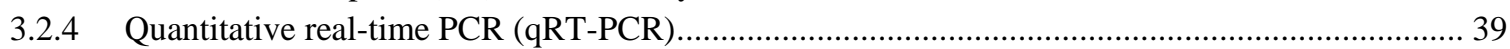

3.3 Protein techniques ...................................................................................................................... 41

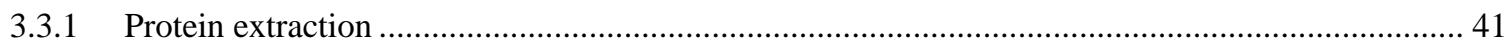

3.3.2 Quantification of protein by bicinchoninic acid (BCA) assay................................................. 41

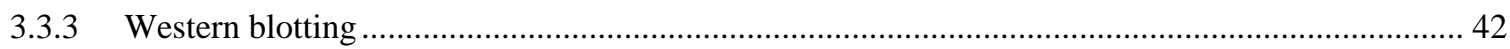

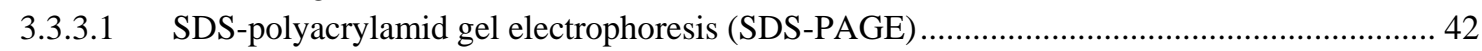

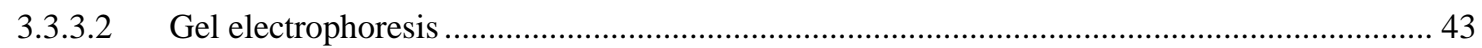

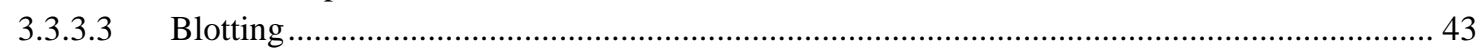

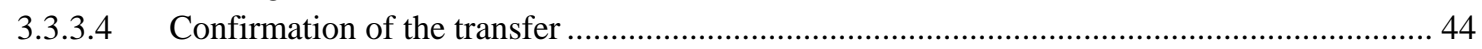

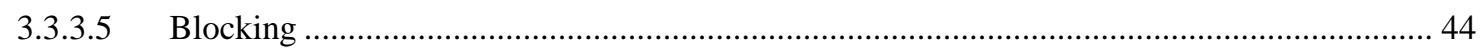

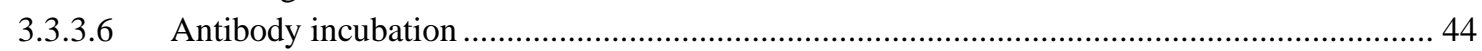

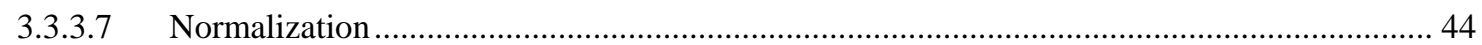

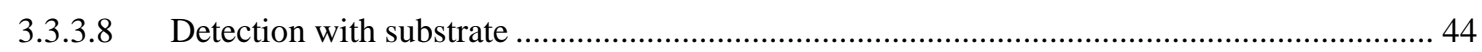

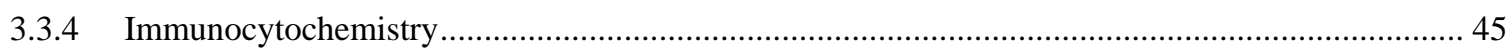

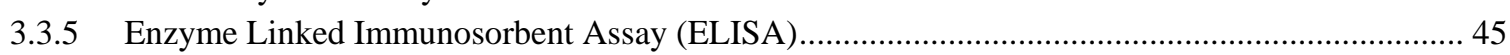

3.4 Working with bacteria .................................................................................................. 46

3.4.1 Growth conditions and long-term storage of bacteria ............................................................ 46

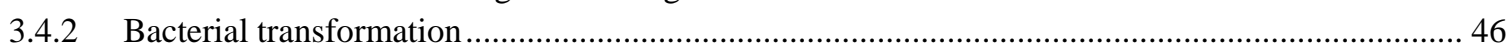

3.5 Mammalian cell culturing........................................................................................... 47

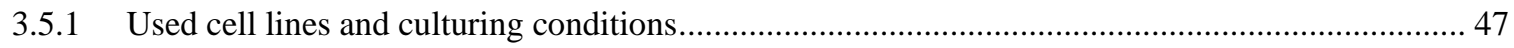

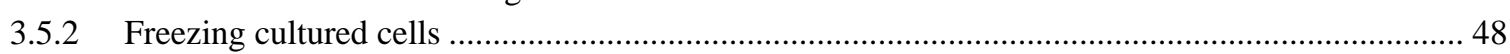

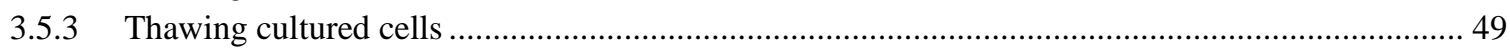

3.6 Mammalian cell transfection ............................................................................................... 49

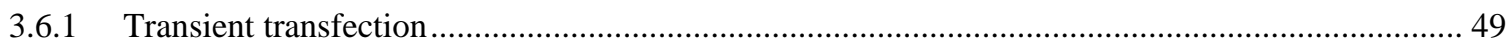

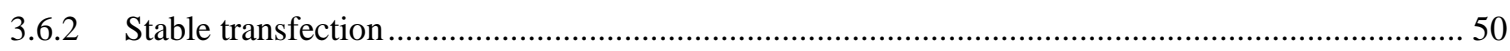

3.6.2.1 Validation of chromosomal integration of the constructs in pcDNA 5.1 plasmid................. 51

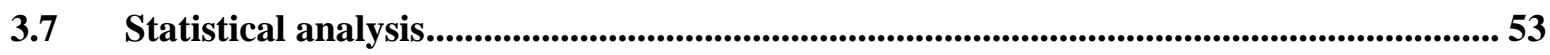

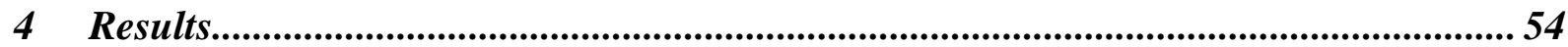

4.1 Generation and confirmation of stably transfected $T G F B 1$ constructs ..................... 54

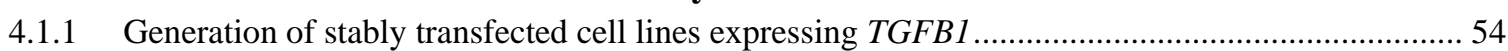




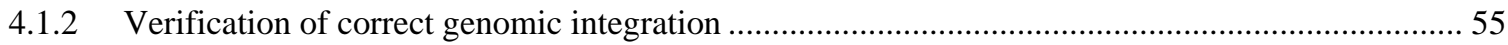

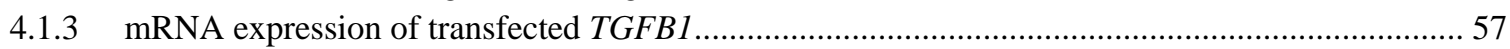

4.1.4 TGF $\beta 1$ protein expression in transfected cells .................................................................. 58

4.2 Localization of TGFß1 protein ............................................................................5 59

4.2.1 Generation and transient transfection TGFB1 with FLAG-tag behind methionine (MetFLAG) .... 60

4.2.2 Generation and transient transfection TGFB1 with FLAG tag at N-terminus of mature TGF $\beta 1$.... 62

4.2.3 Western blotting of transiently transfected TGFB1 with FLAG tags ........................................ 63

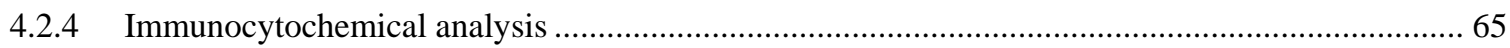

4.3 Arg25Pro polymorphism: Effects on expression ................................................................ 66

4.4 Arg25Pro polymorphism: Impact on secretion ………………………............................... 67

4.5 Arg25Pro polymorphism: Impact on activation of TGFß1 ............................................... 68

4.6 Arg25Pro polymorphism: Impact on simulated RCT......................................................... 71

4.7 Prediction of signal peptide cleavage .................................................................................. 73

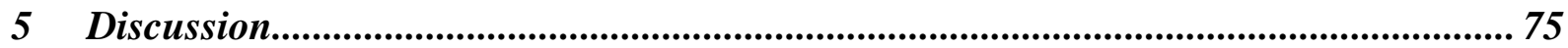

5.1 Pro25 variant results in higher secretion rate....................................................................... 75

5.2 Increased sensitivity toward $\mathrm{pH}$ activation of TGFß1 in constructs with Arg25 ........... 77

5.3 Arg25Pro polymorphism may affect cleavage of signal peptide ....................................... 77

5.4 Mechanistic suggestion for clinically observed radiotoxicity ............................................ 78

5.5 Limitations ............................................................................................................................... 80

5.6 Perspectives................................................................................................................................ 80

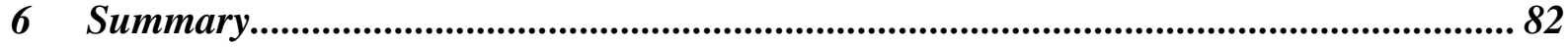

$7 \quad$ References ...................................................................................................................... 84

$8 \quad$ List of publications......................................................................................................... 95 


\section{List of Abbreviations}

\begin{tabular}{|c|c|}
\hline $5-\mathrm{FU}$ & 5-Fluorouracil \\
\hline A & Adenine \\
\hline BSA & Bovine serum albumin \\
\hline $\mathrm{bp}$ & Base pair \\
\hline $\mathrm{C}$ & Cytosine \\
\hline cDNA & copy DNA \\
\hline d- & Desoxy- \\
\hline dd- & Didesoxy- \\
\hline $\mathrm{ddH}_{2} \mathrm{O}$ & Bi-distilled water \\
\hline DMEM & Dulbecco’s Modified Eagle Medium \\
\hline DMFA & Dimethylformamid \\
\hline DMSO & Dimethylsulfoxide \\
\hline DNA & Desoxyribonucleic acid \\
\hline dNTP & Deoxynucleosidetriphosphate \\
\hline DMSO & Dimethyl sulfoxide \\
\hline DTT & Dithiothreitol \\
\hline E. coli & Escherichia coli \\
\hline EDTA & Ethylene di-amine tetra-acetic acid \\
\hline ELISA & Enzyme-linked immunosorbent assay \\
\hline et al. & et alii \\
\hline Fig. & Figure \\
\hline FBS & Fetal bovine serum \\
\hline G & Guanine \\
\hline $\mathrm{g}$ & Gravity acceleration $\left(9.81 \mathrm{~m} / \mathrm{s}^{2}\right)$ \\
\hline GAPDH & Glyceraldehyde 3-phosphate dehydrogenase \\
\hline Gy & Gray \\
\hline $\mathrm{h}$ & Hour \\
\hline HGAOT & High grade acute organ toxicity \\
\hline HEK 293 & Human embryonic kidney 293 cell line \\
\hline HRP & Horseradish peroxidase \\
\hline (k)bp & (Kilo) basepairs \\
\hline $\mathrm{kDa}$ & Kilodalton \\
\hline
\end{tabular}




\begin{tabular}{|c|c|}
\hline $\mathrm{kV}$ & Kilovolt \\
\hline LAP & Latency-associated peptide \\
\hline LB & Luria-Bertani medium \\
\hline $\mathrm{LD}$ & Linkage disequilibrium (with respect to genetic polymorphisms) \\
\hline LTBP & Latent TGF $\beta$ binding protein \\
\hline M & Molarity \\
\hline $\min$ & Minute \\
\hline mRNA & Messenger RNA \\
\hline N-RCT & Neoadjuvant radiochemotherapy \\
\hline ORF & Open reading frame \\
\hline PAGE & Polyacrylamide gel electrophoresis \\
\hline PBS & Phosphate buffered saline \\
\hline PCR & Polymerase chain reaction \\
\hline $\mathrm{pH}$ & Potential hydrogen \\
\hline qRT-PCR & Quantitative real time polymerase chain reaction \\
\hline $\mathrm{RCT}$ & Radiochemotherapy \\
\hline RNA & Ribonucleic acid \\
\hline RNase & Ribonuclease \\
\hline ROS & Reactive oxygen species \\
\hline rpm & Revolutions per minute \\
\hline RT & Room temperature \\
\hline $\mathrm{rpm}$ & Rotations per minute \\
\hline $\sec$ & Second \\
\hline SDS & Sodium dodecyl sulfate \\
\hline SMADs & $\begin{array}{l}\text { Human proteins homologous to "sma" (small TGF } \beta \text {-like pathway } \\
\text { in Caenorhabditis elegans) and "mad" (mothers against } \\
\text { decapentaplegic protein in Drosophila) }\end{array}$ \\
\hline SNP & Single Nucleotide Polymorphism \\
\hline $\mathrm{T}$ & Thymine \\
\hline Tab. & Table \\
\hline Taq & Thermus aquaticus \\
\hline TBE-Buffer & Tris-Borat-EDTA-buffer \\
\hline TE-Buffer & Tris-hydroxymethyl-aminomethan-EDTA-buffer \\
\hline TEMED & "N,N,N',N'-Tetramethylethylenediamine \\
\hline
\end{tabular}




\begin{tabular}{ll}
\hline TGF $\beta 1 / 2 / 3$ & Transforming growth factor $\beta 1 / \beta 2 / \beta 3$ \\
TGFB1 & Gene encoding transforming growth factor $\beta 1$ \\
TGFBR1/TGF $\beta$ R1 & Gene/protein name of TGF $\beta$ receptor 1 \\
TGFBR2/TGF $\beta$ R2 & Gene/protein name of TGF $\beta$ receptor 2 \\
Tris & Tris-hydroxymethyl-aminomethane \\
U & Unit \\
UV & Ultraviolet \\
v/v & Volume per volume \\
Vol & Volume \\
w/v & Weight per volume \\
\hline
\end{tabular}

Gene names are denoted in italics and the respective protein names in roman letters 


\section{List of Figures}

Fig. 1 Processing and cleavage of TGF $\beta 1$ precursor ......................................................... 7

Fig. 2 TGF $\beta 1-$ Smad signaling from the cell membrane to nucleus....................................... 9

Fig. 3 Schematic structure of the TGFB1 genetic locus on human chromosome 19 .............. 11

Fig. 4 Scheme of cloning of TGFB1 into the expression vector pcDNA5.1 .......................... 55

Fig. 5 Scheme for PCR verifying correct introduction of the hygromycin resistance region ..56

Fig. 6 Integration-specific PCR confirming the correct integration of the hygromycin resistance gene in the genome of T-REx HEK 293 cells ............................ 56

Fig. 7 Scheme for gene-of-interest PCR ........................................ 57

Fig. 8 Integration-specific PCR confirming the correct integration of the plasmid constructs in the genome of T-REx HEK293 cells...........................................57

Fig. 9 Expression rate of TGFB1 in the stably transfected T-Rex HEK 293 cells................... 58

Fig. 10 Western blot of TGF $\beta 1$ protein in transfected T-REx HEK 293 cells..........................59

Fig. 11 Scheme for insertion of FLAG tag behind methionine in signal peptide of TGF $\beta 1 \ldots 61$

Fig. 12 Scheme for insertion of FLAG at the N-terminal site of mature TGF $\beta 1$....................63

Fig. 13 Western blot for the translated product of FLAG tag behind methionine.................... 64

Fig. 14 Western blot for the translated product of FLAG tag at the N-terminus of mature

TGF $\beta 1$ 65

Fig. 15 Immunocytochemistry images indicating localization of the translated product with

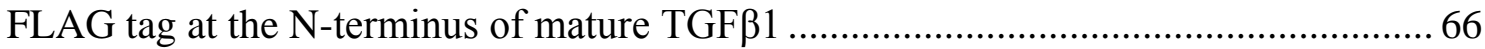

Fig. 16 Arg25Pro in regard to intracellular expression of LAP and mature TGF $\beta 1$............67

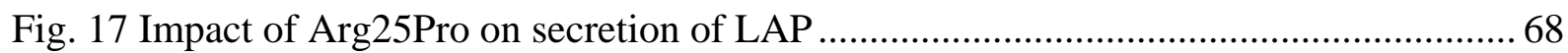

Fig. $18 \mathrm{pH}$-dependent activation of TGF $\beta 1$ in relation to total protein (A) and LAP (B)......70

Fig. 19 Impact of Arg25Pro on secretion of LAP when simulating RCT............................. 72

Fig. 20 In silico prediction of signal peptide cleavage site of the TGF $\beta 1$ precursor. .............. 74

Fig. 21 Suggested link between LAP-TGF $\beta 1$ secretion rate and acute radiotoxicity dependent on Arg25Pro. 


\section{List of Tables}

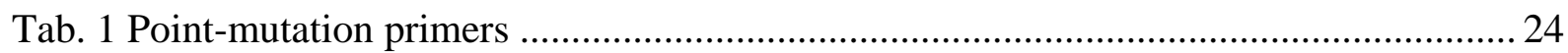

Tab. 2 Primers for amplification and subsequent insertion of $T G F B 1$ into pcDNA5.1 vector 24

Tab. 3 Primers for cloning of MetFLAG in signal peptide of TGF $\beta 1$................................... 24

Tab. 4 Sequence for cloning of FLAG at N-terminus of mature TGFß1 ............................... 24

Tab. 5 Primers for validation of chromosomal integration of the TGFB1 constructs in the

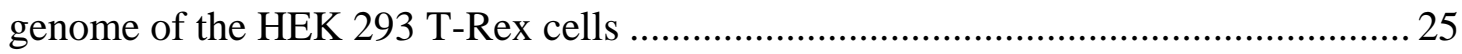

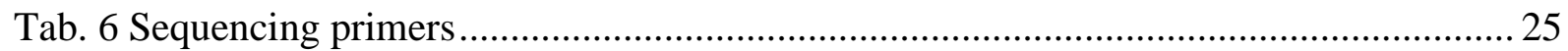

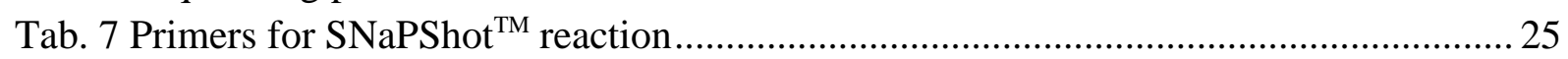

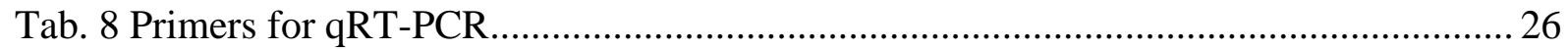

Tab. 9 PCR-reaction mixture used for site-directed mutagenesis .......................................... 29

Tab. 10 PCR conditions used for site-directed mutagenesis ................................................. 30

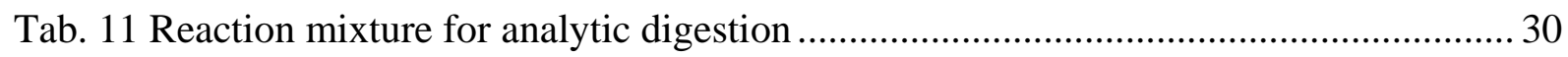

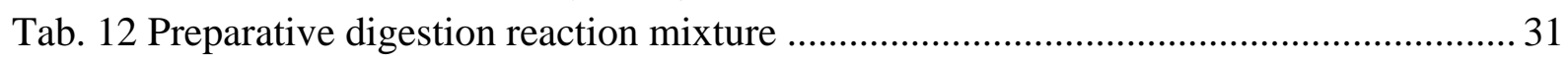

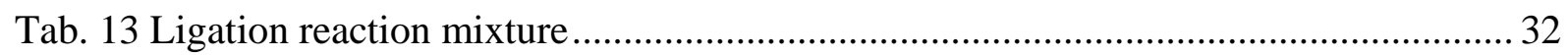

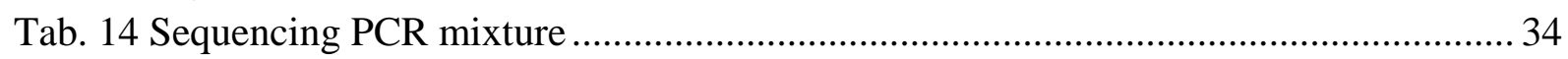

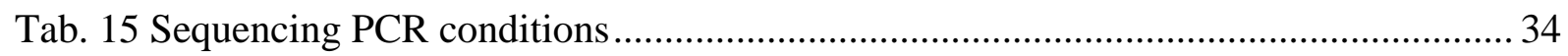

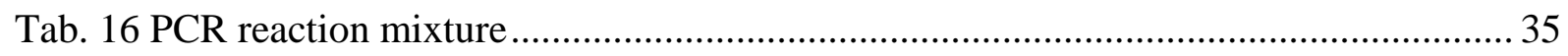

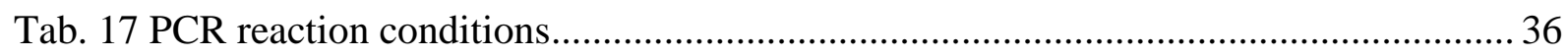

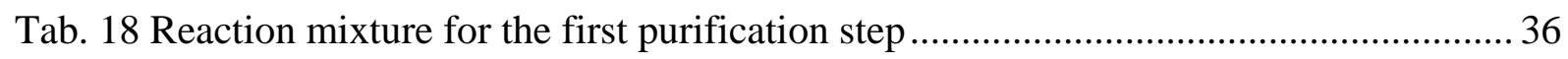

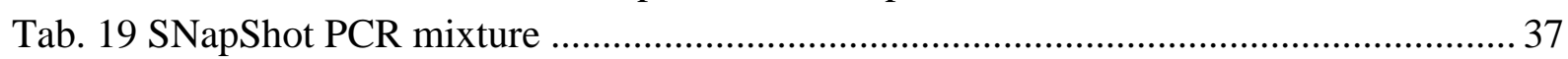

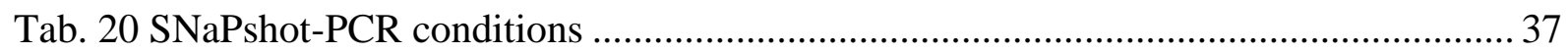

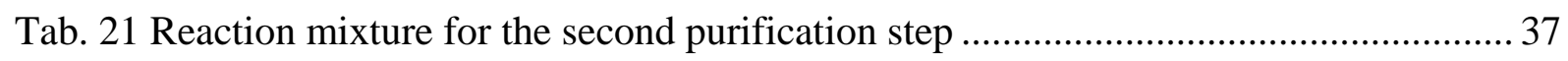

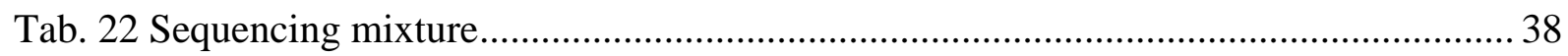

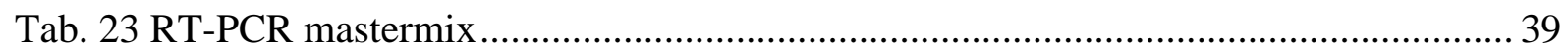

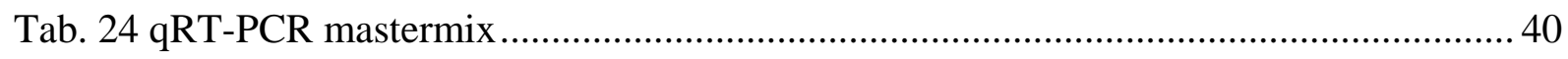

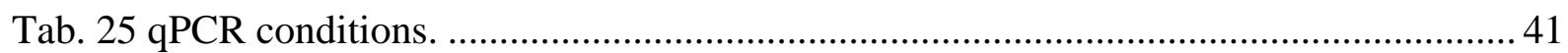

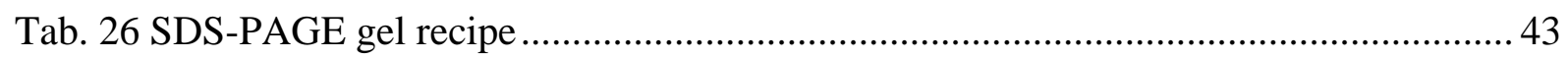

Tab. 27 Mixture for confirmatory PCR for hygromycin resistance gene integration..............51

Tab. 28 Conditions for confirmatory PCR for hygromycin resistance gene integration ..........52

Tab. 29 Mixture for confirmatory PCR for gene of interest ................................................ 52

Tab. 30 Conditions for confirmatory PCR for gene of interest.............................................. 53

Tab. 31 Linear regression analysis for the fraction of secreted LAP ................................... 74 


\section{Introduction}

The balance of signaling pathways is essential for maintaining cellular homeostasis. Signal transmission via ligands circulating through the cell surface receptors triggers specific signal transduction pathways. Inappropriate activation or inhibition of cell signaling pathways have been implicated in the development of numerous human diseases.

Among others, the transforming growth factor (TGF $\beta$ ) pathway regulates a variety of cellular processes and is playing a pivotal role in the maintenance of homeostasis of most human tissues (Gordon and Blobe 2008).

\subsection{TGF $\beta$ ligand family}

TGF $\beta$ is a multifunctional cytokine, which represents a large superfamily, composed of more than 30 related proteins in mammals, including activins and inhibins, isoforms of TGF $\beta s$ (1-3), nodal, myostatin, bone morphogenetic proteins (BMPs), anti-Müllerian hormone (AMH) and growth and differentiation factors (GDFs). The members of the family are dimeric proteins and share common sequence and structural features (Kubiczkova et al. 2012, Leask and Abraham 2004, Massague 1990, Ruiz-Ortega et al. 2007). It was shown that not only increased or decreased production of TGF $\beta$ but also mutations in the genes for TGF $\beta$ and its receptors are associated with various diseases and disorders, like cancer (Massague 2008, Massague et al. 2000), fibrotic disease of the kidney (August and Suthanthiran 2003, Bottinger and Bitzer 2002), liver and lungs (Leask and Abraham 2004, Verrecchia and Mauviel 2007, Wells 2000), atherosclerosis (Grainger 2007, Lutgens et al. 2002) hereditary hemorrhagic telangiectasia (HHT), immunomodulation (Tang et al. 2003).

Of the three known isoforms of TGF $\beta$ (TGF $\beta 1$, TGF $\beta 2$ and TGF $\beta 3$ ), TGF $\beta 1$ is the most abundant and ubiquitously expressed protein (Kubiczkova et al. 2012).

TGF $\beta 1$ is implicated in many physiological and pathological processes. It is a key player in cell proliferation, differentiation, apoptosis, adhesion, and migration. Furthermore, TGF $\beta 1$ induces production of extracellular matrix $(\mathrm{ECM})$ proteins and mediates fibrotic response (Dennler et al. 2002, Leask and Abraham 2004, Shi and Massague 2003). 


\subsection{Medical relevance of TGFß1}

\subsubsection{Role of TGFß1 in fibrosis}

Trauma or insult activates immune cells resulting in a chronic inflammatory response that initiates and perpetuates fibrosis. TGF $\beta 1$ is a major orchestrator in tissue repair, wound healing and fibrotic development in many organs including lungs, heart, liver, kidney, brain, pancreas, skin, bone, muscle (Branton and Kopp 1999, Hold et al. 2009). Depending on the disease phase, TGF $\beta 1$ plays an exacerbating or ameliorating role (Pohlers et al. 2009). Acute und limited tissue damage (like wound or inflammation) increases liberation and activation of TGF $\beta 1$ that attracts neutrophils, macrophages and fibroblasts, which in turn liberate more TGF $\beta 1$ (Leask and Abraham 2004). TGF $\beta 1$ induces the expression of ECM proteins, particularly collagen I, by stimulating gene transcription of COL1A1 and COL1A2 that encode polypeptides forming type I collagen. Simultaneously, TGF $\beta 1$ inhibits the metalloproteinases (TIMP) and matrix metalloproteinases (MMP), which degrade ECM. Transient activity of TGF $\beta 1$ leads to tissue repair and remodeling. In case of repeated injury and in a number of fibrotic diseases, persistent overproduction of TGF $\beta 1$ leads to progressive production and deposition of ECM and tissue fibrosis, that results in organ failure (Border and Noble 1994, Hold et al. 2009).

\subsubsection{Role of TGFß1 in atherosclerosis}

Numerous studies elucidated the role of TGF $\beta 1$ in the maintenance of the normal blood vessel wall architecture (Grainger 2007, Mallat and Tedgui 2002). TGFß1 was found to be an important modulator of fibrosis and immuno-inflammatory balance, which is critical in maintenance of plaque stability in atherosclerosis (Mallat and Tedgui 2002). An antiatherogenic role of TGF $\beta 1$ signaling is due to inhibition of $\mathrm{T}$ cells resulting in antiinflammatory effects (Hansson and Robertson 2004). Consistent with this hypothesis, reduced levels of circulating TGF $\beta 1$ in the plasma of patients with atherosclerosis were found (Toma and McCaffrey 2012). Due to its pro-fibrotic effects, TGF $\beta 1$ overexpression leads, on the one hand, to stabilization of atherosclerotic plaques (Mallat and Tedgui 2002), but also favors extracellular matrix growth and thus further development of the plaque (Mehta and Attramadal 2007). Inhibition of TGF $\beta 1$ signaling pathway by Apolipoprotein A, a homologue of plasminogen, promoted the proliferation of vascular smooth muscle cells. Additionally, treatment with neutralizing anti-TGF $\beta$ antibodies led to increased vascular inflammation and increased plaque instability (Grainger et al. 1994, Lutgens et al. 2002, Mallat et al. 2001). 


\subsubsection{Role of TGFß1 in renal disease}

A number of studies showed a role of TGF $\beta 1$ as a key modulator in the development and progression of renal fibrosis and inflammation in chronic renal disease (Border and Noble 1994, Bottinger and Bitzer 2002, Lan and Chung 2012). Many renal cells produce TGF $\beta 1$ and are sensitive to its effects. Mesangial cells were suggested to be one of the major sources of TGF $\beta 1$ secretion as well as to be involved in TGF $\beta 1$ activation in the affected glomeruli. In various renal disorders, such as glomerulonephritis and diabetic nephropathy TGF $\beta 1$ is upregulated in the glomeruli. TGF $\beta 1$ induces expression of ECM proteins (collagens type I, III, IV; laminin; fibronectin and heparin sulphate proteoglycans), inhibits matrix degradation by reducing the activity of ECM-degrading proteinases and upregulates synthesis of proteinase inhibitors, leading to excessive matrix accumulation. Moreover, by upregulating plasminogen activator inhibitor production, TGF $\beta 1$ counteracts the activity of matrix-degrading metalloproteinases (Kitamura and Suto 1997, Loeffler and Wolf 2014). Friedman and colleagues demonstrated overproduction of local TGF $\beta 1$ and concomitant accumulation of ECM in both acute and chronic renal diseases (Border and Noble 1993). Furthermore, in patients with different renal diseases increased urine TGF $\beta 1$ levels were observed together with increased intestitial fibrosis and mesangial matrix (Murakami et al. 1997). As TGFß1 is overexpressed in almost all renal diseases, TGF $\beta 1$ suppressing treatment with anti-TGF $\beta$ antibodies might inhibit excessive ECM accumulation and amelioration of renal fibrosis in chronic kidney disease as well as possible prevention of early glomerular lesions (Fukasawa et al. 2004). Moreover, Trachtman and colleagues first administered single-dose fresolimumab, a human monoclonal anti-TGF $\beta$ antibody, in treatment-resistant primary focal segmental glomerulosclerosis (FSGS). This phase I clinical trial showed that fresolimumab was well tolerated in patients with FSGS. Thereby, for assessment of this agent's efficacy additional evaluation in larger studies is required (Trachtman et al. 2011).

\subsubsection{Role of TGFß1 in liver disease}

Among the various cytokines, TGF $\beta 1$ secreted from both paracrine and autocrine sources is a central modulator of fibrogenic remodeling in the liver (Bottinger and Bitzer 2002, Lan and Chung 2012). In different stages of liver disease development and progression, TGF $\beta 1$ has either profibrotic or antifibrotic roles (Rosenstein 2011). Once the liver is injured, TGF $\beta 1$ stimulates proliferation of hepatocytes and induces hepatic stellate cells (HCC) activation into myofibroblasts (Bottinger and Bitzer 2002, Lan and Chung 2012, Pohlers et al. 2009). Activated myofibrobalsts orchestrates production of ECM proteins like fibronectin; collagen type I, III 
and IV, elastin, biglycan in normal and fibrotic liver (Kitamura and Suto 1997, Lan and Chung 2012). Repeated injury and/or persistent inflammation in liver, caused by various risk factors including hepatitis $\mathrm{B}$ and $\mathrm{C}$ virus infection, alcoholic liver disease, fatty liver disease, promotes liver fibrosis (Pohlers et al. 2009). Liver fibrosis is characterized by excessive deposition of ECM that distorts the architecture of the liver by forming fibrotic scars leading to organ dysfunction. Furthermore, subsequent development of nodules of regenerating hepatocytes leads to liver cirrhosis (Murakami et al. 1997, Parsons et al. 2007). Moreover, hepatocyte tolerance to TGF $\beta 1$ changes during cirrhosis development. The cells appear to become resistant to TGF $\beta 1$-induced apoptosis suggesting the presence of pre-neoplastic changes in the cirrhotic liver (Wolff et al. 2011). During liver disease progression, chronic inflammation changes the tumor-suppressive role of TGF $\beta 1$ to fibrinogenetic, therefore accelerating liver fibrosis (Arestrom et al. 2012). With progression of fibrinogenesis the expression of integrin is elevated. Integrin is a major cell surface receptor for ECM that interacts with TGF $\beta 1$ and other ECM proteins and is able to modulate signal transduction cascade (Pohlers et al. 2009). Further, a shift of TGF $\beta 1$-induced pattern of phosphorylated Smads and subsequently altered transcriptional activities were shown (Arestrom et al. 2012). Nagata and colleagues indicated that in rat administration of JNK kinases, which phosphorylate linker regions of Smads, inhibited progression of hepatocellular carcinoma (Nagata et al. 2009).

\subsubsection{Role of TGFß1 in cancer}

TGF $\beta 1$ regulates cellular proliferation, differentiation, and apoptosis. Dependent on the cell type, growth conditions and the presence of other growth factors, TGF $\beta 1$ plays multiple functions during normal development or in pathological conditions (Hyytiainen et al. 2004, Jakowlew 2006). In contrast to healthy tissues with a constant liberation of TGF $\beta 1$, injured tissues start to express TGF $\beta 1$ in high amounts to prevent inflammation (Massague 2008). During tumorigenesis, TGF $\beta 1$ has a dual nature, acting as a tumor suppressor in early stages of cancer, and switching the role to a tumor promoter at later stages (Drabsch and ten Dijke 2011). TGF $\beta 1$ exerts tumor suppressive effect by inhibiting cell proliferation and inducing apoptosis through arresting the cell cycle in G1 phase. It stimulates the production of the cyclin-dependent kinase (CDK) inhibitor p15 and thus inhibits the function of CDKs like c - Myc, which is the gene that regulates progression through the cell cycle (Blobe et al. 2000, Kubiczkova et al. 2012).

Malignant tissue often features high levels of active TGF $\beta 1$ released from the stored latent complex by increased protease expression, plasmin generation and degradation of extracellular 
matrix. During tumor development, malignant cells become resistant to growth inhibition by TGF $\beta$ through mutations and/or inactivation of TGF $\beta 1$ signaling components (such as TGF $\beta$ receptors or SMAD 2/4 transcriptional factors). TGF $\beta 1$ now appears as a pro-oncogenic factor and promotes tumor progression and metastasis. It increases invasiveness of the tumor and affects the tumor micro-environment, which induces formation of new blood vessels for delivery of nutrients and oxygen to the cancer cells (Derynck et al. 2001). Numerous studies have shown associations between an inactivated TGF $\beta$ signaling pathway and increased tumor spreading and metastasis in breast, pancreatic, colon, intestinal cancers (Border and Noble 1995, Branton and Kopp 1999, Kubiczkova et al. 2012).

\subsubsection{TGFß signaling and radiotoxicity}

Radiotherapy alone or in combination with chemotherapy is a standard treatment widely applied for patients in oncology. Whenever treatment modalities are intensified many patients suffer from acute toxicity and long-term side effects (Schirmer et al. 2012). Patients receiving same therapeutic regimens exhibit a broad range of response and side effects. In severe cases, the latter can limit a definitive cure, e.g. if dose reduction or therapy stop is required (Guirado and Ruiz de Almodovar 2003, Raabe et al. 2012, Tucker et al. 1996). It has been suggested that individual radiosensitivity is under genetic control and the radiation-induced normal tissue reactions could be potentially predicted with the help of biomarkers (Andreassen et al. 2003, Andreassen et al. 2006, Ho et al. 2006, Schirmer et al. 2011).

TGF $\beta 1$ is considered as key extracellular player for initiating and promoting adverse effects of radiotherapy (Martin et al. 2000). In plasma, elevated levels of TGF $\beta 1$ were suggested to be correlated with radiotherapy toxicity (Anscher et al. 2003, Zhao et al. 2008). However, findings were controversial (De Jaeger et al. 2004). Since tumors often produce high amounts of TGF $\beta 1$ circulating levels of this cytokine may decrease with tumor shrinking during therapy (Zhao et al. 2008).

Early response of cells toward radiation was assessed by in vivo experiments. Parenchymal and mesenchymal cells exhibited increased secretion of TGF $\beta 1$ when damaged by irradiation. Induction of TGF $\beta 1$ has been observed at the protein and messenger RNA(mRNA) level in pig skin 6 hours after $\gamma$-irradiation (16-64 Gy), and on mRNA level in mouse skin 6 hours after $\beta$ radiation (50 Gy). Moreover, elevated TGF $\beta 1$ protein level was detected in irradiated rat small intestine and mouse mammary gland and sustained from 7 (for intestines) up to 26 ( for mammary gland) days (Martin et al. 2000). 
Radiation-induced TGF $\beta 1$ expression can sustain after acute response and cause late radiation damage, particularly development of radiation fibrosis in irradiated skin (Bouquet et al. 2011). In general, via inhibition of epithelial cells and activation of fibroblasts TGF $\beta 1$ induces development of fibrous scars. TGF $\beta 1$-induced apoptosis results in parenchymal damage and fibrotic replacement of normal tissue, which affects various types of organs like intestine, bladder, lung, and liver (Martin et al. 2000).

\subsection{From transcription to activation and signaling of TGFß1}

\subsubsection{TGFB1 expression}

Transcription of TGF $\beta 1$ is induced through the activation of cellular kinases JNK, p38 MAPK, Src, and ERK. Upon binding of transcription factors such as AP-1, Sp1, NF-kB, STAT-3, which are mediated by upstream cellular kinases and belong to a category of rapid acting transcription factors (Kim et al. 1990, Presser et al. 2013), transcription and translation starts with a TGF $\beta 1$ precursor (SP-LAP- TGF $\beta 1$ ). The latter comprises a complex of 290 amino acids, which contains the TGF $\beta 1$ latency associated peptide (LAP) co-translated with the 112 amino acid sequence corresponding to the mature TGF $\beta 1$. A signal peptide of 29 amino acids precedes the LAP. This peptide chain is termed as pre-pro TGF $\beta 1$ (Janssens et al. 2005).

\subsubsection{Intracellular processing}

Processing of the TGF $\beta 1$ precursor (Fig. 1) starts with translocation to the rough endoplasmatic reticulum (ER) governed by the signal peptide, which is cut off there (Gentry et al. 1988, ten Dijke and Arthur 2007). This cutting occurs most likely between the positions Gly29 and Leu30. The released LAP-TGF $\beta 1$ monomers form disulfide-bonded homodimers within the ER. The protein structure is stabilized by several intramolecular disulfide bonds between cysteine residues. Further cysteine bonds link each the two domains of the mature TGF $\beta 1$ with one another and analogously the two LAP domains (Javelaud and Mauviel 2004, Marín-García 2011, Munger et al. 1997, ten Dijke and Arthur 2007). These pro-TGF $\beta 1$ homodimers are then translocated to the Golgi apparatus and undergo glycosylation there. Moreover, in Golgi endoproteolytic cleavage between the LAP and the mature TGF $\beta 1$ is executed by furin type enzymes (Munger and Sheppard 2011). However, the two peptide fragments (homodimeric TGF 1 1, $25 \mathrm{kDa}$, and homodimeric LAP, $~ 57 \mathrm{kDa}$ ) remain non-covalently associated termed "small latent complex" (SLC) of TGF $\beta 1$. A further protein transcribed from another genetic 
locus, i.e. a latent TGF $\beta 1$ binding protein 1 (LTBP1, $190 \mathrm{kDa}$ ), can optionally join the SLC and the complex is then called "large latent complex" (LLC) of TGF $\beta 1$ (Kanzaki et al. 1998, Khalil 1999, Maeda et al. 2002, Miyazono et al. 1991). In the LLC, LTBP binds to LAP via covalent disulfide bonds (Taipale et al. 1998).

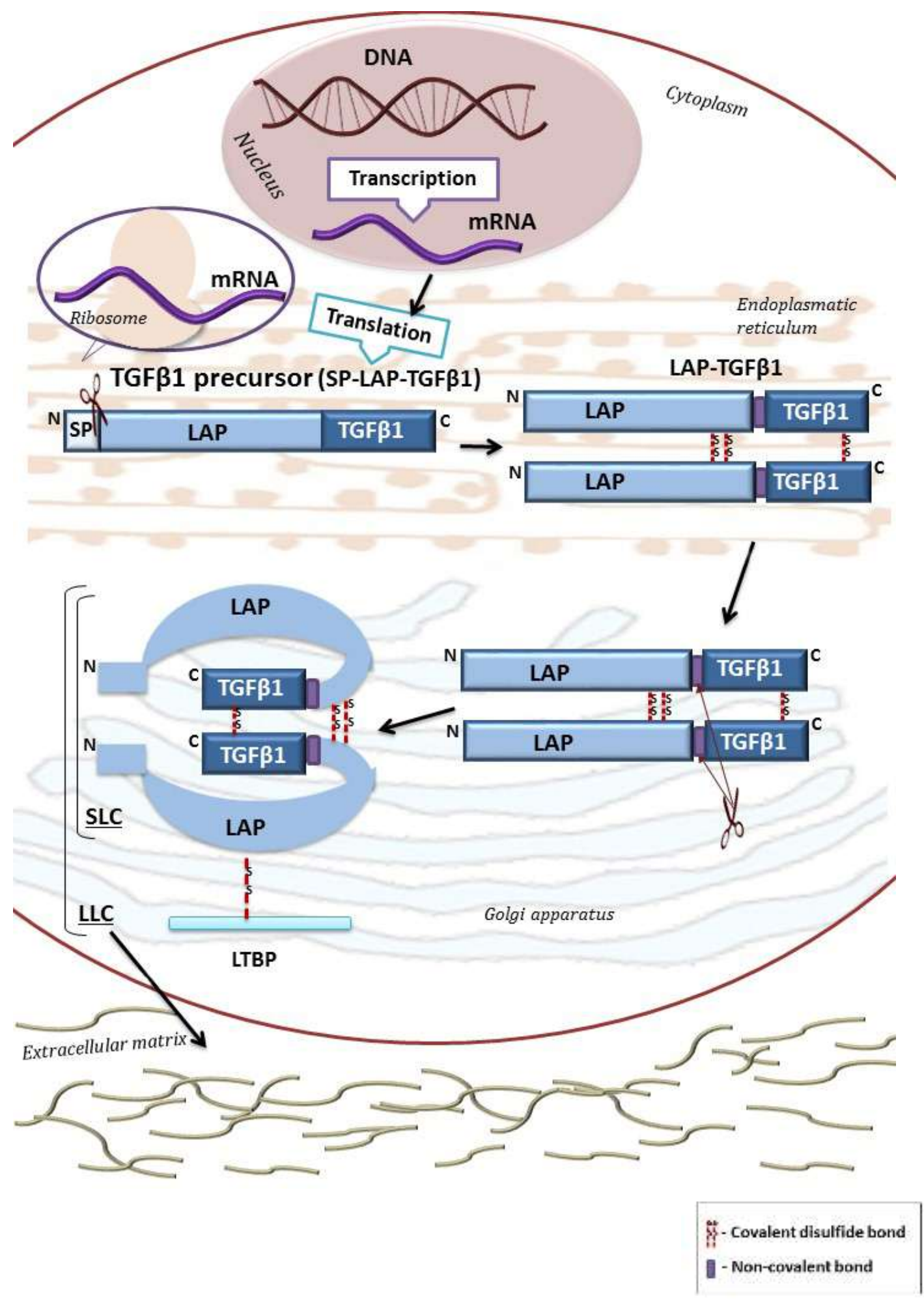

Fig. 1 Processing and cleavage of TGFß1 precursor (modified according to Miyazono, 1991). 


\subsubsection{TGFB1 secretion}

TGF $\beta 1$ can be secreted in two fashions, as SLC or LLC complex. Secretion as part of the SLC is less efficient (Dallas et al. 1994 Miyazono et al. 1991). In absence of LTBP, a major fraction of SLC is retained in the Golgi apparatus (Saharinen et al. 1999).

TGF $\beta 1$ exports in conjunction with the LLC, which is the major route for most cells secreting TGFß1 (Koli et al. 2001). Within 15 min after synthesis, LTBP binds via covalent disulfide bonds to the SLC resulting in LLC composing. Upon further $15 \mathrm{~min}$, LLC is secreted whereby LTBP targets this complex by interactions with extracellular proteins to the ECM where it is stored (Miyazono et al. 1991). Particularly, the hinge region in the N-terminus of the LTBP facilitates targeting of the LLC to the extracellular location. An isopeptide bond, i.e. a covalent link between the side chains of acidic amino acids on the one and lysine on the other side, fixes the LTBP at ECM proteins (Annes et al. 2004, Unsold et al. 2001). Subsequently, proteolysis of LTBP in the protease-sensitive hinge region liberates SLC which can bind to the cell surface where active TGF $\beta 1$ is released (Taipale et al. 1998).

\subsubsection{TGFB1 activation}

Upon binding of the SLC to the cell surface, mature TGF $\beta 1$ dissociates from LAP in order to become biologically active, i.e. to bind to the cellular receptors and to elicit multifunctional activities by launching signal cascades (Annes et al. 2003, Kubiczkova et al. 2012).

Several mechanisms for the activation of TGF $\beta 1$ are known, e.g. cleavage by furin (Dubois et al. 1995) and other proteases such as plasmin, thrombin, plasma transglutaminases or endoglycosylases (Jenkins 2008). Cleavage mostly occurs at the carboxyl-terminal site of LAP in the LAP-TGF $\beta 1$ amino acid sequence. E.g. furin, an ubiquitously expressed convertase, mostly localized in the trans-Golgi apparatus, processes the pro-protein at the carboxyl site of the consensus R-H-R-R cleavage motif (Dubois et al. 1995).

Alternatively, mature TGF $\beta 1$ can be released by physico-chemical interactions of the LAP with thrombospondin-1 (Murphy-Ullrich and Poczatek 2000), integrins (ITGs) (Mu et al. 2002, Munger et al. 1999, Sheppard 2005), hormones, vitamin A derivates, extreme pH (2-8), heat, chaotropic substances like SDS and urea (Khalil 1999). Moreover, ionizing radiation and reactive oxygen species (ROS) can be involved in TGF $\beta 1$ activation (Barcellos-Hoff and Dix 1996). Via oxidation of specific amino acid residues in the LAP ROS confer conformational changes resulting in release of active TGF $\beta 1$. This action of ROS seems to be specific for the 
TGF $\beta 1$ isoform (Jobling et al. 2006). Upon activation, TGF $\beta 1$ exerts functions via further signaling (Kubiczkova et al. 2012).

\subsubsection{Signal cascade triggered by active TGFß1}

The mechanisms elicited by receptor binding of active TGF $\beta 1$ are schematically illustrated in the Fig. 2. Active TGF $\beta 1$ binds to the TGF beta type II receptor (TGF $\beta$ R-II), which recruits a type I receptor (TGFßR-I). TGF $\beta$ R-I and TGF $\beta$ R-II are transmembrane serine/threonine kinases and form a dimeric complex on the cell surface. They have a cysteine rich extracellular domain, a transmembrane domain and an intracellular serine/threonine kinase domain. The TGF $\beta R$-II is a constitutively active kinase and activates and phosphorylates TGF $\beta$ R-I kinase in a region rich in glycine and serine/threonine residues termed the GS domain (Dennler et al. 2002, Massague and Gomis 2006). In turn, the type I receptor activates the regulatory Smad 2 and 3 transcription factors (R-Smads) by phosphorylation. Phosphorylated Smads 2/3 bind to Smad 4 and shuttle to the cell nucleus. In the nucleus, they form a nuclear complex with other co-transcription factors causing stimulation or inhibition of target genes depending on the type of co-factors present (Karathanasi et al. 2013, Massague 1998, Massague and Gomis 2006, Massague and Wotton 2000).

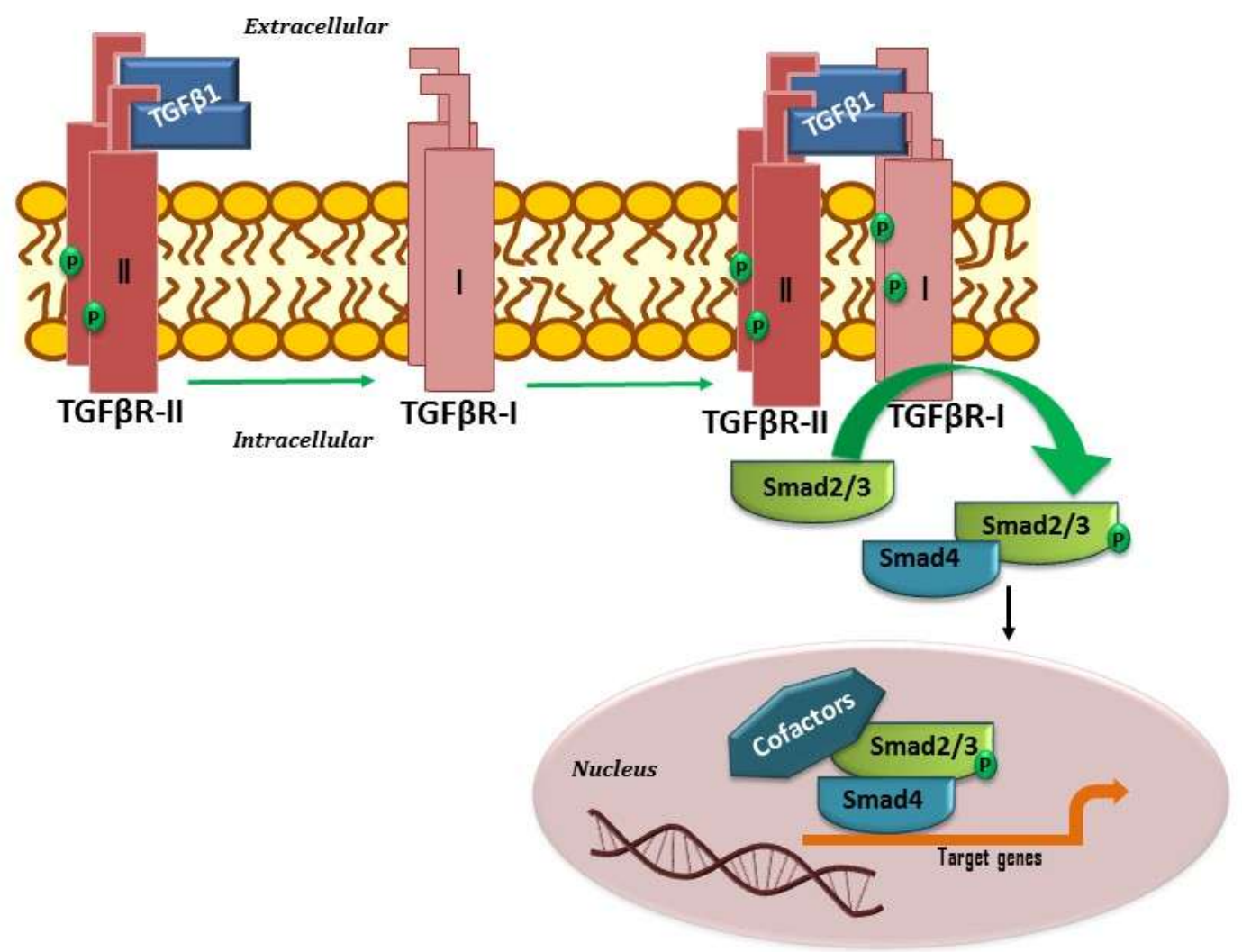

Fig. 2 TGFß1-Smad signaling from the cell membrane to nucleus (modified according to Massague 1998). 


\subsection{Inherited genetic variability in TGFB1 and radiotoxicity}

It was suggested that TGF $\beta 1$ expression is under the genetic control and several single nucleotide polymorphisms (SNPs) in TGFB1 gene were associated with the impact of circulating TGFß1 (Grainger et al. 1999) and radiotoxicity (Ho et al. 2006, Schirmer et al. 2011, Schirmer et al. 2012).

Most studies have evaluated the risk of late side effects of radiotherapy in association with two TGFB1 SNPs in high linkage disequilibrium (LD) in Caucasians: -509C>T (rs18000469) and Leu10Pro (rs1800470). However, the findings are controversial and more studies are required (Barnett et al. 2012, Raabe et al. 2012, Rosenstein 2011, Schirmer et al. 2011, Schirmer et al. 2012, Zhu et al. 2013).

Less is known about associations of TGFß1 SNPs with acute organ toxicity. Zhang and colleagues showed the significant association between TGF $\beta 1-509 \mathrm{C} / \mathrm{T}$ polymorphism and a higher radiation-induced esophageal toxicity risk in patients with locally advanced lung cancer treated with radiotherapy (Zhang et al. 2010). Moreover, relationship of the TGF $\beta 1$ Arg25Pro polymorphism and high-grade acute organ toxicity in patients with rectal cancer receiving neoadjuvant radiochemotherapy (N-RCT) was reported. In two independent cohorts, all patients carrying the TGF $\beta 1$ Pro25 allele experienced acute toxicity in organ systems typically affected by local radiation therapy. Moreover, the effect of the variant was observed regardless of concomitant chemotherapy. Therefore, Arg25Pro polymorphism was suggested as a promising biomarker for individual treatment stratification in N-RCT (Schirmer et al. 2012).

\subsubsection{Arg25Pro polymorphism}

The human gene encoding TGF $\beta 1$ protein is located on the long (q) arm of human chromosome 19 at cytoband 13.1 and has seven exons (Fig. 3) (Derynck et al. 2001). The entire TGFB1 gene transcript coding for a signal peptide, LAP, and mature TGF $\beta 1$ features 23,166 base pairs (bp). Arg25Pro polymorphism (rs1800471, position +74 , codon 25) is located in exon 1 of the TGF $\beta 1$ ligand in the signal peptide, which is cleaved during maturation of TGF $\beta 1$ at codon 29. This polymorphism corresponds to a non-synonymous substitution of the big polar amino acid arginine for the small apolar proline (Stoll et al. 2004). This exchange could affect the adjacent cleavage site (Awad et al. 1998). 


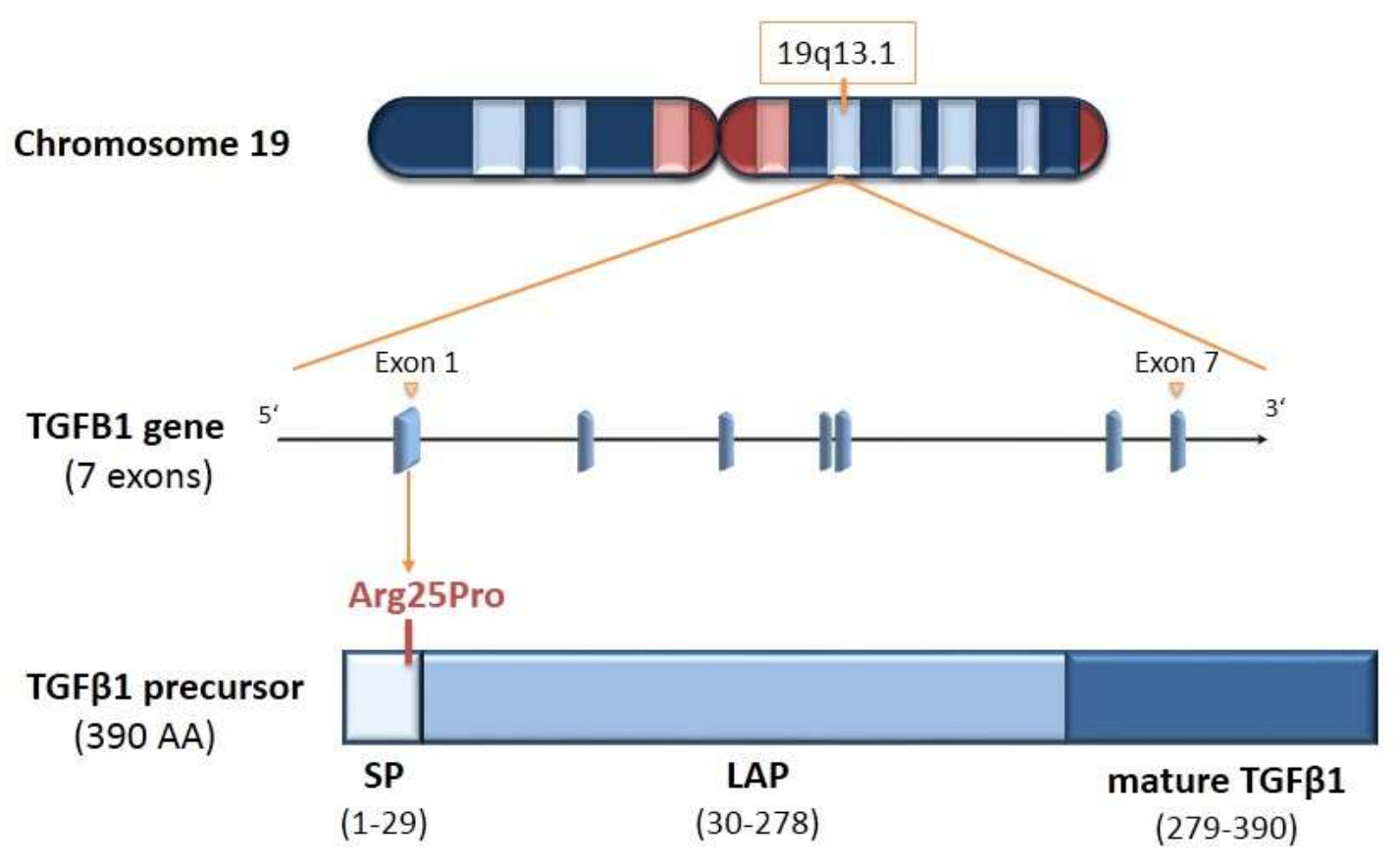

SP - signal peptide

LAP - latency-associated peptide

Fig. 3 Schematic structure of the TGFB1 genetic locus on human chromosome 19.

The human TGFB1 gene is located in chromosome 19 at position 13.1 and encodes 7 exons. The TGFB1 gene is translated into an inactive TGF $\beta 1$ precursor containing 390 amino acids (AA) with a signal peptide (AA 1-29), a LAP (AA 30-278) and a mature TGF31 (AA 279-390). The Arg25Pro polymorphism is located in the signal peptide. The sense strand of the transcribed product corresponds to the reverse strand with respect to the chromosomal orientation.

Few studies have examined Arg25Pro polymorphism effects. This SNP was reported to be associated with chronic inflammation, fibrosis (Awad et al. 1998, Cambien et al. 1996, Khalil et al. 2005, van de Wetering et al. 2006) and radiotoxicity (Peters et al. 2008, Schirmer et al. 2012). However, not all studies are consistent (Berndt et al. 2007, Densem et al. 2004, Ogawa et al. 2007).

Awad and colleagues observed an association between the Arg25Pro polymorphism and TGF $\beta 1$ production in vitro. Stimulated TGF $\beta 1$ production from peripheral blood leucocytes was higher for Arg25. Moreover, presence of the Arg25 variant predisposed to the development of pretransplant lung fibrosis as also to the fibrosis after lung transplantation (Awad et al. 1998). Similarly, progressing renal failure with proteinuria, elevated circulating TGF $\beta 1$ levels and glomerulosclerosis was more frequent in homozygotes for Arg25 (Khalil et al. 2005).

Other studies claimed unfavorable effects of the Pro25 variant, which affects about $10 \%$ of the Caucasian population. Van de Wetering and collegues observed an increased risk of developing 
end-stage renal failure for Pro25 carriers (van de Wetering et al. 2006). Additionally, the Pro25 allele was associated with increased risk of myocardial infarction (Cambien et al. 1996).

Moreover, patients with prostate cancer carrying the Pro25 variant developed side effects after radiation like erectile dysfunction and late rectal bleeding more frequently (Peters et al. 2008). Furthermore, Schirmer and colleagues observed an increased risk of acute radiotherapy-related toxicity in patients with rectal cancer carrying the Pro25 allele (Schirmer et al. 2012).

If independently confirmed, identification of patients harboring the Arg25Pro polymorphism may help to predict risks for TGF $\beta 1$-related side effects of therapies. In addition, to understand modes of actions and for possible pharmacological interventions detailed studies are required to determine possible molecular mechanisms how the Arg25Pro polymorphism may exert its effects.

\subsection{Aim of this work}

The aim of my thesis work was to clarify possible molecular mechanisms behind the clinical association of the Arg25Pro polymorphism in the TGFB1 gene. The hypothesis was that the amino acid exchange Arg25Pro located in the signal peptide might affect TGF $\beta 1$ translation, secretion, or post-translational processes such as cellular trafficking or whether it modulates TGF $\beta 1$ activation from its latent complex.

Therefore, to investigate allele-specific effects of the Arg25Pro polymorphism overexpression of Arg25 and Pro25 in a model cell line had to be set up. The generated cell models should be characterized to evaluate the correct genome integration and an equal mRNA expression rate for both variants. Using these constructs, allele-specific functional effects had to be evaluated. It should be investigated whether translation, secretion, trafficking or activation of TGF $\beta 1$ is different for the Pro25 in comparison to the Arg25 allele. These issues should be addressed both with and without simulation of radiotherapy as used in daily treatment of the patients. 


\section{Materials}

\subsection{Equipment}

\begin{tabular}{|c|c|}
\hline Equipment & Manufacturer* \\
\hline Accu-jet@ & Brand, Wertheim \\
\hline Bacteria Incubator-Incudrive & Schütt, Göttingen \\
\hline Biofuge fresco & Heraeus, Hanau \\
\hline Biofuge pico & Heraeus, Hanau \\
\hline BioPhotometer 6313 & Eppendorf, Hamburg \\
\hline Cell counting chamber (Neubauer improved) & Schütt, Göttingen \\
\hline Centrifuge $5810 \mathrm{R}$ & Eppendorf, Hamburg \\
\hline Centrifuge JA-20 Rotor & Beckman, München \\
\hline $\mathrm{CO}_{2}$-Incubator BBD 6220 & Heraeus, Hanau \\
\hline Concentrator 5301 & Eppendorf, Hamburg \\
\hline Electroblotting apparatus Fastblot B43 & Biometra, Göttingen \\
\hline Electrophoresis chamber (Mighty Small II) & Hoeffer, Holliston, USA \\
\hline Electroporator Gene Pulser II & BioRad, Hercules, USA \\
\hline Fine weight machine & Sartorius, Göttingen \\
\hline Fluor-STM MultiImager & BioRad, Hercules, USA \\
\hline Freezer V.I.P. ${ }^{\circledR}$ Series $-86^{\circ} \mathrm{C}$ Ultra Low & Sanyo Electric Co Ltd., Japan \\
\hline Gel chamber (ComPhor Mini) & Biozym, Oldendorf \\
\hline Gel chamber (Mighty Small SE Dual Gel Caster) & Hoeffer, Holliston, USA \\
\hline $\begin{array}{l}\text { Gel electrophoresis power supply } \\
\text { (Standard Power Pack P 25) }\end{array}$ & Biometra, Göttingen \\
\hline Labofuge 400R & Heraeus, Hanau \\
\hline Magnetic stirrer (IKAMAG RET) & IKA, Staufen \\
\hline Membrane vacuum pump & Vacuubrand, Wertheim \\
\hline Microplate Reader (96-well plate, Tecan ULTRA) & Tecan, Crailsheim \\
\hline Microscope Axiovert 40 CFL & Zeiss, Jena \\
\hline Microscope Olympus IX81 & $\begin{array}{l}\text { Olympus Europa Holding } \\
\text { GmbH, Hamburg }\end{array}$ \\
\hline Microscope Telava 131 & Zeiss, Jena \\
\hline
\end{tabular}


Microwave MWS 2820

Minishaker MS 2

Multipipette plus

Nanodrop cuvette

PCR-Gradient-Cycler (384-well plate), Master-Cycler

PCR-Gradient-Cycler (96-well plate), PTC-200 Peltier

Thermal Gradient Cycler

Pipettes $(0.1$ - $2.5 \mu \mathrm{l} ; 0.5$ - $10 \mu \mathrm{l} ; 10$ - $100 \mu \mathrm{l}$;

100 - $1000 \mu \mathrm{l} ; 1000$ - $2500 \mu \mathrm{l})$

pH meter CG 822

PTC-200 Peltier

QiaCube

Sequencer ABI PRISM ${ }^{\circledR} 3100$ Genetic Analyser

Shaker for bacteria K2 260 basic

Stereomicroscope Stemi 1000

Sterile Bench-Clean Air type DFL/REC4 KL2A

TaqMan 7900HT

Thermomixer 5436

Transilluminator TI 2

Vacuum centrifuge SpeedVac Plus® SC110A

VersaDoc-3000

Vertical-Autoclave KSG 40/60

Vertical-Autoclave: FV

Water bath GFL 1083

Xstrahl RS225
Bauknecht, Schorndorf

IKA, Staufen

Eppendorf, Hamburg

Implen, München

Eppendorf, Hamburg

MJ Research/BioRad,

Hercules, USA

Eppendorf, Hamburg

Schott Geräte, Mainz

MJ Research/BioRad,

Hercules, USA

Qiagen, Hilden

Applied Biosystems,

Darmstadt

IKA, Staufen

Zeiss, Jena

Mahl, Trendelburg

Applied Biosystems,

Darmstadt

Eppendorf, Hamburg

Biometra, Göttingen

Schütt, Göttingen

BioRad Laboratories,

Hercules, USA

KSG, Olching

Tecnorama, Fernwald

Schütt, Göttingen

GulmayMedical Limited, UK

\footnotetext{
* Country was not mentioned for Germany.
} 


\subsection{Used laboratory materials}

\begin{tabular}{|c|c|}
\hline Laboratory materials & Delivery/manufacturer* \\
\hline Absolute QPCR Seal (Optical folie for Taqman) & Thermo Scientific, UK \\
\hline Adhesive PCR Foil Seals & ABgene, Epsom \\
\hline CryoTubes (2 mL) & Nunc, Thermo Scientific, Denmark \\
\hline Culture flask $25 \mathrm{~cm}^{2}, 75 \mathrm{~cm}^{2}$ & Sarstedt, Nümbrecht \\
\hline Dialyse membrane filter VSWP01300 & Millipore, Bedford, USA \\
\hline Electroporation cuvette $2 \mathrm{~mm}$ & PeqLab, Erlangen \\
\hline Filter paper \#2668 & Schleicher und Schuell \\
\hline Filter paper \#2CHR & Schleicher und Schuell \\
\hline Flat cap strips, 12er & ABgene, Epsom \\
\hline Flat cap strips, 8er & ABgene, Epsom \\
\hline Freezing container, Nalgene $®$, Mr. Frosty & Sigma-Aldrich, Deisenhofen \\
\hline Glass pasteur pipette $230 \mathrm{~mm}$ & WU, Mainz \\
\hline Lid for ELISA plate & Nunc, Roskilde, Dänemark \\
\hline Filter Minisart 2000, $0.2 \mu \mathrm{m}$ & Sartorius, Göttingen \\
\hline Filter Minisart-plus, $0.2 \mu \mathrm{m}$ & Sartorius, Göttingen \\
\hline Filter pipett tip, sterile & Kisker, Steinfurt \\
\hline Cell strainer, 40 micron & BD Falcon (352340) \\
\hline Multidishes 6 und 12-well & Nunc, Wiesbaden \\
\hline Nitrocellulose filter (13 mm, $0.025 \mathrm{~m})$ & Millipore, Schwalbach \\
\hline Parafilm® & Brand, Wertheim \\
\hline Petri dish & Sarstedt, Hamburg \\
\hline Pipette tips $(10 \mu \mathrm{l}, 100 \mu \mathrm{l}, 1000 \mu \mathrm{l}, 2500 \mu \mathrm{l})$ & Sarstedt, Hamburg \\
\hline Pipette tips for multipipette $(0.1 ; 0.2 ; 0.5 ; 1.0 ; 2.5$; & Eppendorf, Hamburg \\
\hline \multicolumn{2}{|l|}{$5 \mathrm{ml})$} \\
\hline Plate loader for sephadex & Millipore, Schwalbach \\
\hline Plate retainer for sequencing & Applied Biosystems, Darmstadt \\
\hline Plate 96 Well, Thermo-Fast & ABgene, Epsom \\
\hline Plate 96 Well, Millipore MAHV N45 & Millipore, Bedford, USA \\
\hline Plate 96 Well for ELISA, Nunc Maxisorp & Nunc, Roskilde, Dänemark \\
\hline Plate 96 Well, Millipore MANU 030 PCR- & Millipore, Bedford, USA \\
\hline Plate 384 Well, FrameStar® & 4titude, Wotton \\
\hline Plate 384 Well, Thermo fast & ABgene, Epsom \\
\hline
\end{tabular}


PVDF membranes/Westran ${ }^{\circledR} \mathrm{S}(0.45 \mu \mathrm{m})$

Sterile pipette $(5 \mathrm{ml}, 10 \mathrm{ml}, 25 \mathrm{ml})$

Sterile polypropylen-tube $15 \mathrm{ml}$

Sterile polypropylen-tube $50 \mathrm{ml}$

Whatman papers (Filter paper Nr. 2668)
Schleicher \& Schuell, Dassel

Sarstedt, Hamburg

Greiner, Frickenhausen

Sarstedt, Hamburg

Schleicher und Schüll, Dassel

* Country was not mentioned for Germany.

\subsection{Reagents, kits, media}

\begin{tabular}{|c|c|}
\hline Reagents, kits, media & Delivery/manufacturer \\
\hline $1 \mathrm{~kb}$ Size standard ladder (for agarose gel) & Rapidozym, Berlin \\
\hline 100 bp Size standard ladder (for agarose gel) & Rapidozym, Berlin \\
\hline 2-Mercaptoethanol $\geq 99 \%$ & Sigma-Aldrich, Deisenhofen \\
\hline 40\% (w/v) Acrylamide:Bisacrylamide/ & Biomol, Hamburg \\
\hline \multicolumn{2}{|l|}{ Mix 37.5:1 } \\
\hline 5- Fluorouracil $(50 \mathrm{mg} / \mathrm{ml})$ & Medac GmbH, Hamburg \\
\hline 5 x HOT FIREPol ${ }^{\circledR}$ EvaGreen ${ }^{\circledR}$ & Solis BioDyne, Tartu, Estonia \\
\hline \multicolumn{2}{|l|}{ qPCR Mix Plus (ROX) } \\
\hline Agar (for bacteriology) & AppliChem, Darmstadt \\
\hline Agarose Ultra Pure (for gel electrophoresis) & Invitrogen, Karlsruhe \\
\hline Ampicillin 99\% & AppliChem, Darmstadt \\
\hline Bicinchoninic acid solution & Sigma-Aldrich, Deisenhofen \\
\hline BigDye ${ }^{\circledR}$ Sequencing Kit & Applied Biosystems, Darmstadt \\
\hline \multicolumn{2}{|l|}{ (fluorescence based Sanger sequencing) } \\
\hline Bovine serum albumin (BSA) & Sigma-Aldrich, Deisenhofen \\
\hline Bromphenolblue Na-Salt & Roth, Karlsruhe \\
\hline Chloroform $\geq 99.8 \%$ & J.T. Baker, Phillipsburg, USA \\
\hline Complete, EDTA-free & Roche, Mannheim \\
\hline \multicolumn{2}{|l|}{ (protease inhibitor cocktail tablets) } \\
\hline Coomassie Brilliant Blue R 250 & BioRad, München \\
\hline DNeasy Blood \& Tissue Kit (for DNA extraction) & Qiagen, Hilden \\
\hline DAPI & Invitrogen, Karlsruhe \\
\hline Dimethyl sulfoxide (DMSO) & AppliChem, Darmstadt \\
\hline DMEM & Invitrogen, Karlsruhe \\
\hline dNTP Set & ABgene, Hamburg \\
\hline
\end{tabular}


EDTA $0.5 \mathrm{M}$ in water solution

EDTA pure

Ethanol 96\%

Ethanol denatured 99\% (disinfection agent)

Ethidium bromide $1 \%$ in $\mathrm{H}_{2} \mathrm{O}$ (for electrophorese)

Exonuclease I E.coli (ExoI) $(20 \mathrm{U} / \mu \mathrm{l})$

Expand Long Template PCR System

Fetal bovine serum (FBS)

FuGene $6^{\circledR}$ (transfection agent)

GeneScan LIZ 120

(size standard ladder for $\mathrm{SNaPshot}{ }^{\mathrm{TM}}$ )

Glycerol $85 \%$

Helipur® H plus N (desinfection agent)

Human LAP (TGFß1) Ready-Set-Go

Human/Mouse TGF $\beta 1$ ELISA Ready-Set-Go ${ }^{\circledR}$

Hygromycin B $(50 \mathrm{mg} / \mathrm{mL})$

Isoamylalcohol $98 \%$

Isopropanol $\geq 99.9 \%$

Kanamycin $\geq 750 \mathrm{U} / \mathrm{mg}$

KOD HotStart DNA Polymerase

Ligate-ITTM Rapid Ligation Kit

Neodisher® A 8, cleaning powder

PBS

PBS Powder (Dulbeccos 10x)

Penicillin/Streptomycin-Solution

PhosStop (phosphatase inhibitor cocktail tablets)

Polylysin-D-hydrobromide (for cell culture)

Ponceau S 10x (for blotting membrane staining)

Q-Solution

QIAquick Gel Extraction Kit

QIAquick PCR Purification Kit

Random hexanucleotide primers dN6

Rnase-Zap
Sigma-Aldrich, Deisenhofen

Merck, Darmstadt

Merck, Darmstadt

Chemie-Vertrieb, Hannover

Merck, Darmstadt

Fermentas, St. Leon-Roth

Roche, Mannheim

Gibco/Invitrogen, Karlsruhe

Roche, Mannheim

Applied Biosystems, Darmstadt

Central Pharmacy, University

medical center Göttingen

Braun, Melsungen

eBioscience, San Diego, USA

eBioscience, San Diego, USA

Invitrogen, Karlsruhe

Schuchardt, Hohenbrunn

Merck, Darmstadt

AppliChem, Darmstadt

Novagen Merck, Darmstadt

Usb, Staufen

Chem. Fabrik Dr. Weigert, Hamburg

Invitrogen, Karlsruhe

AppliChem, Darmstadt

Invitrogen, Karlsruhe

Roche, Mannheim

Sigma-Aldrich, Deisenhofen

Carl Roth, Karlsruhe

Qiagen, Hilden

Qiagen, Hilden

Qiagen, Hilden

Roche, Mannheim

Sigma, St.Louis, USA 
RNeasy Plus Mini Kit

RLT-Plus buffer

Roti $^{\circledR}$-Histofix 4\%

Roti ${ }^{\circledR}$-Block -

SeeBlue ${ }^{\circledR}$ Plus2 Prestained Standard

Sephadex ${ }^{\text {TM }}$ G-50 Superfine

Shrimp Alkaline Phosphatase (SAP) (1 U/ $\mu$ l)

SnapShotTM Multiplex Kit

Sodium chloride

S.O.C. media (for bacterial transformation)

Sulfuric acid

Super Script II Reverse Transcriptase

Supersignal ${ }^{\circledR}$ West Pico Kit

T4 DNA Ligase

TEMED $\geq 99 \%$

TopTaq DNA Polymerase

Tris $100 \%$

Triton X-100

Trypan blue -solution $(0.4 \%)$

TrypLETM Express

Tween 20 (Polyoxyethylen-Sorbit-Monolaurat)

Wheat Germ Agglutinin, Alexa Fluor ${ }^{\circledR} 488$

Conjugate

Wheat Germ Agglutinin, Alexa Fluor® 594

Conjugate

Yeast extract

Zeocin
Qiagen, Hilden

Qiagen, Hilden

Carl Roth, Karlsruhe

Carl Roth, Karlsruhe

Invitrogen, Karlsruhe

Amersham Bioscience, Freiburg

USB, Staufen

Applied Biosystems, Darmstadt

Merck, Darmstadt

Invitrogen, Karlsruhe

Merck, Darmstadt

Invitrogen, Karlsruhe

Thermo Scientific, Schwerte

MBI Fermentas, St. Leon-Roth

Sigma-Aldrich, Deisenhofen

Qiagen, Hilden

Roth, Karlsruhe

Roth, Karlsruhe

Sigma-Aldrich, Deisenhofen

Gibco/Invitrogen, Karlsruhe

BioRad, München

Invitrogen, Carlsbad, USA

Invitrogen, Carlsbad, USA

AppliChem, Darmstadt

Invitrogen, Karlsruhe

* Country was not mentioned for Germany. 


\subsection{Antibodies}

\begin{tabular}{|c|c|c|c|}
\hline Antibody & Dilution & Application & Manufacturer \\
\hline \multicolumn{4}{|c|}{ Primary antibodies } \\
\hline TGF $\beta 1$ & $1: 1000$ & $\begin{array}{l}\text { Western blotting, } \\
\text { Immunocytochemistry }\end{array}$ & $\begin{array}{l}\text { Cell Signaling, } \\
\text { Danvers, USA }\end{array}$ \\
\hline FLAG M2 & $1: 1000$ & $\begin{array}{l}\text { Western blotting, } \\
\text { Immunocytochemistry }\end{array}$ & $\begin{array}{l}\text { Cell Signaling, } \\
\text { Danvers, USA }\end{array}$ \\
\hline GAPDH & $1: 10000$ & Western blotting & Serotec \\
\hline \multicolumn{4}{|c|}{ Secondary antibodies } \\
\hline $\begin{array}{l}\text { Anti-mouse IgG } \\
\text { HRP-conjugated }\end{array}$ & $1: 10000$ & Western blotting & $\begin{array}{l}\text { Cell Signaling, } \\
\text { Danvers, USA }\end{array}$ \\
\hline $\begin{array}{l}\text { Anti-rabbit IgG- } \\
\text { HRP-conjugated }\end{array}$ & $1: 10000$ & Western blotting & $\begin{array}{l}\text { Cell Signaling, } \\
\text { Danvers, USA }\end{array}$ \\
\hline $\begin{array}{l}\text { Anti-mouse } \quad \operatorname{IgG} \\
\text { Alexa Fluor }{ }^{2} 488\end{array}$ & $1: 400$ & Immunocytochemistry & $\begin{array}{l}\text { Life Technologies, } \\
\text { Carlsbad, USA }\end{array}$ \\
\hline $\begin{array}{l}\text { Anti-mouse } \\
\text { Cy3-conjugated } \\
\text { antibody }\end{array}$ & $1: 400$ & Immunocytochemistry & $\begin{array}{l}\text { Jackson Immuno } \\
\text { Research, West Grove, } \\
\text { USA }\end{array}$ \\
\hline
\end{tabular}

* Country was not mentioned for Germany.

\subsection{Restriction enzymes}

\begin{tabular}{ll}
\hline Restriction enzyme & Delivery/manufacturer* $^{*}$ \\
\hline BamHI & Fermentas, St. Leon-Roth \\
BstXI & New England Biolabs, Beverly, USA \\
DpnI & New England Biolabs, Beverly, USA \\
HincII & New England Biolabs, Beverly, USA \\
HindIII & Fermentas, St. Leon-Roth \\
NotI & New England Biolabs, Beverly, USA \\
SacI & Fermentas, St. Leon-Roth \\
SalI & Fermentas, St. Leon-Roth \\
$X h o \mathrm{I}$ & Fermentas, St. Leon-Roth \\
$X m a \mathrm{I}$ & New England Biolabs, Beverly, USA \\
\hline
\end{tabular}

* Country was not mentioned for Germany. 


\subsection{Strains of bacteria}

\begin{tabular}{|c|c|c|c|}
\hline Strain of bacteria & Origin & Application & $\begin{array}{l}\text { Delivery/ } \\
\text { manufacturer* }\end{array}$ \\
\hline $\begin{array}{l}\text { Top10 } \\
\text { (One shot TOP10 } \\
\text { Electro-comp. E.coli) }\end{array}$ & $\begin{array}{l}\text { Escherichia } \\
\text { coli }\end{array}$ & Electrocompetent & $\begin{array}{l}\text { Invitrogen, } \\
\text { Karlsruhe }\end{array}$ \\
\hline DH10B & $\begin{array}{l}\text { Escherichia } \\
\text { coli }\end{array}$ & Electrocompetent & $\begin{array}{l}\text { Invitrogen, } \\
\text { Karlsruhe }\end{array}$ \\
\hline
\end{tabular}

* Country was not mentioned for Germany.

\subsection{Vectors}

\begin{tabular}{lll}
\hline Vector & Resistance & Delivery/manufacturer* $^{*}$ \\
\hline pOTB7/TGFB1 & Chloramphenicol & $\begin{array}{l}\text { SourceBioscience, } \\
\text { Nottingham, UK }\end{array}$ \\
\hline pcDNA5/FRT & Ampicillin & Invitrogen, Karlsruhe \\
\hline pEX-A/FLAG & Ampicillin & Eurofins MWG Operon, Ebersberg \\
\hline pOG44 & Ampicillin & Invitrogen, Karlsruhe \\
\hline
\end{tabular}

* Country was not mentioned for Germany.

\subsection{Cell lines}

\begin{tabular}{lll}
\hline Cell line & Origin & Manufacturer* $^{*}$ \\
\hline $\begin{array}{l}\text { Flp-In }{ }^{\mathrm{TM}} \text { T-REx HEK 293 } \\
\text { (Embryonic kidney cell line, which } \\
\text { contains Flp Recombination } \\
\text { Target (FRT)- integrated in genome) }\end{array}$ & Human & Invitrogen, Karlsruhe \\
\hline & & \\
Primary skin fibroblasts & Human & Departments of Dermatology and \\
& & Medical Center Göttingen \\
\hline NIH 3T3 & Mouse & Institute for Pharmacology, \\
(Embryonic fibroblast cell line) & & University Medical Center Göttingen \\
\hline
\end{tabular}

* Country was not mentioned for Germany. 


\subsection{Buffers and solutions}

TBE buffer (pH 8.3)

\begin{tabular}{|ll|}
\hline Tris & $100 \mathrm{mM}$ \\
Boric Acid & $100 \mathrm{mM}$ \\
EDTA & $3.0 \mathrm{mM}$ \\
\hline
\end{tabular}

Loading dye (5 $x$ ) for agarose gel electrophoresis

\begin{tabular}{|ll|}
\hline Glycerol & $30 \%(\mathrm{v} / \mathrm{v})$ \\
EDTA & 50 \\
Bromphenol blue & $0.25 \%(\mathrm{v} / \mathrm{v})$ \\
Xylene cyanol & $0.25 \%(\mathrm{v} / \mathrm{v})$ \\
\hline
\end{tabular}

Resuspension buffer (B1) for plasmid mini-preparation

\begin{tabular}{|lc|}
\hline Tris-HCl (pH 8.0) & $150 \mathrm{mM}$ \\
EDTA & $10 \mathrm{mM}$ \\
RNase A & $100 \mu \mathrm{g} / \mathrm{ml}$ \\
\hline
\end{tabular}

(store at $4^{\circ} \mathrm{C}$ )

Lysis buffer (B2) for plasmid mini-preparation

\begin{tabular}{|ll|}
\hline $\mathrm{NaOH}$ & $200 \mathrm{mM}$ \\
$\mathrm{SDS}$ & $1 \%(\mathrm{w} / \mathrm{v})$ \\
\hline
\end{tabular}

Neutralization buffer (B3) for plasmid mini-preparation

Potassium acetate $(\mathrm{pH} 5.5) \quad 3 \mathrm{M}$

BSA stock solution (1mg/ml)

\begin{tabular}{|ll|}
\hline BSA & $50 \mathrm{mg}$ \\
1x RIPA buffer & $50 \mathrm{ml}$ \\
\hline
\end{tabular}


RIPA buffer

\begin{tabular}{|ll|}
\hline Tris- $\mathrm{HCl}$ & $50 \mathrm{mM}$ \\
$\mathrm{NaCl}$ & $150 \mathrm{mM}$ \\
EDTA & $1 \mathrm{mM}$ \\
$\mathrm{NP}-40$ & $1 \%(\mathrm{v} / \mathrm{v})$ \\
Na-deoxycholate & $0.25 \%(\mathrm{w} / \mathrm{v})$ \\
PMSF (optional) & $1 \mathrm{mM}$ \\
\hline
\end{tabular}

Cupric sulfate pentahydrate solution $\left(\mathrm{CuSO}_{4} \times \mathrm{X}_{2} \mathrm{H}_{2} \mathrm{O}\right)$

$\begin{array}{ll}\text { Cupric sulfate } 4 \% & 2 \mathrm{mg} \\ \mathrm{ddH}_{2} \mathrm{O} & 50 \mathrm{~mL}\end{array}$

SDS-PAGE loading buffer ( $4 x)$

\begin{tabular}{|ll|}
\hline Tris- $\mathrm{HCl}(\mathrm{pH} 6.8)$ & $581 \mathrm{mg}$ \\
Bromphenolblau & $1.6 \mathrm{mg}$ \\
DTT $400 \mathrm{mM}$ & $1.234 \mathrm{~g}$ \\
Glycerol $28 \%(\mathrm{v} / \mathrm{v})$ & $6.59 \mathrm{ml}$ of $85 \%$ \\
& Glycerol \\
SDS & $1.6 \mathrm{mg}$ \\
$\mathrm{ddH}_{2} \mathrm{O}$ & Add to $20 \mathrm{~mL}$ \\
\hline
\end{tabular}

Run buffer (pH 8,4) for Western blotting

\begin{tabular}{|ll|}
\hline Tris-HCl & $3.03 \mathrm{~g}$ \\
Glycin & $14.41 \mathrm{~g}$ \\
SDS & $1 \mathrm{~g}$ \\
ddH2O & Add to $1 \mathrm{~L}$ \\
\hline
\end{tabular}


Transfer buffer (pH 9) for Western blotting

\begin{tabular}{|ll|}
\hline Tris- $\mathrm{HCl}$ & $48 \mathrm{mM}$ \\
Glycin & $39 \mathrm{mM}$ \\
$\mathrm{SDS}$ & $0.0374 \%(\mathrm{w} / \mathrm{v})$ \\
Methanol & $15 \%$ \\
$\mathrm{ddH}_{2} \mathrm{O}$ & Add to $1 \mathrm{~L}$ \\
\hline
\end{tabular}

Blocking solution for Western blotting

\begin{tabular}{ll}
\hline Roti®-Block & $5 \mathrm{~mL}$ \\
$\mathrm{ddH}_{2} \mathrm{O}$ & $45 \mathrm{~mL}$
\end{tabular}

TBS buffer 10x $(p H=7,6)$ for Western blotting

$\begin{array}{ll}\text { Tris- } \mathrm{HCl}(200 \mathrm{mM}) & 24.2 \mathrm{~g} \\ \mathrm{NaCl}(1,505 \mathrm{M}) & 88 \mathrm{~g} \\ \mathrm{ddH}_{2} \mathrm{O} & \text { Add to } 1 \mathrm{~L}\end{array}$

TBST buffer (1x) for Western blotting

\begin{tabular}{|ll}
\hline TBS $(10 \mathrm{x})$ & $100 \mathrm{ml}$ \\
Tween 20 & $500 \mu \mathrm{l}$ \\
$\mathrm{ddH}_{2} \mathrm{O}$ & Add to $1 \mathrm{~L}$
\end{tabular}

Luria-Bertani (LB) media for bacterilogy

\begin{tabular}{|ll|}
\hline Trypton & $10 \mathrm{~g}$ \\
Yeast extract & $5 \mathrm{~g}$ \\
$\mathrm{NaCl}$ & $5 \mathrm{~g}$ \\
$\mathrm{ddH}_{2} \mathrm{O}$ & Add to $1 \mathrm{~L}$ \\
\hline
\end{tabular}

(store at $4^{\circ} \mathrm{C}$ ) 


\subsection{Primers}

Tab. 1 Point-mutation primers

\begin{tabular}{ll}
\hline Primer name & Sequence \\
\hline TGFB1-Pro25-for & 5'-GTGCTGACGCCTGGCCCGCCGGCCGCGGGACTA-3' \\
TGFB1-Pro25-rev & 5'-TAGTCCCGCGGCCGGCGGGCCAGGCGTCAGCAC-3' \\
\hline
\end{tabular}

The mutated base is bolded and genetic codons are underlined

Tab. 2 Primers for amplification and subsequent insertion of TGFB1 into pcDNA5.1 vector

\begin{tabular}{ll}
\hline Primer name & Sequence \\
\hline TGFB1-f_Hind-III & 5'-GGGGGGCGAAGCTTCCCCCATGCCGCCCTCCGG-3' \\
TGFB1-r_Xho-I & 5'-GGTGGGCTCGAGGCACGGGTGTCCTTAAATAC-3' \\
\hline
\end{tabular}

Restriction sites are marked in italic

Tab. 3 Primers for cloning of MetFLAG in signal peptide of TGF $\beta 1$

\begin{tabular}{ll}
\hline Primer name & Sequence \\
\hline TGFB1- & 5'-TCAAAGCTTCACCATGGACTACAAAGACGATGAC \\
MetFLAG-for & GACAAGCCGCCCTCCGGGCTGCGGCT-3' \\
TGFB1- & 5'-TGATCAGCGGGTTTAAACGGGCCCTCTAGACTC-3' \\
MetFLAG-rev & \\
\hline
\end{tabular}

Sequence of the FLAG epitope is bolded and underlined

Tab. 4 Sequence for cloning of FLAG at N-terminus of mature TGFB1

\begin{tabular}{ll}
\hline Name & Sequence \\
\hline TGFBl-FLAG & 5'-CCACCCCGCTGGAGAGGGCCCAGCATCTGCAAAGCTCCC \\
& GGCACCGCCGAGCCCTGGACACCAACGACTACAAAGACG \\
& ATGACGACAAGGCCCTGGACACCAACTATTGCTTCAGCTC \\
& CACGGAGAAGAACTGCTGCGTGCGGCAGCTGTACATTGAC \\
& TTCCGCAAGGACCTCGGCTGGAAGTGGATCC-3'
\end{tabular}

Sequence of the FLAG epitope is bolded and underlined.

Restriction sites are marked in italic. 
Tab. 5 Primers for validation of chromosomal integration of the TGFB1 constructs in the genome of the HEK 293 T-Rex cells

\begin{tabular}{ll}
\hline Primer name & Sequence \\
\hline Psv40 & 5'-AGCTGTGGAATGTGTGTCAGTTAGG-3' \\
Hyg_r2 & 5'-ACGCCCTCCTACATCGAAGCTGAAA-3' \\
LacZ & 5'-CCTTCCTGTAGCCAGCTTTCATCAA-3' \\
PCMv & 5'-CCATGGTGATGCGGTTTTGGCAGTA-3' \\
\hline
\end{tabular}

Tab. 6 Sequencing primers

\begin{tabular}{ll}
\hline Primer name & Sequence \\
\hline TGFB1-Seq1-for & 5'-CCCCACCACACCAGCCCTGTT-3' \\
TGFB1-Seq1-rev & 5'-GCAGCTTGGACAGGATCTG-3' \\
TGFB1-Seq2-for & 5'-GTGGAAACCCACAACGAAATC-3' \\
TGFB1-Seq3-for & 5'-CTCCTGTGACAGCAGGGATAAC-3' \\
\hline
\end{tabular}

Tab. 7 Primers for SNaPShotTM reaction

\begin{tabular}{lc}
\hline Primer name & Sequence \\
\hline & Primers for fragment amplification \\
\hline pcDNA5-TGFB1-for & 5'-AGCTGGCTAGCGTTTAAACTTAAGC-3' \\
TGFB1-human-rev & 5'-TGTTGCTGTATTTCTGGTACAGCTC-3' \\
& Primers to detect Arg25Pro site \\
rs1800471-c & 5'-AAAAAAAGTGCTGACGCCTGGCC-3' \\
\hline
\end{tabular}


Tab. 8 Primers for qRT-PCR

\begin{tabular}{lc}
\hline Primer name & \multicolumn{1}{c}{ Sequence } \\
\hline TGFB1-human-for & 5'-GGTACCTGAACCCGTGTTGCT-3' \\
TGFB1-human-rev & 5'-TGTTGCTGTATTTCTGGTACAGCTC-3' \\
GAPDH-human-for & 5'-CCCTTCATTGACCTCAACTACAT-3' \\
GAPDH-human-rev & 5'-ACGATACCAAAGTTGTCATGGAT-3' \\
\hline
\end{tabular}

\subsection{Software}

\begin{tabular}{|c|c|}
\hline Software & Manufacturer* \\
\hline 3100 Data Collection Software & Applied Biosystems, Darmstadt \\
\hline Adobe Photoshop & Adobe Systems GmbH, München \\
\hline Clone Manager Suite & SECentral, Cary NC, USA \\
\hline CorelDRAW X3 & Corel Corporation, Ontario, Canada \\
\hline DNA Sequencing Analysis & Applied Biosystems, Darmstadt \\
\hline EndNote X7 & Thomson Reuters, Philadelphia PA, USA \\
\hline GeneMapper, v 3.7 & Applied Biosystems, Darmstadt \\
\hline Oligo, v. 6.58 & $\begin{array}{l}\text { Molecular Biology Insights, Cascade CO, } \\
\text { USA }\end{array}$ \\
\hline Olympus xcellence pro & $\begin{array}{l}\text { Olympus soft imaging solutions } \mathrm{GmbH} \text {, } \\
\text { Münster }\end{array}$ \\
\hline Quantity One S, v. 4.3.1 & BioRad, München \\
\hline SDS 2.1 & Applied Biosystems, Darmstadt \\
\hline SPSS, v. 12.0 & SPSS Inc., Chicago, USA \\
\hline Staden Package & $\begin{array}{l}\text { Medical research council laboratory of } \\
\text { molecular Biology, Cambridge, UK }\end{array}$ \\
\hline XFluor4 & Tecan, Crailsheim \\
\hline SignalP 4.1 prediction tool & http://www.cbs.dtu.dk/services/SignalP/ \\
\hline
\end{tabular}

"Country was not mentioned for Germany. 


\section{Methods}

\subsection{DNA techniques}

\subsubsection{Polymerase chain reaction (PCR)}

Polymerase chain reaction (PCR) is a molecular technique for enzymatic replicating of DNA in vitro. The typical reaction components are DNA template, DNA polymerase, oligonucleotide primers, nucleotides, and reaction buffer. To improve the amplification of templates with high GC content Q-Solution can be used. Standard PCR involves three steps: The first step is denaturation of the DNA template into single stranded molecules (performed at $95^{\circ} \mathrm{C}$ ). The second step is annealing of the primers with the denatured target DNA. Depending on the size and composition of the primers, the second step is usually performed at temperatures between $50-70^{\circ} \mathrm{C}$. The third step is extension of a new DNA strand complementary to the DNA template strand using DNA polymerase by adding dNTPs in $5^{\prime}-$ to $3^{\prime}$-direction at $65-75^{\circ} \mathrm{C}$. The temperature depends on the DNA polymerase used and the time depends on the length of the expected product.

Under optimal conditions, the amount of DNA target is doubled per cycle leading to exponential amplification of the specific DNA fragment. In this work, 18 to 35 cycles depending on the aim of the PCR were carried out. As PCR enzymes KOD Hot Start DNA polymerase, Top Taq polymerase, and ExpandLong polymerase were used. To determine the PCR conditions (optimal annealing temperature, with or without Q-solution) gradient PCR was performed. The PCR reactions were carried out in gradient thermal cyclers. The optimal PCR conditions (annealing temperature, optional use of Q solution) were defined by visualization on agarose gels.

\subsubsection{Agarose gel electrophoresis}

Agarose gel electrophoresis is an effective way of separating the different sized fragments of DNA for analytical or preparative purposes, such as cloning, DNA sequencing. In gel electrophoresis nucleic acid molecules are separated by the electric field, where the negatively charged molecules migrate toward anode (positive) pole. The migration flow is determined by the molecular weight, where the small weight molecules migrate faster than larger ones. To prepare the gel, appropriate amount of agarose $(0.8 \%-2,5 \%)$ was dissolved in boiling TBE buffer. The solution was cooled to approximately $55^{\circ} \mathrm{C}$. Then, $0.5 \mu \mathrm{g} / \mathrm{mL}$ ethidium bromide 
(EtBr) was added and mixed using magnet stirrer. EtBr is a fluorescent dye and it intercalates between nucleic acids bases and allows to detect nucleic acid fragments in gels. Afterwards, the agarose solution was poured into the casting tray. Gel combs were placed in the gel tray to form the wells for samples. After the gel solidified (about 15-30 min), DNA samples were mixed with 1 x loading dye and pipetted into the wells of the gel. DNA size marker (100 bp $1 \mathrm{~kb}$ DNA Ladder) was used to estimate the size of the analyzed DNA fragments. The electrophoresis was performed with $120 \mathrm{~V}$ for 30-40 min (depending on the size of DNA fragments) using a ComPhor L Mini Gel chamber. The obtained DNA bands were visualized by Fluor-S ${ }^{\mathrm{TM}}$ MultiImager using Quantity One ${ }^{\circledR} \mathrm{S}$ Version 4.3.1 software.

\subsubsection{DNA purification from agarose gel}

After separating DNA fragments by length in the agarose gel electrophoresis, DNA was visualized under UV-light using transilluminator TI2. The gel slice containing the desired DNA band was excised and transferred to a pre-weighed $1.5 \mathrm{~mL}$ Eppendorf tube. The slices should not exceed $200 \mathrm{mg}$ of $2 \%$ agarose gel. The obtained gel fragments were purified using QIAquick Gel Extraction Kit with QiaCube robot according to the manufacturer's instructions.

\subsubsection{Total genomic DNA isolation}

Total genomic DNA extraction from the cells was performed using DNeasy Blood \& Tissue Kit with the QiaCube robot according to the manufacturer's instructions. In order to obtain optimal DNA quality, about $1 \times 10^{6}$ cells resuspended in $100 \mu 1$ of PBS buffer were used. The amount of extracted DNA was determined by photometric quantification (see section 3.1.5)

\subsubsection{DNA quantification}

DNA concentration was determined photometrically by measuring absorbance at $260 \mathrm{~nm}$ with the BioPhotometer using an Implen-Nanodrop cuvette. Therefore, $3 \mu 1$ of the sample were pipetted in the cuvette. Additionally to the extinction of $260 \mathrm{~nm}$, the absorbance ratio of 260/280 nm, which expresses the purity of DNA, was measured. The DNA samples with 260/280 nm ratio above 1.6 were considered as pure and could be used for further experiments. 


\subsubsection{Site-directed mutagenesis}

Site directed mutagenesis is a method for introducing mutations (either single base pairs or larger insertions, deletions, or substitutions) into a DNA sequence to localize the effects of mutations on genes. Our point mutation was a single amino acids exchange from Arg to Pro at position 25 in the signal peptide of the TGFB1 gene (rs1800471). In order to conduct the side directed mutagenesis, the vector with inserted cDNA of TGFB1 gene with wild type allele (pOTB7/TGFB1; Clone 3356605/IRAU12D01; SourceBioscience, Nottingham, UK) was purchased. To introduce mutation, pOTB7/TGFB1 plasmid was amplified by PCR using the KOD Hot Start DNA Polymerase Kit and point-mutation primers (see section 2.10, Tab. 1). PCR reaction mixture and PCR conditions are shown in Tab. 9 and Tab. 10.

Digestive enzyme DpnI was used to digest the parental DNA template, which is methylated. $D p n I$ enzyme recognizes methylated residue in its target sequence (5'-Gm6ATC-3') and cleaves bacterially generated parental plasmid but not the PCR product. For this reason, PCR product was incubated with $1,5 \mu \mathrm{l}$ of $\mathrm{DpnI}$ for $1 \mathrm{~h}$ at $37^{\circ} \mathrm{C}$ and again $1 \mu \mathrm{l}$ of this enzyme was added for next $1 \mathrm{~h}$. Afterwards, the PCR product was dialyzed for $30 \mathrm{~min}$ and then transformed in E. coli TOP 10 strain by electroporation. The pOTB7/TGFB1 plasmids carrying the required mutation and wild type were isolated by mini-preparation. To check the correctness and exclude other mutations in the plasmid, the entire TGFB1 open reading frame (ORF) for both constructs wild type and variant was sequenced. The sequencing primers are listed in section 2.10, Tab. 6 .

Tab. 9 PCR-reaction mixture used for site-directed mutagenesis

\begin{tabular}{ll}
\hline Reagent & Volume $(\boldsymbol{\mu l})$ \\
\hline $10 \mathrm{x}$ buffer & 5 \\
dNTPs $(2 \mathrm{mM})$ & 5 \\
MgSO4 $(25 \mathrm{mM})$ & 2 \\
Q-Solution (optional) & 10 \\
Forward-Primer $(10 \mathrm{nM})$ & 1.3 \\
Reverse-Primer $(10 \mathrm{nM})$ & 1.3 \\
Plasmid DNA $(50 \mathrm{ng} / \mu \mathrm{l})$ & 1 \\
KOD HotStart Polymerase $(1.0 \mathrm{U} / \mu \mathrm{l})$ & 1 \\
ddH 20 & Add to 50 \\
\hline
\end{tabular}

Final volume 
Tab. 10 PCR conditions used for site-directed mutagenesis

$\left.\begin{array}{lll}\text { Phase } & \text { Duration } & \text { Temperature } \\ \hline \text { Initial Denaturation } & 3 \mathrm{~min} & 95^{\circ} \mathrm{C} \\ \hline \text { Denaturation } & 30 \mathrm{sec} & 95^{\circ} \mathrm{C} \\ \text { Annealing } & 30 \mathrm{sec} & 60^{\circ} \mathrm{C} \\ \text { Elongation } & 1 \mathrm{~min} 30 \mathrm{sec} & 72^{\circ} \mathrm{C} \\ \hline \text { Cool down } & \text { for ever } & 8^{\circ} \mathrm{C}\end{array}\right\} 19 \mathrm{x}$

\subsubsection{Restriction digestion}

Restriction digestion was performed to cleave DNA at specific sequences (restriction sites) using restriction enzymes for analytical and preparative purposes. The correctness of the cleaved DNA fragments was verified by agarose gel electrophoresis.

\subsubsection{Analytical digestion}

Analytic digestion was performed with at least three different digestion enzymes that excise plasmid within several restriction sites. The number and sizes of the yielded fragments after digestion were defined by the number of recognition sites.

Reaction mixture (Tab. 11) was incubated for $1 \mathrm{~h}$ at recommended temperature for the optimal enzyme activity. Subsequently, the reaction mixture was run on the agarose gel electrophoresis.

Tab. 11 Reaction mixture for analytic digestion

\begin{tabular}{ll}
\hline Reagent & Volume $(\boldsymbol{\mu l})$ \\
\hline 10 x Restriction buffer & 1 \\
BSA (optional) & 0.1 \\
DNA $(\sim 1 \mu \mathrm{g})$ & 1 \\
Enzyme & 1 \\
dd $\mathrm{H}_{2} \mathrm{O}$ & Add to 10 \\
\hline Final volume & 10
\end{tabular}




\subsubsection{Preparative digestion}

The aim of the preparative digestion was to generate the "blunt ends" as well as the matching overhangs, called "sticky ends" in the insert fragment and vector. This was achieved by appropriate enzyme cleavage and allowed insertion of the fragment into the vector in the further ligation step.

Briefly, dependent on the activity of the applied digestion enzyme, the reaction mixture (Tab. 12) was incubated for $2-3 \mathrm{~h}$ or overnight. Afterwards, additional $1 \mu \mathrm{l}$ of enzyme was supplemented for further $1 \mathrm{~h}$. In case of double digestion the reaction could be carried out simultaneously using universal buffer (Tango) or buffer, which was suitable for both enzymes. If the enzymes required different buffers, digestion was performed consequently for each enzyme as follows: DNA was digested with one enzyme, the fragment was then isolated by agarose gel electrophoresis followed by agarose gel purification. Subsequently, procedure was repeated in the same way with the other restriction enzyme.

Tab. 12 Preparative digestion reaction mixture

\begin{tabular}{ll}
\hline Reagent & Volume $(\boldsymbol{\mu l})$ \\
\hline 10 x Restriction buffer & 5 \\
BSA (optional) & 0.5 \\
DNA & max. $10 \mu \mathrm{g}$ \\
Enzyme (dependent on star activity) & 5 \\
$\mathrm{ddH}_{2} \mathrm{O}$ & Add to 50 \\
\hline Final volume & 50
\end{tabular}

\subsubsection{Ligation of DNA fragments}

Ligation reaction joins two ends of DNA strands and is driven by ligase enzyme. This reaction was used to insert DNA fragment into the plasmid vector. Therefore, the matching DNA ends of both fragment and vector, cleaved by restriction enzymes, were ligated using Ligate-ITTM Rapid Ligation Kit. This kit allows the reaction to occur within only $16 \mathrm{~min}$. In order to perform ligation, an insert:vector ratio of 13:2 (v/v) was used.

The reaction mixture (Tab. 13) was incubated for $8 \mathrm{~min}$ at RT, and afterwards placed for $8 \mathrm{~min}$ on ice. To check the success of ligation experiment and to estimate the number of self-ligated 
plasmid, the reaction was set up along with $\mathrm{ddH}_{2} \mathrm{O}$ as a negative control instead of the insert fragment. High amounts of clones on the negative control plate after transformation into bacterial cells indicated non-successful ligation reaction. In order to increase the efficiency of transformation, ligation mixture was concentrated with the highest temperature in the vacuum centrifuge under 200 mbar for 10 min prior to transformation. The remaining DNA attached on the wall of tube after centrifugation was detached by pipetting the residual liquid.

Tab. 13 Ligation reaction mixture

\begin{tabular}{ll}
\hline Reagent & Volume $(\boldsymbol{\mu l})$ \\
\hline 5 x Ligase buffer & 4 \\
Plasmid vector & 2 \\
Insert fragment & 13 \\
Ligase & 1 \\
\hline
\end{tabular}

Final volume $\quad 20$

\subsubsection{Drop dialysis}

To purify and desalt the ligated DNA prior to bacterial transformation, drop dialysis was performed. For this purpose, nitrocellulose filters with shiny side up were placed for 5 min in a petri disch filled with $\mathrm{ddH}_{2} \mathrm{O}$. The ligation mixture (about $20 \mu \mathrm{l}$ ) was carefully pipetted into the center of the filter preventing direct contact with $\mathrm{ddH}_{2} \mathrm{O}$. After $30 \mathrm{~min}$, dialyzed plasmid solution was carefully transferred from the filter to a new $1.5 \mathrm{ml}$ Eppendorf tube.

\subsubsection{DNA isolation from bacteria}

\subsubsection{Isolation of plasmid DNA by chloroform extraction (plasmid mini-preparation)}

Plasmid mini-preparation was used to isolate high-quality plasmid DNA for restriction digestion or sequencing. Single colonies, which appeared on agar plates after transformation were picked up and resuspended in $5 \mathrm{~mL}$ of LB-medium supplemented with the corresponding antibiotic, and left shaking overnight at $37^{\circ} \mathrm{C}$. Next day, $5 \mu \mathrm{l}$ of this solution were transferred to the agar plate, which has served as an inoculum for the further experiments. The rest of the bacteria solution was centrifuged at $4000 \mathrm{rpm}$ for $10 \mathrm{~min}$ at RT. Then, the supernatant was 
discarded and the pellet was resolved in $250 \mu 1$ of Resuspension buffer (B1) and transferred to a new $1.5 \mathrm{~mL}$ Eppendorf tube. Next, the cells were lysed with $250 \mu \mathrm{l}$ of Alkaline lyses buffer (B2) and strongly shaked. To neutralize the reaction $350 \mu$ of Neutralization buffer (B3) were added and mixed through the inversion. Up five to six times was enough to see the precipitation of the proteins that indicated the neutralization of the mixture. Then, the samples were centrifuged at $13000 \mathrm{rpm}$ for $10 \mathrm{~min}$ at RT. The supernatant was transferred in a new $1.5 \mathrm{~mL}$ Eppendorf tube and mixed with $500 \mu$ of ice cold chlorophorm/isoamylalcohol (24:1) solution. The samples were centrifuged at $13000 \mathrm{rpm}$ for $5 \mathrm{~min}$ at RT. The upper phase, which contains the plasmid DNA, was transferred to a new $1.5 \mathrm{~mL}$ Eppendorf tube. Afterwards, $650 \mu \mathrm{l}$ of isopropanol $\left(-20^{\circ} \mathrm{C}\right)$ were added and the mixture was spined at $13000 \mathrm{rpm}$ for $15 \mathrm{~min}$ at $4^{\circ} \mathrm{C}$. The supernatant was discarded and the pellet washed with $700 \mu 1$ of $70 \%$ ethanol $\left(-20^{\circ} \mathrm{C}\right)$ at 13 $000 \mathrm{rpm}$ for $7 \mathrm{~min}$ at $4^{\circ} \mathrm{C}$. Then, the supernatant was removed and the tube with opened lid was placed on the heat block at $37^{\circ} \mathrm{C}$ shaking until the pellet became dry and clear. Finally, the pellet was resuspended in $50 \mu 1$ of TE-buffer and DNA content was quantified photometrically.

\subsubsection{Isolation of plasmid DNA by solid extraction (plasmid midi-preparation)}

Plasmid midi-preparation extraction was used to isolate larger amounts of high-quality plasmid DNA from transformed E. coli cultures. Later the purified DNA was used for eukaryotic transfection. In this work, midi-prep was conducted with the help of the QIAGEN Plasmid Plus Midi Kit according to the manufacturer's instructions.

\subsubsection{DNA sequencing}

DNA sequencing is a method, which allows sequencing of unknown DNA within the sites in which the sequence is known. The Sanger's method, or dideoxy sequencing, or chain termination is based on the use of the dideoxy nucleotide triphosphates (ddNTP's) in addition to the deoxy-nucleotide triphosphates (dNTP's). The ddNTPs are fluorescently labeled and have different wavelengths of fluorescence and emission. The incorporation of ddNTPs, which contain a hydrogen group on the 3' carbon instead of a hydroxyl group (OH), to the DNA strand prevent the addition of subsequent nucleotides. Thus, the termination of the DNA chain occurs resulting in the labeled ddNTP at the end of each DNA fragment with varying length. The newly produced and labeled DNA fragments are then denatured, and separated by size by capillarygel electrophoresis.

Briefly, the reaction mixture (Tab. 14) was pipetted in a 384-well PCR plate. In this work, the sequencing reaction was performed using the BigDye ${ }^{\circledR}$ terminator v1.1 Sequencing Kit. The 
primers used for sequencing are listed in the section 2.10, Tab. 6. The sequencing PCR was performed for 25 cycles under conditions as stated in the Tab. 15.

Tab. 14 Sequencing PCR mixture

\begin{tabular}{ll}
\hline Reagent & Volume per sample $(\boldsymbol{\mu l})$ \\
\hline DMSO & 0.25 \\
Primer $(10 \mu \mathrm{M})$ & 0.5 \\
BigDye $^{\circledR}$ & 1 \\
$\mathrm{ddH}_{2} \mathrm{O}$ & 2.25 \\
DNA $(\sim 300 \mu \mathrm{g} / \mathrm{ml})$ & 1 \\
\hline Final volume & 5
\end{tabular}

Final volume

5

Tab. 15 Sequencing PCR conditions

$\left.\begin{array}{lll}\hline \text { Phase } & \text { Duration } & \text { Temperature } \\ \hline \text { Initial Denaturation } & 2 \mathrm{~min} & 94^{\circ} \mathrm{C} \\ \hline \text { Denaturation } & 15 \mathrm{sec} & 96^{\circ} \mathrm{C} \\ \text { Annealing } & 15 \mathrm{sec} & 56.5^{\circ} \mathrm{C} \\ \text { Elongation } & 4 \mathrm{~min} & 60^{\circ} \mathrm{C} \\ \hline \text { Final Elongation } & 7 \mathrm{~min} & 60^{\circ} \mathrm{C} \\ \text { Cool down } & \text { for ever } & 8^{\circ} \mathrm{C}\end{array}\right\} 25 \mathrm{x}$

To get rid of any unincorporated dyes, excess primer and salts from the reaction buffers, the PCR product was purified using Sephadex prior to sequencing. Therefore, $35 \mathrm{mg}$ of Sephadex G50 superfine were filled in the wells of a 96-well filter plate. Then $300 \mu$ of ddH2O were added to each well and incubated for $3 \mathrm{~h}$ at RT. To remove the superfluous water the plate was spined at $650 \mathrm{x}$ g for $5 \mathrm{~min}$ at RT. Further $150 \mu \mathrm{l}$ of $\mathrm{ddH}_{2} \mathrm{O}$ were added to each well and incubated for another $30 \mathrm{~min}$ at RT. Again the superfluous water was removed by centrifugation under the same conditions ( $650 \mathrm{x} \mathrm{g}, 5 \mathrm{~min}, \mathrm{RT})$. Afterwards, $5 \mu \mathrm{l}$ of the sequencing-PCRproduct were mixed with $35 \mu \mathrm{l}$ of $\mathrm{ddH}_{2} \mathrm{O}$ and pipetted on Sephadex-containing filter plate and centrifuged under the same conditions (650 x g, $5 \mathrm{~min}$, RT). Afterwards, the purified samples 
were sequenced using 3130xl Genetic Analyser. The sequencing data were analyzed with Staden Package software Version 4.0 and Clone Manager.

\subsubsection{Genotyping by single base primer extension method (SNaPshot ${ }^{T M}$ )}

SNaPshot ${ }^{\mathrm{TM}}$ was used to determine the SNPs in genomic DNA. This method is based on the dideoxy single-base extension of an unlabeled oligonucleotide primer. A primer, which anneals immediately adjacent to the SNP is extended by one base using a fluorescently labeled ddNTP in the presence DNA polymerase, adding a single ddNTP to its 3' end on the SNP position. The ddNTPs do not carry an OH-group on the 3'-terminus, which blocks the further elongation of DNA strand. SNaPshot ${ }^{\mathrm{TM}}$ reaction allows a direct visualization of the genotype of the SNP present in the expected region on a DNA fragment. Four different fluorescently labeled ddNTPs give a colored peak on a electropherogram after capillary electrophoresis when incorporated in the SNP region: Adenine - green $(\mathrm{FS}=\mathrm{dR6G})$; Cytosine -black $\left(\mathrm{FS}=\mathrm{dTAMRA}^{\mathrm{TM}}\right)$; Guanine - blue $(\mathrm{FS}=\mathrm{dR} 110)$, Thymine $-\operatorname{red}\left(\mathrm{FS}: \mathrm{dROX}^{\mathrm{TM}}\right)$.

The SNaPshot ${ }^{\mathrm{TM}}$ reaction in this work was performed as following: At first, the DNA fragment containing Arg25Pro polymorphism in TGFB1 was amplified. Therefore, the PCR reaction mixture was prepared (Tab. 16) and the region was amplified by PCR under the conditions stated in the Tab. 17. A primer pair used for this PCR is stated in the ection 2.10, Tab. 7.

Tab. 16 PCR reaction mixture

\begin{tabular}{ll}
\hline Reagent & Volume per sample $(\boldsymbol{\mu l})$ \\
\hline $\mathrm{ddH}_{2} \mathrm{O}, \mathrm{RNAse}-\mathrm{free}$ & 6.33 \\
Buffer & 1.1 \\
Q-solution & 2.2 \\
dNTPs (10mM) & 0.22 \\
Primer_for (pcDNA5-TGFB1-for) & 0.05 \\
Primer_rev (TGFB1-human-rev) & 0.05 \\
TopTag Polymerase & 0.05 \\
DNA & 1 \\
\hline
\end{tabular}

Final volume 
Tab. 17 PCR reaction conditions

$\left.\begin{array}{lll}\hline \text { Phase } & \text { Duration } & \text { Temperature } \\ \hline \text { Initial Denaturation } & 3 \mathrm{~min} & 94^{\circ} \mathrm{C} \\ \hline \text { Denaturation } & 30 \mathrm{sec} & 94^{\circ} \mathrm{C} \\ \text { Annealing } & 1 \mathrm{~min} & 60.7^{\circ} \mathrm{C} \\ \text { Elongation } & 1 \mathrm{~min} & 72^{\circ} \mathrm{C} \\ \hline \text { Final Elongation } & 10 \mathrm{~min} & 72^{\circ} \mathrm{C} \\ \text { Cool down } & \text { for ever } & 8^{\circ} \mathrm{C}\end{array}\right\} 35 \mathrm{x}$

Afterwards, the first purification step was performed. The PCR product was purified with Exonuclease I (ExoI) enzyme. ExoI was used to remove excess primers and any other singlestranded DNA present in PCR products. Therefore, purification mixture (Tab. 18) was incubated for $3 \mathrm{~h}$ at $37^{\circ} \mathrm{C}$, and then inactivated for $15 \mathrm{~min}$ at $80^{\circ} \mathrm{C}$ in the thermal cycler.

Tab. 18 Reaction mixture for the first purification step

\begin{tabular}{ll}
\hline Reagent & Volume $(\boldsymbol{\mu l})$ \\
\hline 10 x RX buffer & 0.95 \\
Exo1 $(20 \mathrm{U} / \mu \mathrm{l})$ & 0.35 \\
Fast-AP $(1 \mathrm{U} / \mu \mathrm{l})$ & 1.7 \\
PCR product & 4 \\
\hline Final volume & 7
\end{tabular}

Then, the SNaPShot reaction using $\mathrm{SNaPshot}^{\circledR}$ kit was conducted. During preparation, the reaction mixture (Fig. 19) was kept on ice. The SNaPShot PCR are stated in the Tab. 20. 
Tab. 19 SNapShot PCR mixture

\begin{tabular}{ll}
\hline Reagent & Volume per sample $(\boldsymbol{\mu l})$ \\
\hline $\mathrm{SNaPshot}^{\mathrm{TM}}-\mathrm{Master}$ mix & 0.5 \\
Primer mix $(2-12 \mu \mathrm{M})$ & 0.5 \\
$\mathrm{ddH}_{2} \mathrm{O}$ & 2 \\
Purified PCR-product & 2 \\
\hline Final volume & 5
\end{tabular}

Tab. 20 SNaPshot-PCR conditions

$\left.\begin{array}{lll}\hline \text { Phase } & \text { Duration } & \text { Temperature } \\ \hline \text { Initial Denaturation } & 2 \mathrm{~min} & 94^{\circ} \mathrm{C} \\ \hline \text { Denaturation } & 10 \mathrm{sec} & 96^{\circ} \mathrm{C} \\ \text { Annealing } & 5 \mathrm{sec} & 50^{\circ} \mathrm{C} \\ \text { Elongation } & 30 \mathrm{sec} & 60^{\circ} \mathrm{C} \\ \hline \text { Cool down } & \text { for ever } & 8^{\circ} \mathrm{C}\end{array}\right\} 26 \mathrm{x}$

Following SNaPshot ${ }^{\mathrm{TM}}$ reaction, the second purification step was performed. Shrimp alkaline phosphatase (SAP) was applied to dephosphorylate remaining dNTPs from the PCR product. Reaction mixture (Tab. 21) for the second purification step was incubated for $30 \mathrm{~min}$ at $37^{\circ} \mathrm{C}$.

Tab. 21 Reaction mixture for the second purification step

\begin{tabular}{ll}
\hline Reagent & Volume $(\boldsymbol{\mu l})$ \\
\hline SAP $(1 \mathrm{U} / \mu \mathrm{l})$ & 5 \\
Exol $(10 \mathrm{U} / \mu \mathrm{l})$ & 0.2 \\
10 x SAP buffer & 2 \\
PCR product & 13 \\
\hline Final volume & 20
\end{tabular}


Finally, $1 \mu \mathrm{l}$ of the SNaPshot reaction mixture was added to $10 \mu \mathrm{L}$ of the sequencing mixture (Tab. 22). For evaluation and determination of the exact length of the extended primers an internal size standard, Gene $\mathrm{Scan}^{\mathrm{TM}} 120 \mathrm{LIZ}^{\mathrm{TM}}$ Size Standard, was used. The reaction mixture was denatured for $5 \mathrm{~min}$ at $95^{\circ} \mathrm{C}$, and then immediately placed on ice. Finally, the samples were visualized by electrophoreses on ABI 3730 and the data were analyzed with Gene Mapper v3.7 software $^{\circledR}$.

Tab. 22 Sequencing mixture

\begin{tabular}{ll}
\hline Reagent & Volume per sample $(\boldsymbol{\mu l})$ \\
\hline Formamid (Hi-Di ${ }^{\mathrm{TM}}$ Formamid) & 10 \\
Gene ScanTM 120 LIZTM Size & 0.05 \\
Sample & 1 \\
\hline Final volume & 11.05
\end{tabular}

\subsection{RNA techniques}

\subsubsection{RNA extraction}

To prevent quick degradation of RNA and RNAse contamination, sterile plastic ware and pipettes, which are dedicated only for RNA handling, were used. Before starting the procedure of RNA isolation, the working surface was cleaned with anti-RNase spray. For RNA extraction, about $1 \times 10^{6}$ cells were collected in falcone tube and centrifuged at $3500 \mathrm{x} \mathrm{rpm}$ for $3 \mathrm{~min}$ at RT. The supernatant was discarded and the pellet was rinsed with $500 \mu \mathrm{l}$ of PBS buffer. Then, the pellet was lysed with $350 \mu$ of RLT Plus buffer. The total RNA was isolated using the RNeasy Plus Mini Kit with QiaCube robot according to the recommended manufacturer's protocol. After extraction RNA samples were placed immediately on ice, and then stored at $-80^{\circ} \mathrm{C}$.

\subsubsection{RNA quantification}

The concentration of extracted RNA was measured photometrically on the maximum absorption of $260 \mathrm{~nm}$. Three $\mu \mathrm{l}$ of the sample were pipetted into Implen-Nanodrope cuvette and 
measured by BioPhotometer. To assess the purity of RNA, additionally to the extinction of 260 $\mathrm{nm}$, the absorbance ratio of $260 / 280 \mathrm{~nm}$, which expresses the purity of RNA, was measured. The RNA samples with ratio above 1.9 were considered as pure and could be used for further experiments.

\subsubsection{Reverse transcription (RT) and cDNA synthesis}

In order to evaluate gene expression rate, total RNA was converted into complementary DNA (cDNA) via reverse transcription (RT) using SuperScript ${ }^{\mathrm{TM}}$ II reverse transcriptase. For setup of RT reaction, RNA-primer reaction mix was prepared. Therefore, $1 \mu \mathrm{g}$ of mRNA was mixed with $1 \mu 1$ of random primers (dN6). Random hexamer primers bind throughout the entire length of RNA and ensure reverse transcription of all RNA sequences due to their random structure. The samples were incubated at $70^{\circ} \mathrm{C}$ for $10 \mathrm{~min}$ to denature RNA secondary structure, and then placed on ice for $10 \mathrm{~min}$ to allow annealing of the primers. Afterwards, the RT-PCR mastermix (Tab. 23) was added to RNA-primer reaction mix and incubated at $42^{\circ} \mathrm{C}$ for $60 \mathrm{~min}$. Finally, to adjust the concentration of the synthesized cDNA to $10 \mathrm{ng} / \mu \mathrm{l}$, the samples were diluted with $70 \mu \mathrm{l}$ of ddH 20 and stored at $-20^{\circ} \mathrm{C}$,

Tab. 23 RT-PCR mastermix

\begin{tabular}{ll}
\hline Reagent & Volume per reaction $(\boldsymbol{\mu l})$ \\
\hline 5 x Superscript RT buffer & 6 \\
DTT $(0,1 \mathrm{M})$ & 3.5 \\
dNTPs (10 mM) & 1 \\
RNase Inhib P/N $(40 \mathrm{U} / \mu \mathrm{l})$ & 0.5 \\
Super Script ${ }^{\mathrm{TM}} \mathrm{II}(200 \mathrm{U} / \mu \mathrm{l})$ & 0.25 \\
\hline
\end{tabular}

Final volume 11.25

\subsubsection{Quantitative real-time PCR ( $q R T$-PCR)}

qRT-PCR is a method, which allows to monitor the cDNA amplification process in the real time. In qRT-PCR, the amount of PCR product is measured at each cycle via fluorescent dye. With each amplification cycle the increased fluorescencnt signal is directly proportional to the amount of generated amplicons (PCR product molecules). The lower the cycle number the 
higher is the expression of the gene. The fewer the amount of specific cDNA was in the beginning, the more cycles of PCR was necessary to reach a threshold cycle $(\mathrm{Ct})$ of a present DNA quantity (Higuchi et al. 1993). The $\mathrm{Ct}$ is the cycle number at which the fluorescent signal of the reaction crosses the threshold, which is the level of the signal that reflects a statistically significant increase over the calculated baseline signal. To normalize the expression rate of gene of interest, endogenous normalization gene (e.g. GAPDH, TBP etc.), so-called "housekeeping" gene, whose expression should be constant, was used.

To quantify the expression of $T G F B 1$ gene by qRT-PCR the following steps were performed: At first, $7 \mu \mathrm{l}$ of qRT-PCR mastermix (Tab. 24) were pipetted in a 384-wells plate. Then, $3 \mu 1$ of cDNA were added to the plate. The plate was covered with an optical clear foil and measured by TaqMan 7900HT under the conditions as stated in the Tab. 25. The TGFB1 expression was normalized to the GAPDH gene. The primers used for quantification of TGFB1 transcript variants and for the determination of GAPDH are listed in the section 2.10, Tab. 8. Finally, the results were analyzed using software SDS 2.1.

Tab. 24 qRT-PCR mastermix

\begin{tabular}{ll}
\hline Reagent & Volume per sample $(\boldsymbol{\mu l})$ \\
\hline qPCR Master mix & 2 \\
Primer (1:10) & 0.2 \\
$\mathrm{ddH}_{2} \mathrm{O}, \mathrm{RNA}-\mathrm{se}$ free & 4.8 \\
cDNA (1:10) & 3 \\
\hline
\end{tabular}

Final volume 10 
Tab. 25 qPCR conditions.

$\left.\begin{array}{lll}\hline \text { Phase } & \text { Duration } & \text { Temperature } \\ \hline \text { Initial denaturation } & 15 \mathrm{~min} & 95^{\circ} \mathrm{C} \\ \hline \text { Denaturation } & 15 \mathrm{sec} & 95^{\circ} \mathrm{C} \\ \text { Primer annealing } & 20 \mathrm{sec} & 60^{\circ} \mathrm{C} \\ \text { Elongation } & 1 \mathrm{~min} & 72^{\circ} \mathrm{C} \\ \hline \text { Melting curve } & 15 \mathrm{sec} & 95^{\circ} \mathrm{C} \\ & 15 \mathrm{sec} & 60^{\circ} \mathrm{C} \\ & 15 \mathrm{sec} & 95^{\circ} \mathrm{C}\end{array}\right\} 40 \mathrm{x}$

\subsection{Protein techniques}

\subsubsection{Protein extraction}

In order to isolate protein for Western blotting or ELISA, following steps were performed. The cells $\left(5^{*} 10^{5}-1.5^{*} 10^{6}\right)$ were plated in the 6-well plate and incubated for $24-48 \mathrm{~h}$ at $37^{\circ} \mathrm{C}$ under $5 \% \mathrm{CO}_{2}$ and $95 \%$ humidity. Upon reaching approximately $80-90 \%$ confluence, the medium was replaced and the cells were irradiated with 5-25 Gy. Depending on the experiment, the cells were incubated for the next 24-72 h. Afterwards, the cells were carefully collected in $2 \mathrm{ml}$ Eppendorf tube and sedimented at $1000 \mathrm{x}$ g for $3 \mathrm{~min}$ at $4^{\circ} \mathrm{C}$. Supernatant was transferred in a new Eppendorf tube and stored at $-80^{\circ} \mathrm{C}$. The pellet was washed with $500 \mu \mathrm{PBS}$ and centrifuged at $3000 \mathrm{xg}$ for $3 \mathrm{~min}$ at $4^{\circ} \mathrm{C}$. Then, PBS was discarded, the pellet was lysed with $300 \mu \mathrm{l}$ RIPA buffer and shortly vortexed at $1400 \mathrm{rpm}$. To ensure that the cells were broken, several freeze-thawing cycles in liquid nitrogen and warmed at $37^{\circ} \mathrm{C}$ were performed. Finally, prepared samples were stored at $-80^{\circ} \mathrm{C}$.

\subsubsection{Quantification of protein by bicinchoninic acid (BCA) assay}

To quantify total protein in samples, BCA assay was used. This assay is performed in two steps. The first step is reduction of $\mathrm{Cu}^{2+}$ to $\mathrm{Cu}^{1+}$ by protein in an alkaline environment (the biuret reaction), which results in faint blue color, followed by second step - chelation and purple color 
formation by bicinchoninic acid, that can be determined spectro-photometrically with maximum absorption at $562 \mathrm{~nm}$. The intensity of the colored reaction product is in proportion to the amount of protein that can be determined by comparing its absorbance value to a standard curve.

The BCA assay in this work was performed as follows: Working solution was prepared by mixing of BCA solution with cupric sulfate $4 \%$ with ration of 50:1. Ten $\mu 1$ of protein samples, diluted in 1:3 with RIPA buffer, were pipetted in duplicate in a single well of a transparent 96well plate. As a standard bovine serum albumin (BSA) was used. For this reason, the amounts of $0,1,5,10,15,20,25 \mu l$ of BSA stock solution $(1 \mathrm{mg} / \mathrm{ml})$ were pipetted in duplicate. Then, $200 \mu 1$ of BCA-cupric sulfate solution was added to each well.

Then, the plate was incubated for $30 \mathrm{~min}$ at $37^{\circ} \mathrm{C}$. Following incubation, protein absorption was measured at $570 \mathrm{~nm}$ wave length in Tecan Ultra Microplate reader. Protein concentration was determined by reference to a standard curve consisting of known concentration of the standard protein (BSA).

\subsubsection{Western blotting}

Western blotting is a technique to detect the presence and characterize a specific protein in a complex mixture extracted from cells by size separation during gel electrophoresis and then detection by a specifically directed antibody.

\subsubsection{SDS-polyacrylamid gel electrophoresis (SDS-PAGE)}

The purpose of SDS-PAGE is to separate proteins according to their size. Therefore, the protein was denatured by heating in gel loading buffer, which contains glycerol, a tracking dye (bromophenol blue) and a reducing agent like $\beta$-mercaptoethanol, SDS and DTT to reduce disulphide bonds. The polyacrylamide gel casts in two sections. The top section, where the wells are made and samples are loaded, is the stacking gel. The separation gel is the lower section, where the proteins are separated.

Firstly, the separating gel was prepared. Therefore, the reagents were mixed together in the concentrations given in the Tab. 26. The gel was poured in the gel chamber Mighty Small SE Dual Gel Caster until $1.5 \mathrm{~cm}$ of the chamber top. The rest part of gel chamber was filled up with water. To get polymerize the gel was left for $30 \mathrm{~min}$ at room temperature (RT). Meanwhile the stacking gel was prepared. The water from the top of the chamber was discarded and the 
stacking gel was poured on the top of the separation gel and left to polymerize for 30-40 min at RT.

Tab. 26 SDS-PAGE gel recipe

\begin{tabular}{lcc}
\hline Reagent & 4\% stacking gel & 12\% separating gel \\
\hline $\mathrm{ddH}_{2} \mathrm{O}$ & $1625 \mu \mathrm{l}$ & $2180 \mu \mathrm{l}$ \\
$1.5 \mathrm{M}$ Tris- $\mathrm{HCl}(\mathrm{pH} 8,8)$ & - & $1250 \mu \mathrm{l}$ \\
$0.5 \mathrm{M}$ Tris-HCl (pH 6,8) & $625 \mu \mathrm{l}$ & - \\
$10 \%$ (w/v) SDS & $25 \mu \mathrm{l}$ & $50 \mu \mathrm{l}$ \\
$40 \%$ (w/v) Acrylamid/Mix 37:5:1 & $250 \mu \mathrm{l}$ & $1500 \mu \mathrm{l}$ \\
$10 \%$ APS & $12.5 \mu \mathrm{l}$ & $25 \mu \mathrm{l}$ \\
TEMED & $2.5 \mu \mathrm{l}$ & $2.5 \mu \mathrm{l}$ \\
\hline
\end{tabular}

\subsubsection{Gel electrophoresis}

Once the gel was set, it was placed into the electrophoresis chamber Mighty Small II, which was filled with running buffer (1x) and allowed to pre-run at $12 \mathrm{~mA}$ for $30 \mathrm{~min}$ without samples. Meanwhile, the samples were denatured at $95^{\circ} \mathrm{C}$ for $5 \mathrm{~min}$ in the loading buffer (4x), then placed on ice for $5 \mathrm{~min}$. After that, the samples were shortly spined and pipetted into the wells of gel. As a molecular weight marker, SeeBlue ${ }^{\circledR}$ Plus2 Prestained Standard was used. Afterwards, the gel was run at $12 \mathrm{~mA}$ until the loaded samples reached the border of separation gel, and then at $25 \mathrm{~mA}$ until the samples run out of the gel.

\subsubsection{Blotting}

Following the gel electrophoresis, gel was transferred on the blotting membrane. In this work, a semidry transfer method was used. The gel and blotting membrane (polyvinylidene difluoride (PVDF) were assembled into a sandwich along with several sheets of filter paper. Before assembly, the PVDF membrane had to be activated by methanol for $30 \mathrm{sec}$, and then washed with $\mathrm{ddH}_{2} \mathrm{O}$. Then, the washed membrane was soaked in the transfer buffer for 10 min shaking at RT. Six thick and two thin Whatman filter papers were also soaked in transfer buffer for 10 min shaking at RT. The transfer buffer for electroblotting was used to help proteins bind to the blot. The gel sandwich arranged on the electroblotting apparatus. The air bubbles were 
removed by pushing gently across the surface rolling with a pipette. Blotting was performed at $45 \mathrm{~mA}$ (per gel) for1-1.5 h at RT.

\subsubsection{Confirmation of the transfer}

Once the blotting step has been completed, the success of the blotting was evaluated by staining the blotting membrane with Ponceau S solution. Therefore, the membrane was incubated for 5 min in Ponceau S solution. Following incubation, the mebane was washed three times for 5 min with $\mathrm{ddH}_{2} \mathrm{O}$.

\subsubsection{Blocking}

After blotting, to prevent non-specifically binding of antibody to the membrane, the blot containing the transferred protein bands was incubated with $\operatorname{Roti}^{\circledR}{ }^{\circledR}$-Block (1:10 dilution) shaking for $1 \mathrm{~h}$ at RT. After blocking, the blot was rinsed three times in $20 \mathrm{~mL}$ of wash buffer (TBST), every time soaking for $5 \mathrm{~min}$.

\subsubsection{Antibody incubation}

Following washing procedure, the blot was incubated with primary antibody diluted in $5 \mathrm{~mL}$ of TBST buffer $(1 \mathrm{x})$ shaking overnight at $4{ }^{\circ} \mathrm{C}$. Next day, the membrane was washed tree times for 5 min with $20 \mathrm{ml}$ of TBST buffer and incubated with horse radisch peroxidase (HRP) conjugated secondary antibody, diluted in $10 \mathrm{ml}$ of TBST, for 1 hour shaking at RT. Afterwards, the blot was washed again three times for 5 min with $20 \mathrm{~mL}$ of TBST buffer. Antibodies used in this work are listed in the section 2.4.

\subsubsection{Normalization}

In order to compare target protein expression levels between several different samples on the same blot, the "house-keeping gene" GAPDH was used as a loading control to normalize the data. Probing with GAPDH antibody was carried out along with the target antibody. Therefore, the sample was loaded on the gel in duplicate - for target protein of interest as well as for GAPDH detection.

\subsubsection{Detection with substrate}

In the final step of the immunodetection procedure, the HRP in the secondary antibody was detected by the enhanced chemiluminescent (ECL) substrate solution. Therefore, the membrane was incubated for 2 - 3 min with $500 \mu$ l of Luminol/Enhancer and $500 \mu$ l Peroxide Solution from the SuperSignal ${ }^{\circledR}$ West Pico Kit. The chemiluminescent images were captured using VersaDoc-3000 and quantified using Quantity One software. 


\subsubsection{Immunocytochemistry}

Immunocytochemical study aimed to assess the expression and localization of TGF $\beta 1$ protein in the cells. The procedure was performed using primary antibody for target protein and fluorochrome conjugated secondary antibody.

First, to avoid clumps or aggregates of the cells, cell suspension $\left(5 \times 10^{5} \mathrm{cells} / 1 \mathrm{~mL}\right)$ was pipetted through a 40 micron cell strainer. Then, the cells were centrifuged at $1400 \mathrm{rpm}$ for $3 \mathrm{~min}$ and washed with $1 \mathrm{~mL}$ of PBS. Afterwards, the cells were seeded in poly-D-lysine coated 12 wellplate and incubated at $37^{\circ} \mathrm{C}$ until they had reached $80-90 \%$ confluence. As next, culture medium (DMEM, $10 \%$ FBS, 1\% Pen/Strep, Hygromycin B $(100 \mu \mathrm{g} / \mathrm{mL})$ ) was removed and the wells were rinsed once with $1 \mathrm{~mL}$ of PBS buffer. The cells were fixed with $500 \mu \mathrm{l} /$ well of Histofix $4 \%$ and incubated for $20 \mathrm{~min}$ at RT. Afterwards, the cells were permeabilized with $0.5 \%$ Triton $\mathrm{X}-100$ for $5 \mathrm{~min}$ and again washed one time with $1 \mathrm{~mL}$ of PBS buffer. To block unspecific binding of the antibodies, the cells were incubated with $1 \mathrm{~mL}$ of Roti-block solution (1:10 dilution) shaking for $60 \mathrm{~min}$ at RT. Afterwards the primary monoclonal antibody (1:1000) diluted in $500 \mu \mathrm{l}$ of PBS per well was added and incubated shaking for $60 \mathrm{~min}$ at RT. Then, each well was washed twice with $1 \mathrm{~mL}$ of PBS. After washing steps, cells were incubated with Alexa Fluor 488 secondary antibody (1:400 in PBS) and DAPI $(1: 1000)$ shaking in the dark for 60 min at RT. Antibodies used in this work are listed in the section 2.4.

Following incubation, the cells were washed three times with $1 \mathrm{~mL}$ of PBS, soaking for $3 \mathrm{~min}$ each time. Finally, to prevent cells from drying $500 \mu \mathrm{l}$ of PBS were added to each well. The cell were visualized by immunofluorescent microscopy. The plates with fixed cells could be stored for several weeks in the dark at $4^{\circ} \mathrm{C}$.

\subsubsection{Enzyme Linked Immunosorbent Assay (ELISA)}

To quantify the amount of active and latent TGF $\beta 1$ protein in the culture supernatant and cell lysates, sandwich-ELISA was performed. This quantitative enzyme immunoassay is based on indirect immobilization of the antigen by capture antibody and indirect detection by enzymlabelled secondary antibody.

In two independent ELISA assays, the expression rate of LAP versus the active TGF $\beta 1$ was measured. To determine the expression level of active TGF $\beta 1$, the Human/Mouse TGFB1 (2nd generation) ELISA Ready-Set-Go! Kit according to the manufacture's instruction was used. This kit allowed quantification of mature/active form of TGF $\beta 1$ as well as free active TGF $\beta 1$ present without acidification. When acidification was required, the samples were incubated 
with $1 \mathrm{~N} \mathrm{HCl}$ for 10 min at $\mathrm{RT}$, and then, neutralized with $1 \mathrm{~N} \mathrm{NaOH}$. Free active TGF $\beta 1$ in the samples was measured without acid treatment.

The LAP was quantified using the Human LAP (TGF-beta1) ELISA Ready-SET-Go! Kit according to the manufacture's instruction. LAP ELISA kit enables measurement of LAP in non-dissociated samples and does not require sample acidification and neutralization. In each assay the samples as well as the standards were run in duplicate. To determine the concentration of TGF $\beta 1$ and LAP, the mean values of the samples were compared to the standard curve and normalized to the total protein concentration.

\subsection{Working with bacteria}

\subsubsection{Growth conditions and long-term storage of bacteria}

In this study, bacterial transformation was conducted with the electrocompetent bacteria strains One Shot ${ }^{\circ}$ TOP10 Electrocomp ${ }^{\mathrm{TM}}$ E. coli and DH10B. Bacterial strains were cultured both in liquid and solid media. Liquid bacterial clones were incubated with appropriate antibiotic either $5 \mathrm{~mL}$ in $15 \mathrm{~mL}$ falcon tubes (for plasmid mini-preparation, see section 3.1.10.1) or $100 \mathrm{~mL}$ in $500 \mathrm{~mL}$ glass bottles (used for plasmid midi-preparation, see section 3.1.10.2) while shaking on $\mathrm{K} 2260$ basic-shaker at $250 \mathrm{rpm}$ at $37^{\circ} \mathrm{C}$ overnight. The agar plates with bacterial clones could be stored at $4{ }^{\circ} \mathrm{C}$ for about one month sealed with parafilm.

For long time the bacterial cultures were stored at $-80^{\circ} \mathrm{C}$, mixed $1: 1$ with $50 \%$ glycerol solution in a $1.5 \mathrm{~mL}$ Eppendorf tube.

\subsubsection{Bacterial transformation}

Bacterial transformation in this work was performed via electroporation or by the heat shock method.

Transformation via electroporation is used to transfer plasmid DNA into E.coli by applying a short high-voltage electric field pulse ( 2,500 volts/cm). The process results in smalls cracks in the membrane and enables DNA to enter bacteria. Briefly, $10 \mu 1$ of E. coli TOP 10 bacteria, diluted in $30 \mu \mathrm{l}$ of $\mathrm{ddH}_{2} \mathrm{O}$, were mixed with the $2-3 \mu \mathrm{l}$ of the dialyzed plasmid DNA (after drop dyalisis, see section 3.1.9) and transferred in a pre-cooled $2 \mathrm{~mm}$ electroporation cuvette. The electroporation was performed using Gene Pulser II with the settings $2.5 \mathrm{kV}, 25 \mu \mathrm{F}$ and 
$200 \Omega$ for about five milliseconds. Then, the electroporated cells were immediately diluted with $800 \mu \mathrm{l}$ of warm LB- or S.O.C. media and incubated at $37^{\circ} \mathrm{C}$ for $1 \mathrm{~h}$ to allow expression of the antibiotic resistance gene. Subsequently $50-200 \mu$ of the transformed bacteria were spread on the pre-warmed agar plates supplemented with appropriate antibiotic and incubate at $37^{\circ} \mathrm{C}$ overnight.

Transformation via heat shock allows plasmid DNA to enter the bacterial cell via plasma membrane pores, which are formed by sudden increase in temperature. In this work for transformation through heat shock DH10B bacteria was used. Briefly, $50 \mu$ l of bacteria were pipetted in $1.5 \mathrm{~mL}$ Eppendorf tube and placed on ice for $30 \mathrm{~min}$. Then, $25 \mathrm{ng}$ of plasmid DNA were added to the Eppendorf tube and incubated for next $30 \mathrm{~min}$ on ice. When time was up, the bacteria and plasmid mixture were placed in a water bath for $90 \mathrm{sec}$ at $42^{\circ} \mathrm{C}$, and then immediately on ice for five min. Afterwards, the mixture was transferred to a new $1.5 \mathrm{~mL}$ Eppendorf tube containing $800 \mu \mathrm{l}$ of prewarmed S.O.C. media and left shaking at $37^{\circ} \mathrm{C}$ for $1 \mathrm{~h}$. Subsequently, 100-200 $\mu 1$ of transformed bacteria were added to agar plates supplemented with appropriate antibiotic and incubate overnight at $37^{\circ} \mathrm{C}$.

\subsection{Mammalian cell culturing}

\subsubsection{Used cell lines and culturing conditions}

All cell lines were kept in the incubator at $37^{\circ} \mathrm{C}$ under $5 \% \mathrm{CO}_{2}$ and $95 \%$ humidity. The culture media was pre-warmed at $37^{\circ} \mathrm{C}$ in a water bath before applied to the cells. Cells splitting frequency was dependent on the proliferation rate of the cell line and on the purpose of the planned experiment. To calculate the number of cells needed for experiments, Neubauer-cell chamber was used. Therefore, $20 \mu \mathrm{l}$ of cell suspension was mixed 1:1 with Trypan Blue. Then, $10 \mu \mathrm{l}$ of prepared solution were pipetted to the Neubauer-cell chamber. The living cells were counted and the required cell concentration per well was calculated.

Flp-In $^{\mathrm{TM}}$ T-REx 293cell line is a cell line derived from the human embryonic kidney 293 (HEK 293) cells. The Flp-In ${ }^{\mathrm{TM}}$ T-REx 293 cell line, containing Flp Recombination Target (FRT) integrated into a specific site on the genome, enables stable transfection and integration of a gene of interest using the Flp-InTM system. The cells were cultured in DMEM medium supplemented with $10 \%$ FBS and 1\% Penicillin/Streptomycin and 0,1\% Zeocin. The cells were 
trypsinized to assure the homogeneous distribution of the single cell. Therefore, $3 \mathrm{~mL}$ of trypsin were added to the culture flask and incubated for approximately $3 \mathrm{~min}$ at $37^{\circ} \mathrm{C}$. To deactivate trypsin, a $6 \mathrm{~mL}$ of culture media were added. Then, the cells were collected in $50 \mathrm{~mL}$ falcon tube and centrifuged at $300 \mathrm{x}$ g for $3 \mathrm{~min}$. The supernatant was removed and the cell pellet was resuspended in fresh media. The cells were counted and necessary amount of the cells was plated.

Human skin fibroblasts (kindly provided by Departments of Dermatology and General Surgery of University Medical Center Göttingen) were used for transient transfections, followed by immunochemistry. The cells were cultured in DMEM medium containing 10\% FBS and 1\% Penicillin/Streptomycin. The fibroblasts are adherent cells, therefore to detach and to prepare them for splitting or for an experiment trypsinization was required. Three $\mathrm{ml}$ of trypsin was added to the culture flask and incubated for $3-5 \mathrm{~min}$ at $37^{\circ} \mathrm{C}$. For trypsin neutralization, three $\mathrm{ml}$ of culture media was added. The cells were collected in $50 \mathrm{ml}$ falcon tubes and centrifuged at $500 \mathrm{x} \mathrm{g}$ for five min. The supernatant was removed and the cell pellet was resuspended in fresh media. The cells were counted and the necessary amount of cells was plated.

NIH 3T3 mouse embryonic fibroblast cell line is a standard fibroblast cell line, which in this study was used for transient transfections, followed by Western blotting and immunostaining analysis. 3T3 means that the cells were transferred (T) every 3 days and plated $3 \times 10^{6}$ cells per plate. The cells were kindly provided by Naim Kittana (Institute of Pharmacology, University Medical Center Göttingen). NIH 3 T3 fibroblasts were cultured in DMEM media containing $10 \%$ FCS, $1 \%$ Penicillin/Streptomycin, $4.5 \mathrm{~g} / \mathrm{L}$ glucose and L-glutamine. To split the cells or to prepare them for the experiments, the cells were treated with trypsin as described above.

\subsubsection{Freezing cultured cells}

For future experiments and long-term maintenance, cells were stored in liquid nitrogen. For cryopreservation only low-passaged cells were used. After reaching $80 \%$ confluency, the cells were harvested and transferred to $50 \mathrm{~mL}$ falcon tube and pelleted by centrifugation at $300 \mathrm{x} \mathrm{g}$ for $3 \mathrm{~min}$ at RT. The supernatant was discarded and the pellet was resolved in $6.8 \mathrm{~mL}$ of icecold freezing solution containing $90 \%$ of pure FCS and $10 \%$ of sterile DMSO. All steps were performed on ice. Resuspended cells were transferred into $1.8 \mathrm{~mL}$ cryotubes and placed for $1 \mathrm{~h}$ on ice. Then, the cryotubes were transferred to $-80^{\circ} \mathrm{C}$ for one week. For further storage, the cells were transferred to the liquid nitrogen storage container (about $-170^{\circ} \mathrm{C}$ ). 


\subsubsection{Thawing cultured cells}

Cryotubes containing frozen cells were removed from the liquid nitrogen storage container and rapidly thawed in a hand until the outer surface of the cells ice block started to melt. Then, the cells were immediately transferred to the $50 \mathrm{~mL}$ falcon tube containing $10 \mathrm{~mL}$ of pre-warmed culture media and centrifuged at $300 \mathrm{x}$ g for $3 \mathrm{~min}$ at RT. The supernatant was discarded and the pellet was gently resuspended in $10 \mathrm{ml}$ of pre-warmed medium (medium type according to the culture recommendations of the specific cell line), transferred to a $25 \mathrm{~cm}^{2}$ culture flask and cultured under standard condition. After several passages, the cells were transferred to $75 \mathrm{~cm}^{2}$ culture flask.

\subsection{Mammalian cell transfection}

Transfection is the procedure of transporting foreign nucleic acids into mammalian cells by using chemical, lipid or physical based methods. In this study, the cells were transfected transiently and stably by lipofection.

\subsubsection{Transient transfection}

Transiently transfected cells express the gene of interest for a limited period of time (24-48h), but this gene is not integrated into the genome.

Depending on the cell line and approach (Western blotting or immunocytochemical analysis), $2-5 \times 10^{5}$ cells were plated in a 12 well plate and incubated at $37^{\circ} \mathrm{C}$ and $5 \% \mathrm{CO}_{2}$ to reach 70 $80 \%$ confluence. In this study, pcDNA5.1/TGFB1_FLAG plasmid was transiently transfected into the cells using FuGene $6^{\circledR}$ transfection reagent. The procedure was performed as follows: Firstly, $100 \mu \mathrm{l}$ of pure DMEM media were mixed with $12 \mu$ of FuGene 6 transfection reagent in $1.5 \mathrm{~mL}$ Eppendorf tube and incubated for $5 \mathrm{~min}$ at RT. Then, $2 \mu \mathrm{g}$ of plasmid DNA was added to the reaction mix and incubated for $15 \mathrm{~min}$ at RT. In the meantime, the cells were rinsed once with $1 \mathrm{~mL}$ of PBS. After that, $1 \mathrm{~mL}$ of the DMEM medium containing $1 \%$ Penicillin/Streptomycin antibiotics was added to each well and $112 \mu \mathrm{l} /$ well of reaction mix was pipetted. The transfected cells were incubated at $37^{\circ} \mathrm{C}$ for $24-48$ hours and afterwards lysed with RIPA buffer (for Western blotting) or fixed and permeabilized (for immunocytochemistry). 


\subsubsection{Stable transfection}

In contrast to transient transfection, stable transfection allows integration of the gene of interest into the genome of mammalian cells. Chromosomal integration of the transfected DNA construct enables long-term studying of gene expression in the transfected cells. The introduced DNA construct has a marker gene (antibiotic resistance gene) which allows to select stably transfected cells. When applying selective antibiotic to the cells, the cells that were not transfected or were transiently transfected die, and those that express the antibiotic resistance gene at sufficient levels survive.

In this work, stable transfection was performed using Flp-In ${ }^{\mathrm{TM}}$ T-REx HEK 293 cell line. This cell line contains pFRT/lacZeo plasmid with integrated lacZ-Zeocin ${ }^{\mathrm{TM}}$ fusion gene and FlpRecombination Target (FRT) site. FRT is inserted downstream of the ATG initiation codon of the lacZ-Zeocin ${ }^{\mathrm{TM}}$ fusion gene and is a target site for Flp recombinase. Next, an expression plasmid pcDNA5.1 with inserted gene of interest TGFB1 was co-transfected. Expression of the gene of interest is under the control of the human cytomegalovirus (CMV) promoter. The pcDNA5.1 plasmid also contains the hygromycin resistance gene with FRT site. Beyond pFRT/lacZeo and pcDNA5.1/TGFB1 plasmids, Flp recombinase expression plasmid pOG44 was co-transfected. The Flp recombinase catalyzes a homologous recombination event between the FRT sites in the Flp-In ${ }^{\mathrm{TM}}$ T-REx HEK 293 cell line and the pcDNA5.1/TGFB1 plasmid.

In order to transfect pcDNA5.1/TGFB1 construct, the following steps were performed: The cells were plated at $9 \times 10^{5}$ per well in 6-well plate and incubated overnight at $37^{\circ} \mathrm{C}$. After reaching approximately $80-85 \%$ confluence, the cells were ready for transfection. At first, transfection mix was prepared. Therefore, $100 \mu$ l of pure DMEM medium was mixed with $12 \mu 1$ of FuGene 6 transfection reagent per well and incubated for 5 min at RT. Afterwards, $3.6 \mu \mathrm{g}$ of pOG44 plasmid and $0.4 \mu \mathrm{g}$ of pcDNA5.1/TGFB1 plasmid were added to the transfection reagent and incubated for $15 \mathrm{~min}$ at RT. Meanwhile, the cells were rinsed twice with DMEM medium supplemented with $10 \%$ FCS and $1.9 \mathrm{~mL}$ of the same media were added to each well. Then, $112 \mu \mathrm{l}$ of transfection mix/well were added to the cells and incubated for $48 \mathrm{~h}$. Afterwards, the cells were transferred to the $92 \mathrm{~mm}$ petri dish with $9 \mathrm{~mL}$ of DMEM medium supplemented with 10\% FBS serum and 1\% Penicillin/Streptomycin antibiotics. Following overnight culture the old medium was discarded and $9 \mathrm{~mL}$ of DMEM medium supplemented with $10 \%$ FBS serum and 1\% Penicillin/Streptomycin, as well as the screening antibiotic Hygromycin B (300 $\mu \mathrm{g} / \mathrm{ml})$, was added. Ten days following transfection, untransfected cells died and successfully transfected cells have generated colonies. Each single colony was picked up and transferred into a single well of a 12-well plate, then to 6-well plate, and then to $25 \mathrm{~cm}^{2}$, 
and finally to $75 \mathrm{~cm}^{2}$ culture flask. In further culturing steps the Hygromycin B concentration was reduced up to $100 \mu \mathrm{g} / \mathrm{mL}$ in order to increase the cells growth. Afterwards, the stable transfected cells were characterized on genome level by PCR, on mRNA level by qRT-PCR and protein level by Western blotting and ELISA.

\subsubsection{Validation of chromosomal integration of the constructs in pcDNA 5.1 plasmid}

After stable cell lines were generated as previously described (see section 3.6.2) genomic DNA was isolated (see section 3.1.4). Then, the correct chromosomal integration of the gene of interest as well as the hygromycin resistance gene was checked. We have performed two independent PCRs using two pairs of primers complementary to the hygromycin resistance gene and to the TGFBl gene.

First integration-specific PCR was performed in order to verify integration of the hygromycin resistance gene in the chromosomal DNA of the stable transfected T-REX HEK293 cells. The PCR was conducted in a reaction mixture (Tab. 27) with forward primer "PSV40" and reverse primer "Hyg" (primer sequence see in section 2.10, Tab. 5) under conditions stated in Tab. 28. The forward primer annealed in the SV40 promoter of the pFRT/lacZeo plasmid. Reverse primer annealed to the hygromycin resistance region of the pcDNA5.1 plasmid.

Tab. 27 Mixture for confirmatory PCR for hygromycin resistance gene integration.

\begin{tabular}{ll}
\hline Reagent & Volume per sample $(\boldsymbol{\mu l})$ \\
\hline $10 \mathrm{x}$ buffer & 2 \\
$\mathrm{dNTPs}(2 \mathrm{mM})$ & 2 \\
$\mathrm{MgSO}_{4}(25 \mathrm{mM})$ & 0.8 \\
Q-Solution & 4 \\
Forward primer PSv40 $(10 \mathrm{nM})$ & 0.5 \\
Reverse primer Hyg $(10 \mathrm{nM})$ & 0.5 \\
Template DNA $(300 \mathrm{ng} / \mu \mathrm{l})$ & 2 \\
KOD HotStart Polymerase $(1.0 \mathrm{U} / \mu \mathrm{l})$ & 0.5 \\
ddH 20 & 9.7 \\
\hline Final volume & 22
\end{tabular}


Tab. 28 Conditions for confirmatory PCR for hygromycin resistance gene integration

$\left.\begin{array}{lll}\hline \text { Phase } & \text { Duration } & \text { Temperature } \\ \hline \text { Initial denaturation } & 2 \mathrm{~min} & 95^{\circ} \mathrm{C} \\ \hline \text { Denaturation } & 30 \mathrm{sec} & 95^{\circ} \mathrm{C} \\ \text { Annealing } & 30 \mathrm{sec} & 68^{\circ} \mathrm{C} \\ \text { Elongation } & 1 \mathrm{~min} 30 \mathrm{sec} & 72^{\circ} \mathrm{C} \\ \hline \text { Final elongation } & 10 \mathrm{~min} & 72^{\circ} \mathrm{C} \\ \text { for ever } & & 8^{\circ} \mathrm{C}\end{array}\right\} 35 \mathrm{x}$

In order to confirm the correct chromosomally integration of the TGFB1 gene, second PCR was performed using $\mathrm{P}_{\mathrm{CMV}}$ and LacZ primers (primers sequence see in the section 2.10, Tab. 5). This PCR (Tab. 30) amplified the region between the downstream part of $\mathrm{P}_{\mathrm{CMV}}$ promoter and the upstream part of lacZ/Zeocin resistance region which contains TGFB1 cDNA. The reaction mixture was prepared as denoted in the Tab. 29.

Tab. 29 Mixture for confirmatory PCR for gene of interest

\begin{tabular}{ll}
\hline Reagent & Volume per sample $(\boldsymbol{\mu l})$ \\
\hline 10 x ExpandLong buffer & 2.8 \\
dNTPs $(2 \mathrm{mM})$ & 4.5 \\
$\mathrm{MgSO}_{4}(25 \mathrm{mM})$ & 1 \\
Q-Solution & 5.6 \\
Forward primer PcMv $(10 \mathrm{nM})$ & 0.5 \\
Reverse primer LacZ $(10 \mathrm{nM})$ & 0.5 \\
Template DNA (300 ng/ $\mu \mathrm{l})$ & 3 \\
ExpandLong Polymerase Mix & 0.3 \\
ddH 20 & 9.8 \\
\hline Final volume & 28
\end{tabular}


Tab. 30 Conditions for confirmatory PCR for gene of interest

$\left.\begin{array}{lll}\hline \text { PCR-Condition Phase } & \text { Duration } & \text { Temperature } \\ \hline \text { Initial denaturation } & 2 \mathrm{~min} & 94^{\circ} \mathrm{C} \\ \hline \text { Denaturation } & 30 \mathrm{sec} & 96^{\circ} \mathrm{C} \\ \text { Annealing } & 30 \mathrm{sec} & 64.4^{\circ} \mathrm{C} \\ \text { Elongation } & 3 \mathrm{~min} 30 \mathrm{sec} & 70^{\circ} \mathrm{C} \\ \hline \text { Final elongation } & 10 \mathrm{~min} & 68^{\circ} \mathrm{C} \\ \text { for ever } & & 8^{\circ} \mathrm{C}\end{array}\right\} 34 \mathrm{x}$

\subsection{Statistical analysis}

Descriptive analysis refers to visualization of data distribution. In my thesis, different groups according to the allelic configuration and treatment procedures were illustrated by boxplots, which apply also for non-parametrically distributed data. The relationship between two continuous variables, i.e. the $\mathrm{pH}$ and the TGF $\beta 1$ activation, was depicted by two-dimensional plots, displaying mean values of independent experimental repetitions with the respective standard deviations.

Analytical procedures used in this work comprise the Mann-Whitney and the Shapiro-Wilk test as well as linear regression analysis. For the data visualized by boxplots testing for statistical differences between two independent groups (e.g. Arg25 versus Pro25, radiation versus control) was performed by the non-parametric Mann-Whitney U test. For two dimensional plots, fitting of a regression line was indicated by the coefficient of determination. Impact of more than one independent parameters (i.e. $\mathrm{pH}$, allelic configuration) on a dependent variable (i.e. amounts of active TGF $\beta 1$ ) was assessed by linear regression analysis. Prior to linear regression analysis, data distribution was evaluated for compatibility with normal distribution by Shapiro-Wilk test (a p-value $>0.01$ was considered as sufficient to apply the parametric linear regression analysis). In general, p-values of less than 0.05 were regarded as statistically significant. The statistical analyses were carried out using SPSS statistical software package (version 12.0) and Microsoft Excel. 


\section{Results}

To pinpoint the functional role of the Arg25Pro polymorphism, may it be related to expression, intracellular processing, secretion or activation of TGF $\beta 1$, we started with generation of allele-specific constructs.

\subsection{Generation and confirmation of stably transfected TGFB1 constructs}

The two alleles of the Arg25Pro polymorphism had to be cloned in a human model cell line in order to stably express the two referring proteins. At first, genetic constructs were generated prior to transfection. Upon transfection, the correct genomic integration was ascertained by two independent PCRs. Primer extension method was employed to confirm the allelic identities of Arg25 and Pro25-bearing constructs. Expression of transfected TGFB1 was assessed by qRT-PCR and Western blotting.

\subsubsection{Generation of stably transfected cell lines expressing TGFB1}

For subsequent functional analyses, the first aim was to introduce the entire TGFB1 coding region for both the Arg25 and Pro25 variant in the mammalian expression vector pcDNA5.1 containing a FRT site for later stable genomic integration. Starting with the bacterial pOTB7 plasmid, in which the TGFB1 coding region containing Arg25 was supplied, as a first step site-directed mutagenesis was carried out to generate Pro25 (see section 3.1.6). Second, the TGFB1 coding regions were transferred from pOTB7 into pcDNA5.1 plasmids by cutting with HindIII and XhoI restriction enzymes and subsequent ligation (Fig. 4, for methodological details see sections 3.1.8 and 3.1.8). Ligated plasmids were then transformed into One Shot ${ }^{\circledR}$ TOP10 E. coli strain via electroporation (see section 3.4.2), and purified by plasmid mini-preparation (see section 3.1.10.1). The correctness of TGFB1 insertion into pcDNA5.1 plasmid was checked by analytical digestion (see section 3.1.7.1) and sequencing including evidence of either the Arg25 and Pro25 allele (see section 3.1.11).

The generated constructs were intended to stably transfect into human T-REx HEK 293 cells using the Flp-In system (see section 3.6.2). 

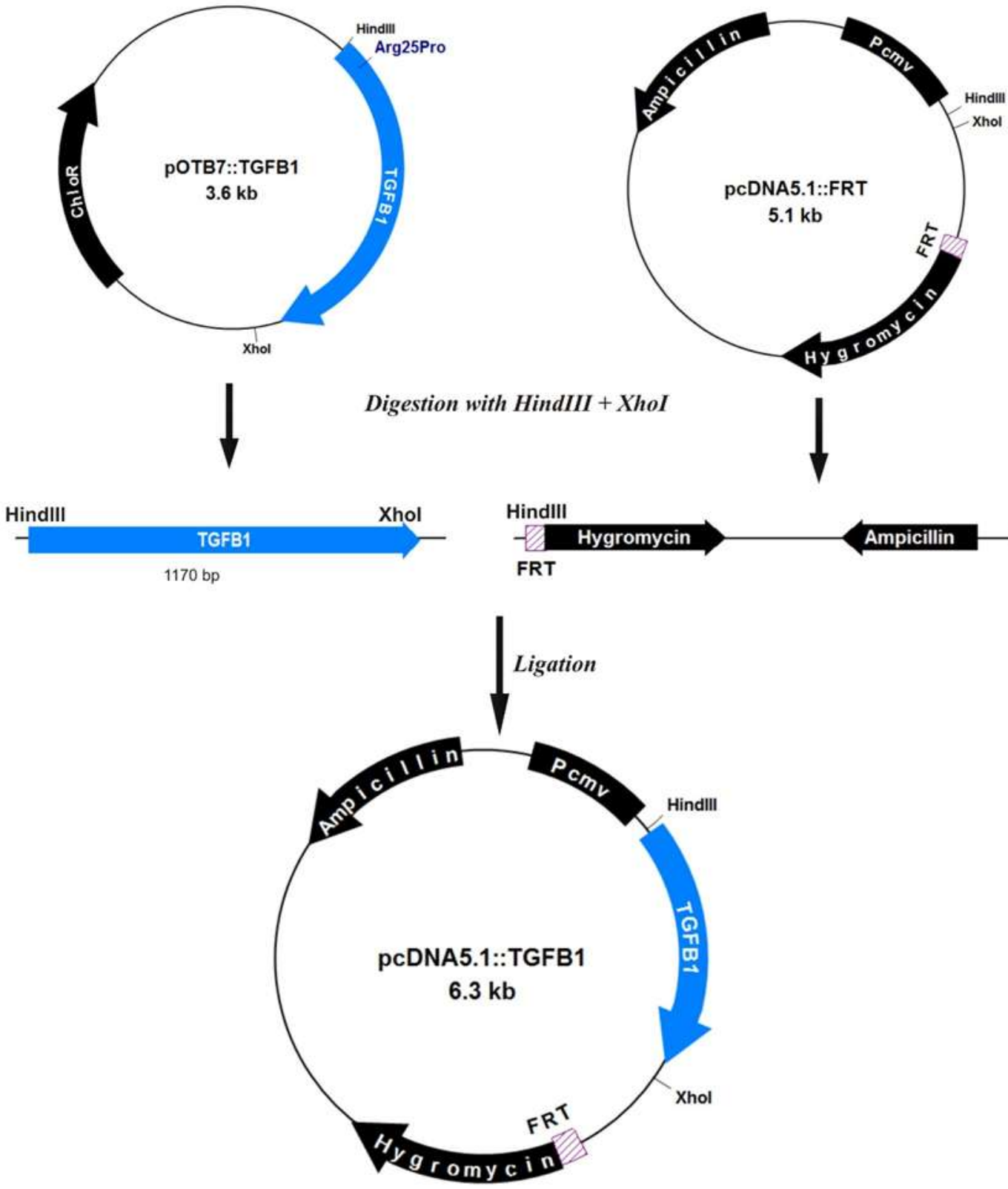

Fig. 4 Scheme of cloning of TGFB1 into the expression vector pcDNA5.1.

In the upper part, the two vectors pOTB7 and pcDNA5.1 (with the Flip-in Recombinant Target, FRT) are displayed. After digestion with the indicated restriction enzymes, ligation was performed resulting in the plasmid shown at the bottom of the figure.

\subsubsection{Verification of correct genomic integration}

Successfully transfected cells were screened for hygromycin resistance by antibiotic selection. Positive clones were then cultured as described previously (see section 3.6.2). Next, successful genomic insertion of the pcDNA5.1/TGFB1 constructs was confirmed by two integration-specific PCRs. The first PCR (labeled as "PCR 1" in Fig. 5) amplifies the 
region from the pSV40 promoter to the hygromycin resistance gene. The product of the expected length (614 bp) revealed the correct integration of all six pcDNA5.1/TGFB1 constructs (three each for Arg25 and Pro25) into the HEK cells genome (Fig. 6.).

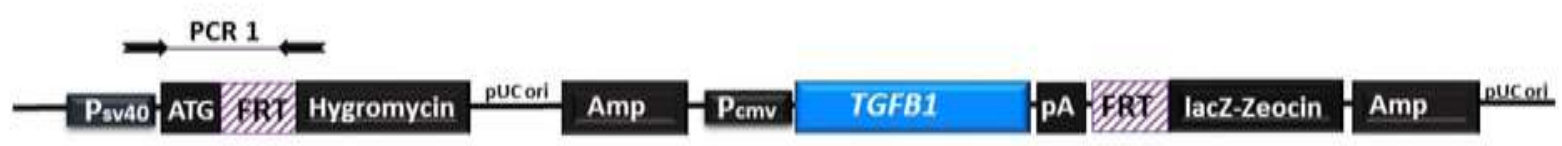

Fig. 5 Scheme for PCR verifying correct introduction of the hygromycin resistance region.

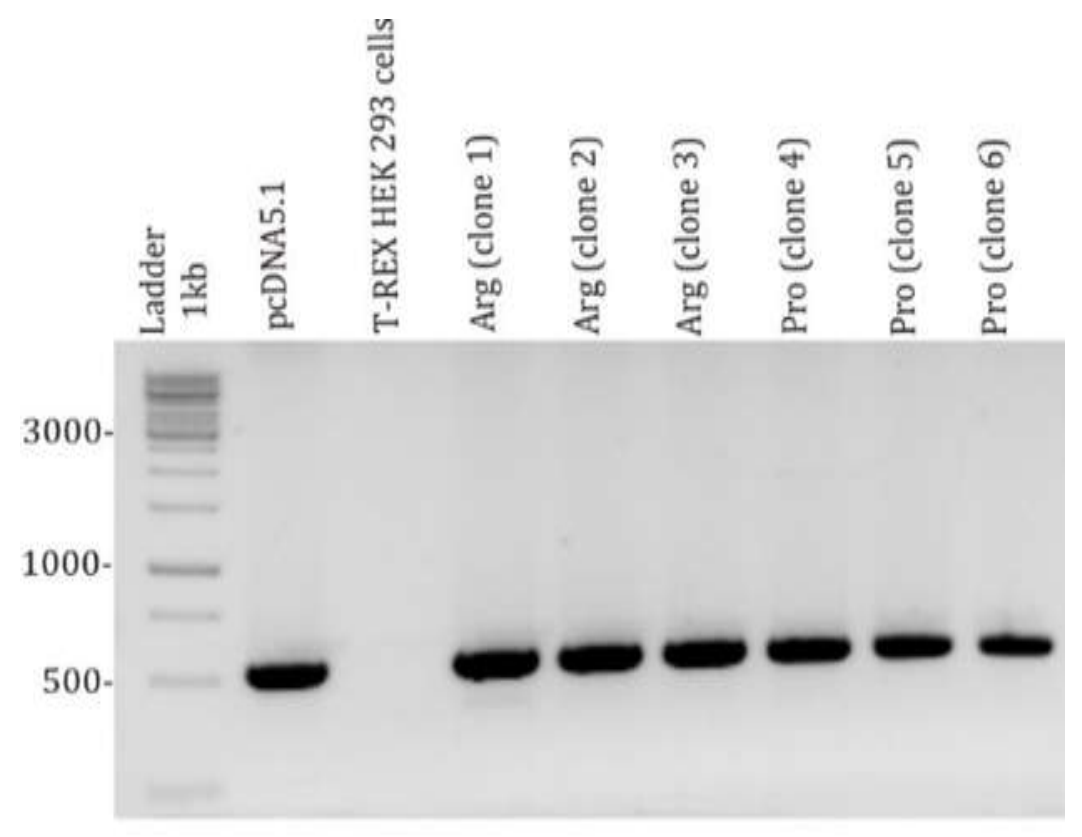

Fig. 6 Integration-specific PCR confirming the correct integration of the hygromycin resistance gene in the genome of T-REx HEK 293 cells.

Transfected constructs containing pcDNA5.1 with TGFB1 (three clones each for Arg25 and Pro25) and pcDNA5.1 without TGFB1 insert (second column next to the $1 \mathrm{~kb}$ ladder). Non-transfected T-REx HEK 293 cells (column 3) served as a negative control. The desired product length of the fragment was about $614 \mathrm{bp}$.

The second PCR was done to prove the correct genomic integration of the TGFB1 gene into the HEK 293 host cells (Fig. 7). Therefore, the region between the downstream part of $\mathrm{P}_{\mathrm{CMv}}$ promoter and the upstream part of the lacZ-Zeocin resistance region was amplified. As shown in the Fig. 8, the expected fragment length of $2594 \mathrm{bp}$ could be verified for five of the six transfected TGFBl-containing clones 


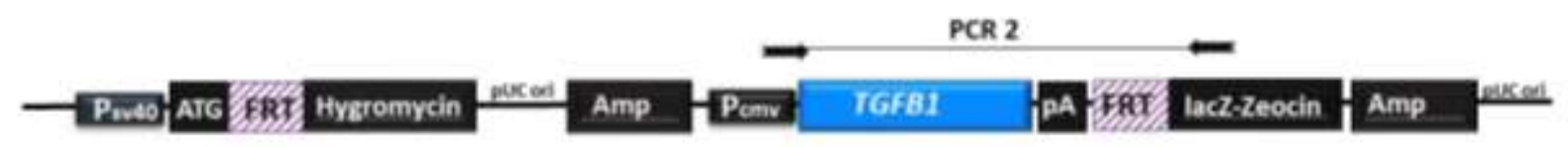

Fig. 7 Scheme for gene-of-interest PCR.

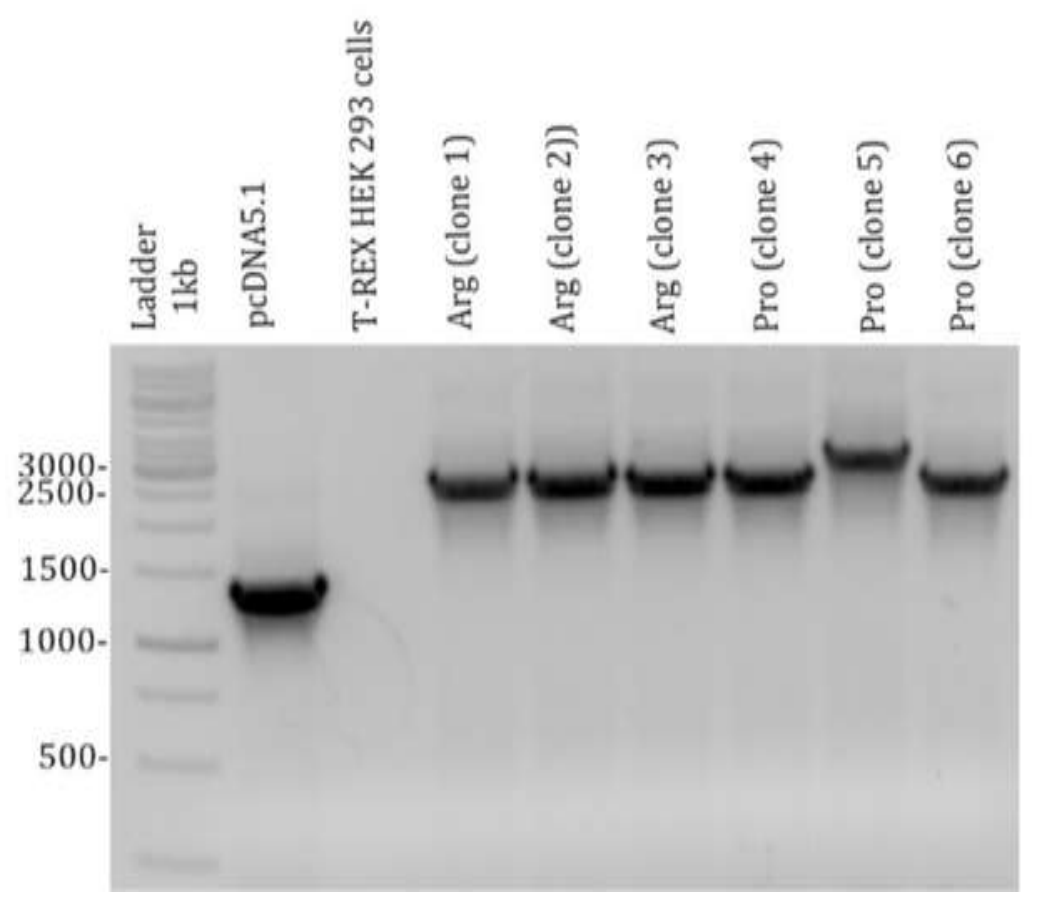

Fig. 8 Integration-specific PCR confirming the correct integration of the plasmid constructs in the genome of T-REx HEK293 cells.

Samples positioning is identical to Fig. 6. The desired product length of the fragment of interest was $2594 \mathrm{bp}$. For the vector without TGFBl insert this product accounts for $1424 \mathrm{bp}$.

Presence of the two alleles in the transfected host cells was confirmed by SNaPShot ${ }^{\mathrm{TM}}$ reaction (see section 3.1.12). This reaction was preceded by a PCR with a primer pair (see Tab. 7), which was specific for the pcDNA5.1/TGFB1 construct; thus, the respective host TGFB1 genomic region was not amplified. The subsequent $\mathrm{SNaPShot}{ }^{\mathrm{TM}}$ confirmed the allelic identities at the Arg25Pro polymorphism in the transfected cells.

\subsection{3 mRNA expression of transfected TGFB1}

Using qRT-PCR, mRNA expression of the transfected TGFBl coding region in the HEK 293 cells was quantified. The obtained results showed that TGFB1 mRNA expression 
level in cells carrying the wild-type Arg25 or variant Pro25 was about 12 to 19 -fold higher compared to empty vector-transfected control (Fig. 9). Furthermore, when comparing the three clones with Arg25 with those of Pro25 there was no significant differences ( $p=0.4$ according to t-test). Based on the above-mentioned genetic analysis and the qRT-PCR, one clone each for the Arg25 wild type and one for the Pro25 variant was selected for further experiments (highlighted by arrows in the Fig. 9).

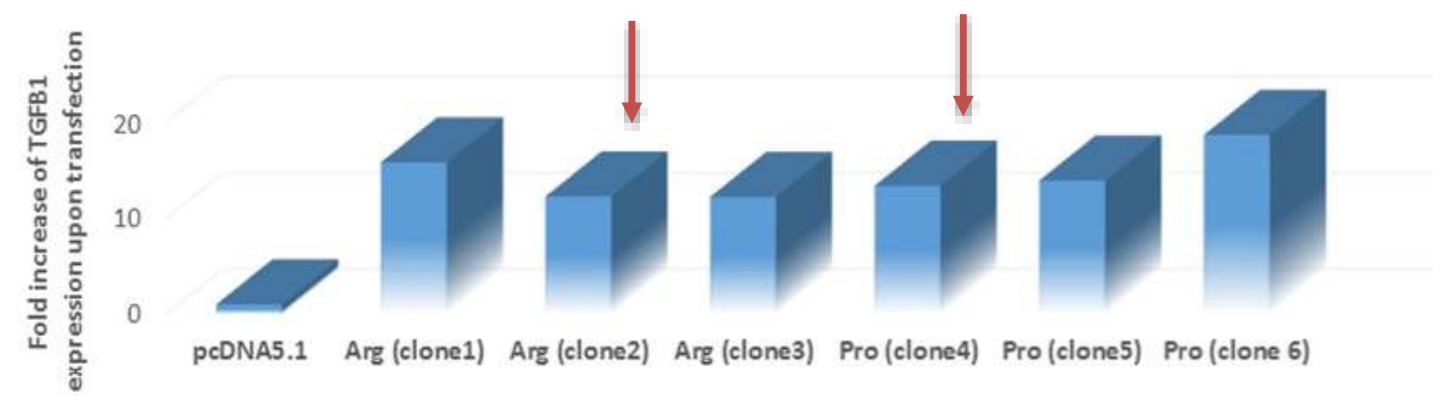

Fig. 9 Expression rate of $T G F B 1$ in the stably transfected T-Rex HEK 293 cells.

The raw TGFB1 relative transcript levels were normalized to $G A P D H$ expression and this ratio was referred to the empty vector pcDNA5.1. The red arrows indicate the clones chosen for subsequent functional analyses.

\subsubsection{TGFß1 protein expression in transfected cells}

To evaluate TGF $\beta 1$ protein expression Western blotting was performed. Immunoblotting with an antibody against TGF $\beta 1$ showed a strong band with about $50 \mathrm{kD}$ reflecting intracellular monomeric LAP-TGF $\beta 1$ protein. The analysis for the supernatant demonstrated mature TGF $\beta 1$ protein at $12.5 \mathrm{kDa}$ (monomer). These patterns were detected for both the constructs with the Arg25 and the Pro25 allele. Regarding supernatant, the amount of secreted mature TGF $\beta 1$ appeared much higher for the Pro-transfected constructs than for those with Arg25 as confirmed by three independent repetitions. 


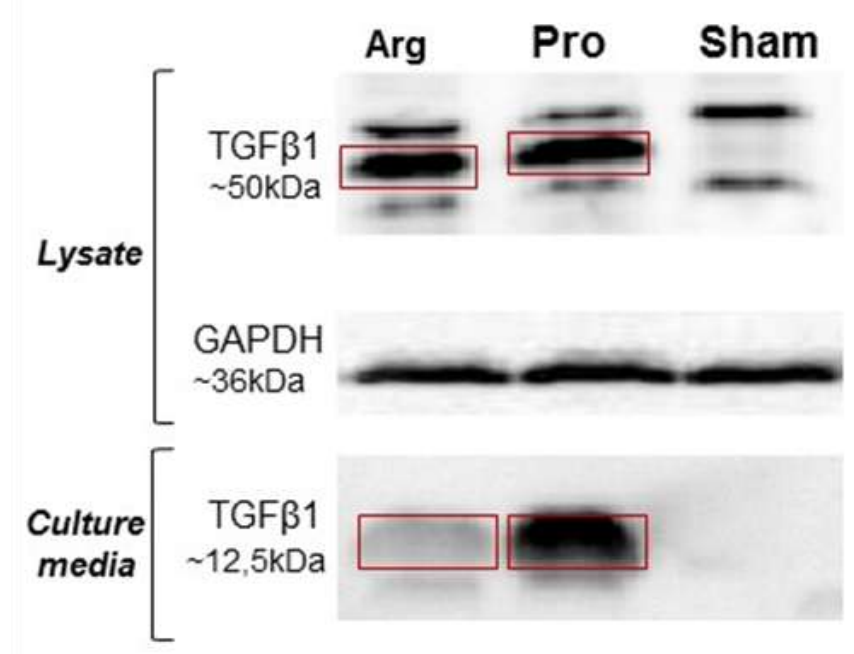

Fig. 10 Western blot of TGFß1 protein in transfected T-REx HEK 293 cells.

The top panel shows the lysate (with GAPDH as reference), the bottom the supernatant. Untransfected cell were used as a control. The presented qualitative pattern is representative for three independent immunoblots. Input of equal protein amounts was ascertained by prior assessment of total protein by BCA assay.

In summary, assessment of correct genomic integration, mRNA transcription and translation into protein demonstrated proper cellular models overexpressing either Arg25 or Pro25 of the TGF $\beta 1$ precursor protein suitable for further functional analyses.

\subsection{Localization of TGFß1 protein}

To gain better insights into localization of TGF $\beta 1$ protein in the cell, we generated constructs for Arg25 and Pro25 with a FLAG tag as an indicator of TGF $\beta 1$ localization. FLAG-protein is an eight amino acids epitope tag (DYKDDDDK), which allows better detection of expressed proteins (Terpe 2003). Two approaches for positional insertion of the FLAG tag were chosen. First, directly behind the first methionine in the signal peptide of the TGF $\beta 1$ precursor due to the vicinity of the index polymorphism Arg25Pro. Second, at the $\mathrm{N}$-terminus of the mature TGF $\beta 1$ protein, to address the question whether trafficking of mature TGF $\beta 1$ is affected by Arg25Pro. Both cloning approaches were carried out for Arg25 and Pro25. 


\subsubsection{Generation and transient transfection of TGFB1 with FLAG tag behind methionine (MetFLAG)}

To place a FLAG tag into the signal peptide, 24 nucleotides coding for FLAG were inserted in the common open reading frame sequence immediately after the three initial nucleotides coding for methionine.

Starting from the two previously generated plasmids of pcDNA5.1 with either Arg25 or Pro25 (see section 4.1.1) a PCR was set up comprising the entire open reading frame of TGFB1 with a nucleotide sequence coding for FLAG inserted in the forward primer (for primers see Tab. 3). The PCR products were digested with HindIII and XhoI restriction enzymes and ligated into pcDNA5.1 plasmid harboring the same restriction sites. The correct insertion of FLAG in the generated constructs was proven by sequencing (see section 3.1.11).

The constructs were transiently transfected (see section 3.6.1) into HEK 293 cells using FuGENE®6 transfection reagent. Following 24-48 h incubation in serum-free defined conditions, the cells were lysed for Western blotting or fixed for immunocytochemistry. 

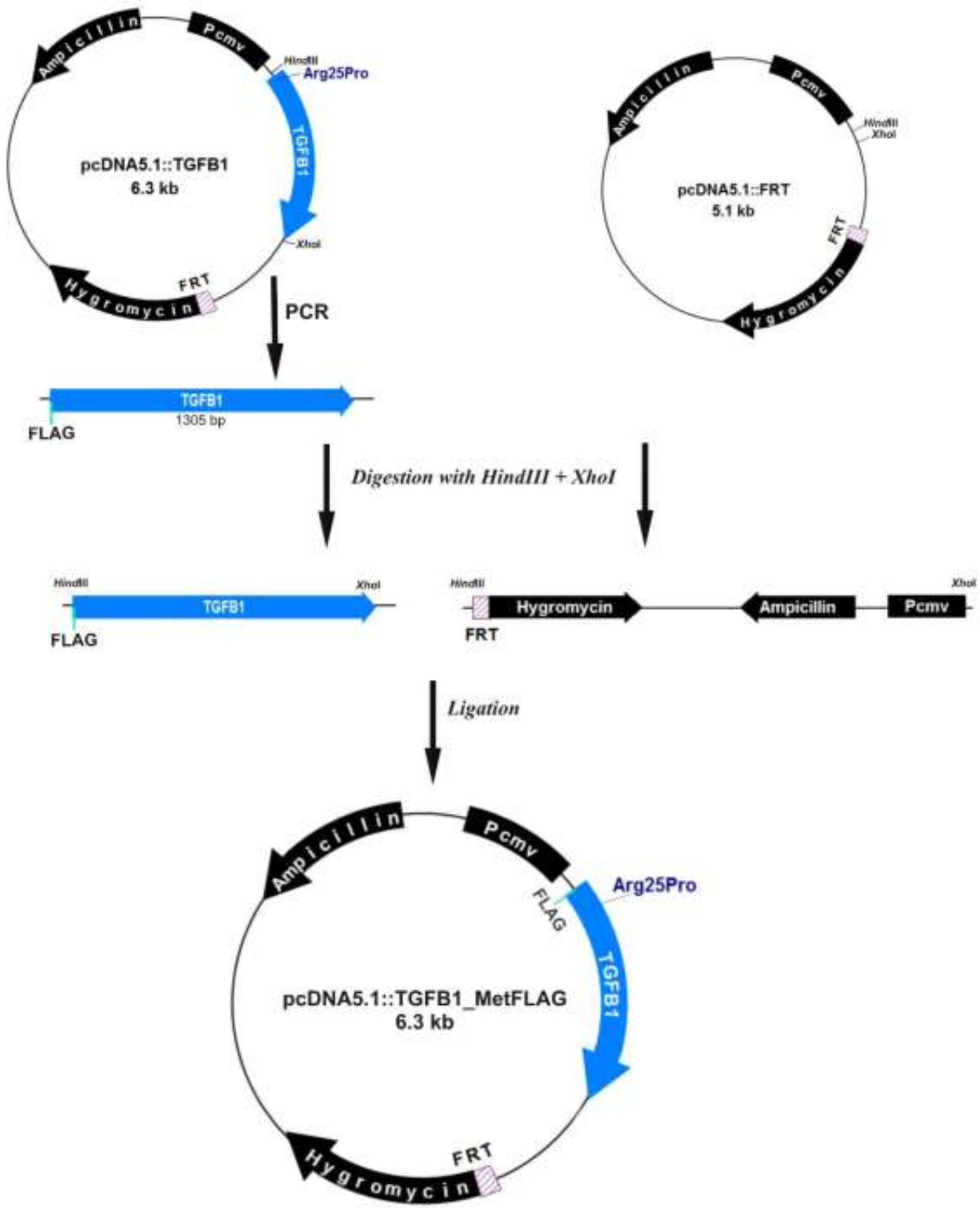

Fig. 11 Scheme for insertion of FLAG tag behind methionine in signal peptide of TGF $\beta 1$.

A fragment containing TGFB1 coding region and FLAG coding sequence was inserted behind methionine in signal peptide and amplified by PCR. After digestion with the indicated restriction enzymes ligation was performed resulting in the plasmid shown at the bottom of the figure. The steps were performed for $\operatorname{Arg} 25$, as well as for Pro25 simultaneously. 


\subsubsection{Generation and transient transfection of TGFB1 with FLAG tag at $N$ - terminus of mature TGF 1}

In the second approach, the FLAG tag was inserted at the 5'-end of the nucleotide sequence coding for mature TGF $\beta 1$. To minimize the possibility of reduced cleavage efficiency we reiterate the nucleotides for the first five amino acids of mature TGF $\beta 1$ directly before the FLAG tag as described formerly (Chubet and Brizzard 1996).

A sequence of 189 bps (Tab. 4) was commercially synthesized and cloned into the pEX-A vector with restriction sites for BamHI and BstXI. This sequence contains the 24 nucleotides coding for FLAG flanked on either side by the 15 nucleotides coding for the first five amino acids of mature TGF $\beta 1$ as well as additional sequence parts of the Cterminal LAP (5'-side) and further parts of the N-terminal mature TGF $\beta 1$. Next, the obtained pEX-A was transferred into DH10B bacteria by heat shock to amplify the plasmid amount (see section 3.4.2). Bacteria were harvested and plasmids were isolated by minipreparation (see section 3.1.10.1). Isolated plasmids were simultaneously digested by BstXI and BamHI. The previously generated pcDNA5.1/TGFB1 plasmids for either Arg25 or Pro25 were digested with the same enzymes. Finally, the digested samples were visualized by agarose gel electrophoresis (see section 3.1.2). The desired fragments were cut out from the gel, purified (see section 3.1.3) and ligated (see section 3.1.8). The steps performed for preparation of the constructs are illustrated in the Fig. 12. Preparation and further investigations of these generated constructs were performed in collaboration with Naim Kittana (Institute of Pharmacology, University Medical Center Göttingen).

The constructs for Arg25 and Pro25 with FLAG tag at the N-terminus of mature TGF $\beta 1$ were transiently transfected (see section 3.6.1) into the HEK 293, NIH 3 T3 cells and human skin fibroblast (see section 3.5.1). Following 24-48 h incubation in serum-free defined conditions, the cells were lysed for Western blotting or fixed for immunocytochemistry. 

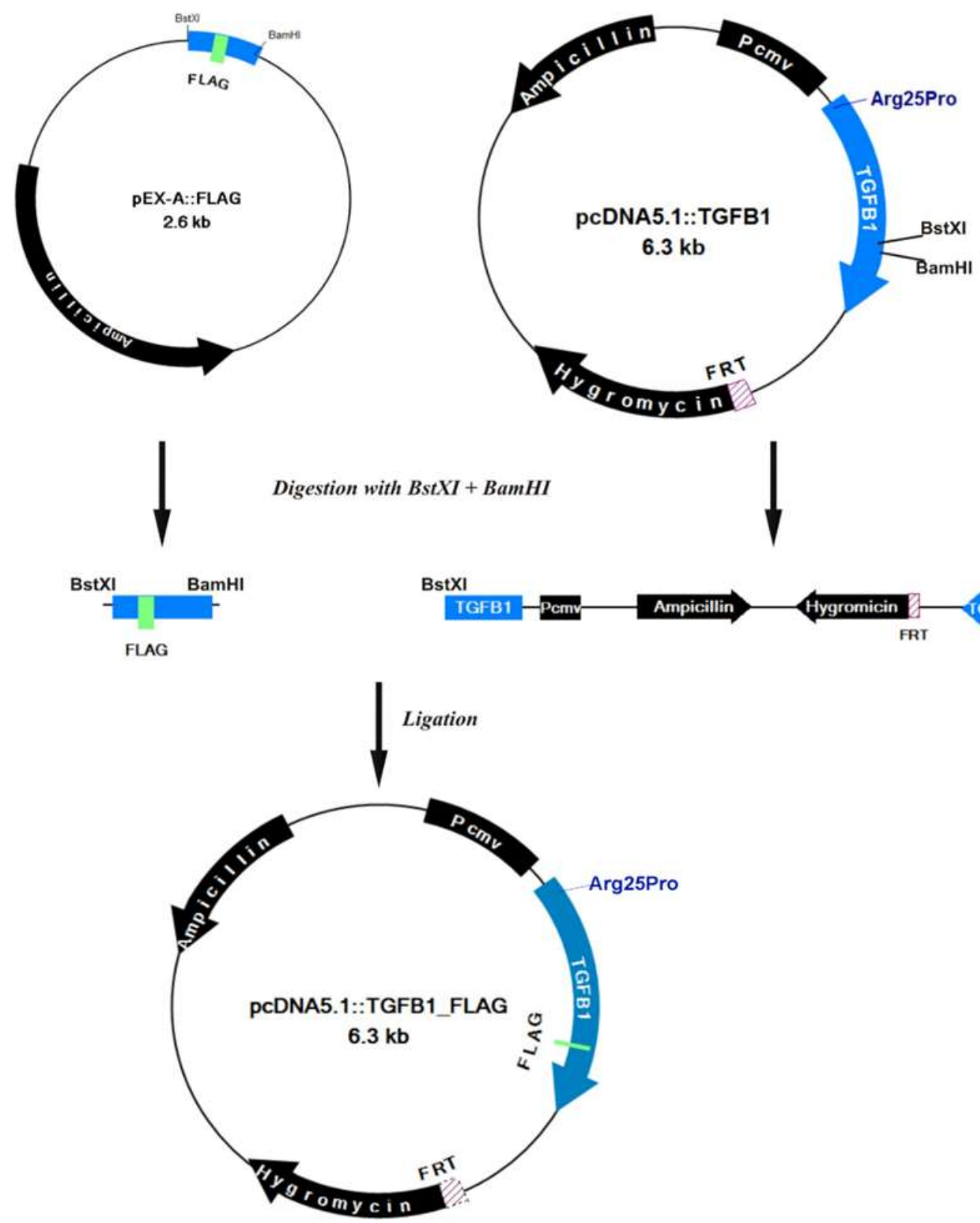

Fig. 12 Scheme for insertion of FLAG at the N-terminal site of mature TGF $\beta 1$.

A fragment containing C-terminal parts of LAP and N-terminal parts of mature TGF $\beta 1$ with FLAG in between was used to replace corresponding regions in previously generated plasmids of pcDNA5.1 with TGFß1 (one for Arg25 and one for Pro25, see Fig. 4).

\subsubsection{Western blotting of transiently transfected TGFB1 with FLAG tags}

Constructs with FLAG tag either following the first methionine or at the N-terminus of mature TGF 31 , each for Arg25 and Pro25, were transfected into HEK 293 cells. Expression of the respective protein was checked by Western blotting with antibodies directed against either TGF $\beta 1$ or FLAG. 
For the constructs with the FLAG tag inserted following the first methionine, probing with anti-FLAG did not show any band neither for cell lysates nor for cell culture media. However, when probing with antibody against TGF $\beta 1$ a strong band with about $55 \mathrm{kD}$ reflecting intracellular monomeric LAP-TGF $\beta 1$ was observed (Fig. 13).

This protein size corresponds to what was seen for the stably transfected T-REx HEK 293 cell (Fig. 10). However, in culture media no TGF $\beta 1$ was detected.

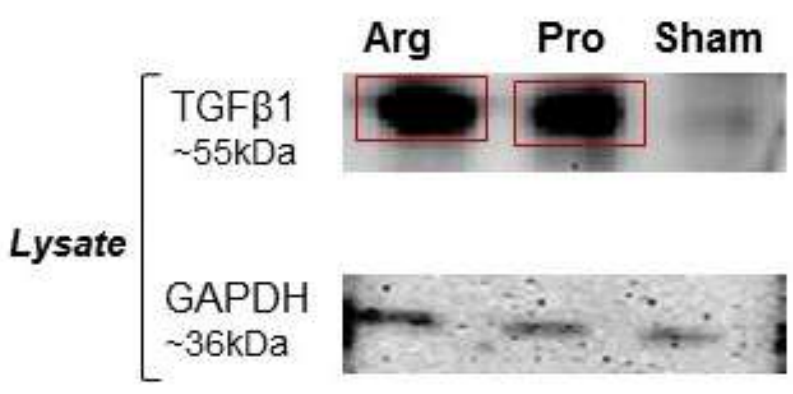

Fig. 13 Western blot for the translated product of FLAG tag behind methionine.

As host cells HEK 293 cells were used. Lysate and cell culture media were probed by FLAG and TGF $\beta 1$ antibodies separately (image only shows probing with TGF $\beta 1$ antibody, no bands were obtained for FLAG antibody). Untransfected cell were used as a control. GAPDH was employed as reference for intracellular protein levels.

For the constructs with the FLAG tag inserted at the N-terminus of mature TGF $\beta 1$ probing with FLAG antibody demonstrated strong signals with HEK 293 and NIH 3T3 cells as host (Fig. 14) with protein sizes corresponding to what was seen for the stably transfected T - REx HEK 293 cell (Fig. 10). In the cell lysate, a signal of $\sim 55 \mathrm{kDa}$ for TGF $\beta 1$ protein in precursor state was obtained. In culture media of HEK 293 cells, a signal of $\sim 13 \mathrm{kDa}$ for the mature TGF $\beta 1$ was observed. This was true for both alleles of the Arg25Pro polymorphism. In the culture media of NIH 3 T3 cells no secretion of mature TGF $\beta 1$ was seen. 
A

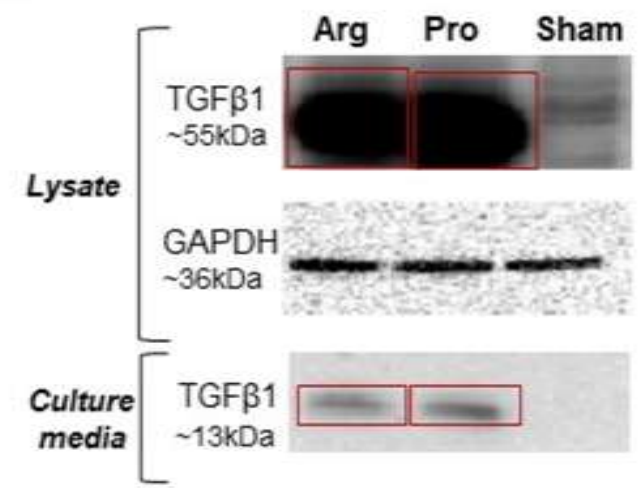

B

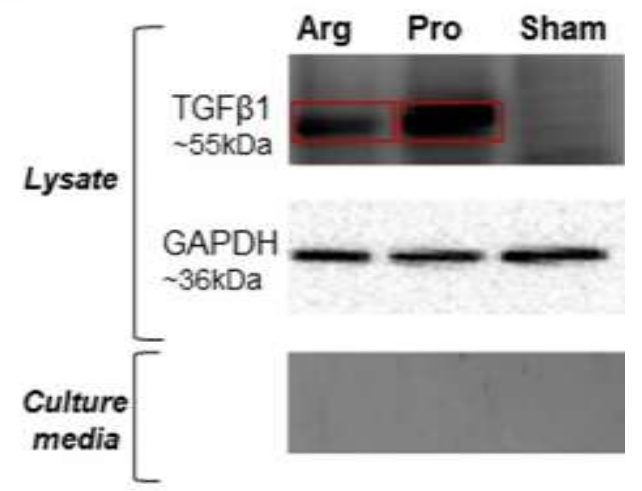

Fig. 14 Western blot for the translated product of FLAG tag at the N-terminus of mature TGFß1. As host cells HEK 293 (A) or NIH 3T3 (B) cells were used. For both cell lines, lysate and cell culture media were probed separately. Untransfected cell were used as a control. GAPDH was employed as reference for intracellular protein levels.

\subsubsection{Immunocytochemical analysis}

To determine TGF $\beta 1$ protein localization in the transiently transfected HEK 293, NIH 3T3 cells as well as in human skin fibroblast immunocytochemical assay was performed. The cells expressing FLAG tag at the N-terminus of the sequence corresponding to mature TGF $\beta 1$ as well as untransfected cells as control were immunostained as described before (see section 3.3.4) and visualized by immunofluorescence microscopy. The obtained immunofluorescence images (Fig. 15) showed perinuclear localization of the protein translated from the transfected constructs in all three cell types investigated. This localization suggests association with endoplasmatic reticulum or Golgi apparatus. These signals were specific for transfected cell lines and were not present in sham-transfected cells. 
A

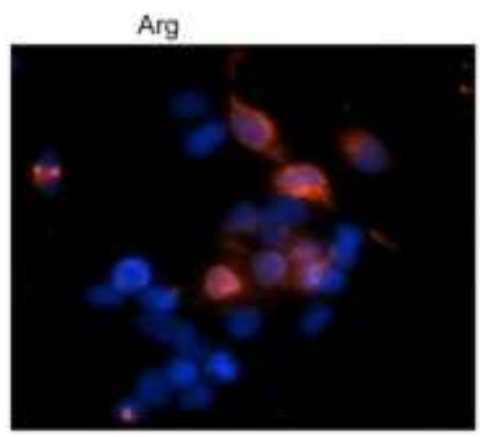

B

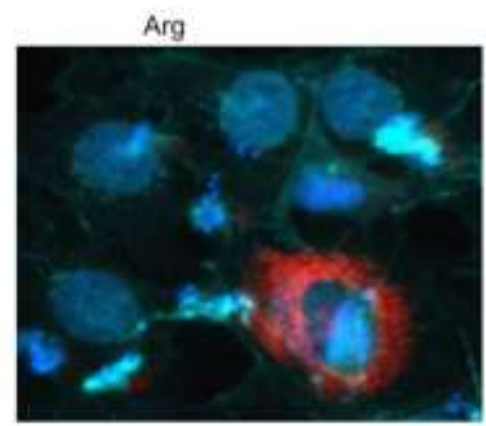

C

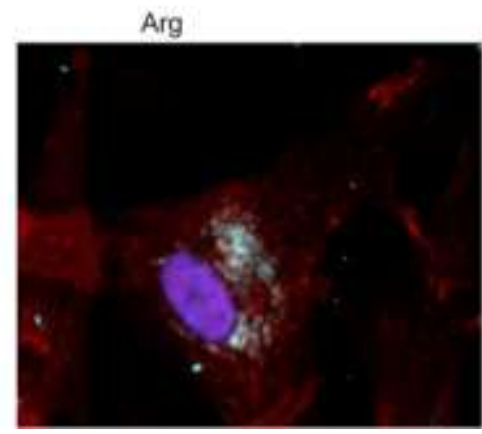

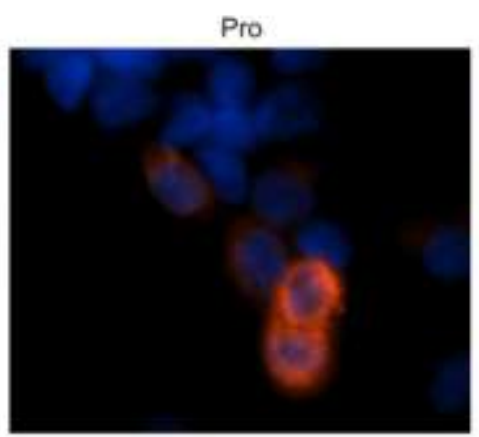

Pro

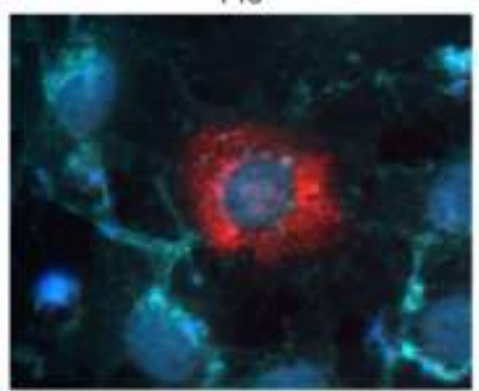

Pro

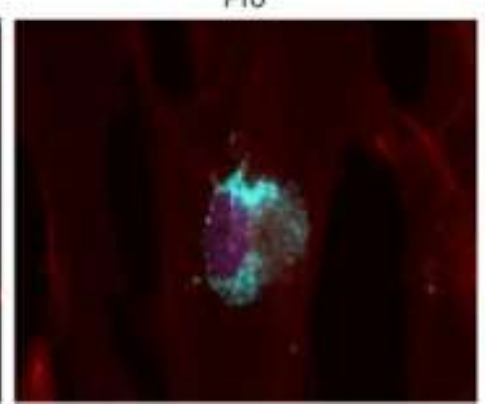

Sham

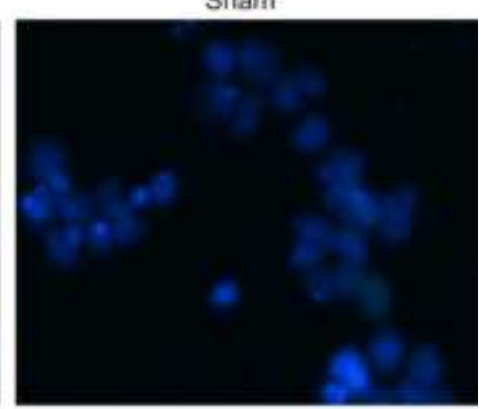

Sham

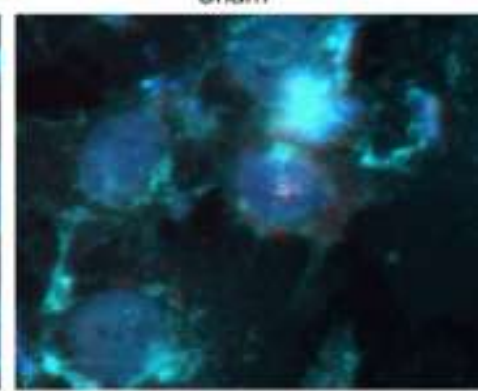

Sham

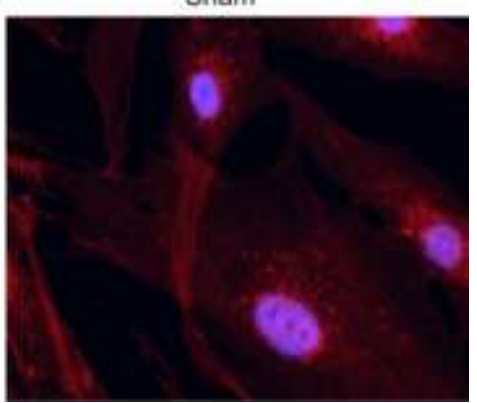

Fig. 15 Immunocytochemistry images indicating localization of the translated product with FLAG tag at the N-terminus of mature TGFß1.

As host cells HEK 293 cells (A), NIH 3T3 (B) cells and primary human skin fibroblasts (C) were used. For all three cell types, immunocytochemistry by FLAG antibody was carried out for transfected constructs containing Arg25, Pro25 or for untransfected host cells. In the first row (A), TGF $\beta 1$ with FLAG is indicated by red and nucleus by blue (DAPI). In the second row (B), TGF 1 with FLAG is indicated by red, nucleus by blue (DAPI), and ER and Golgi by green staining. In the third row (C), TGF $\beta 1$ with FLAG is indicated by green, nucleus by blue (DAPI), and ER and Golgi by red staining.

\subsection{Arg25Pro polymorphism: Effects on expression}

Several mechanisms how allelic variants may exert biological functions are conceivable (see section 1.3). First, it was investigated whether Arg25Pro affects expression of the encoded protein. As modulation of mRNA expression was ruled out previously (Schirmer et al. 2012) possible alterations on translation were analyzed here using the generated stably transfected cell lines. Therefore, intracellular contents of LAP and of active TGF $\beta 1$ were repeatedly examined for both variants. 
Amounts of LAP and active TGF $\beta 1$ did not significantly differ on baseline level between cells transfected with either Arg25 or Pro25 (Fig. 16). Upon irradiation with 1 x 25 Gy a trend toward decreased LAP expression in presence of Pro25 was observed. Intracellularly, contents of LAP representative for the inactive LAP-TGF $\beta 1$ were about 50,000-fold higher than those of active TGF $\beta 1$.
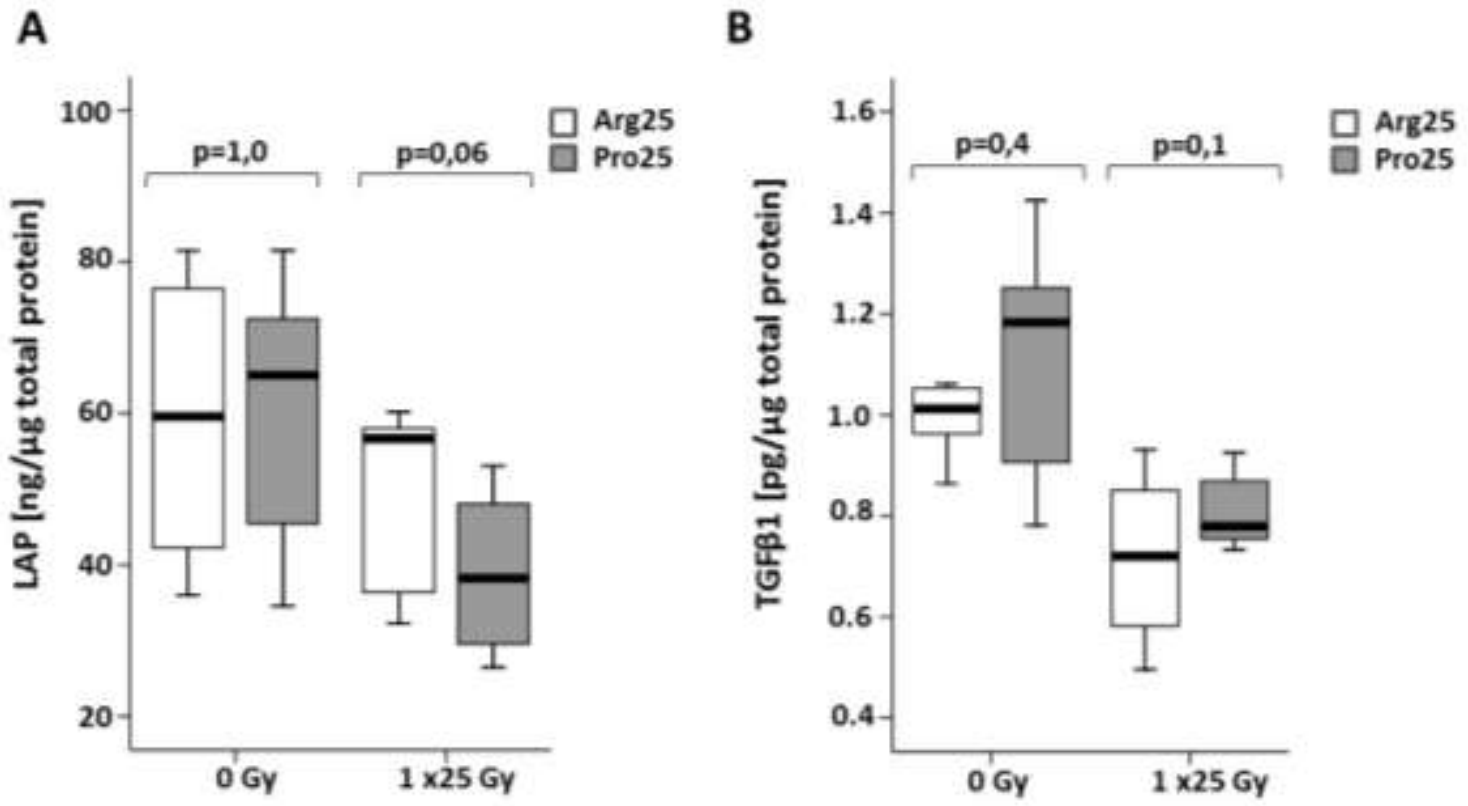

Fig. 16 Arg25Pro in regard to intracellular expression of LAP (A) and mature (B) TGFß1.

T-REx HEK 293 cells were plated at $1.25 \times 106$ per well and cultured for $24 \mathrm{~h}$ at $37^{\circ} \mathrm{C}$. Then, the cells were irradiated or sham-irradiated followed by further incubation of $24 \mathrm{~h}$. Cell lysates were quantified either for LAP (A) or TGF $\beta 1$ (B) by ELISA and referred to total protein contents as ascertained by BCA assay with each sample determined in duplicate. Regarding panel B, the amounts of active TGF $\beta 1$ were assayed by ELISA, i.e. without prior acidification. The shown data refer to eight independent experiments for each allele. The cells were lysed with RIPA buffer containing protease and phosphatase inhibitors. Statistical difference between the two alleles was assessed by Mann-Whitney U test.

\subsection{Arg25Pro polymorphism: Impact on secretion}

The effect of Arg25Pro on secretion of LAP-TGF $\beta 1$ was determined in the generated stably transfected cells. Taking into account that active TGF $\beta 1$ may be incompletely dissociated after acidification or be re-associated with LAP after neutralization (Arestrom et al. 2012), measurement of LAP secretion was considered as proxy for TGF $\beta 1$ precursor.

The amount of secreted LAP protein was significantly higher for Pro25 than for Arg25 under baseline conditions, i.e. cell culturing without any specific treatment. Actually, for cells transfected with Pro25 secretion of LAP was two times higher than for Arg25. 
Moreover, upon irradiation with one shot of 25 Gy the amount of secreted LAP remained significantly higher for the cells carrying the Pro25 variant (Fig. 17 A) whereby irradiation resulted in decreased LAP secretion for both alleles.

When considering the ratio of secreted versus intracellular LAP it clearly turned out that a much higher fraction of LAP is secreted in cells with Pro25 (Fig. 17 B). This was true for baseline conditions as well as upon irradiation.

A

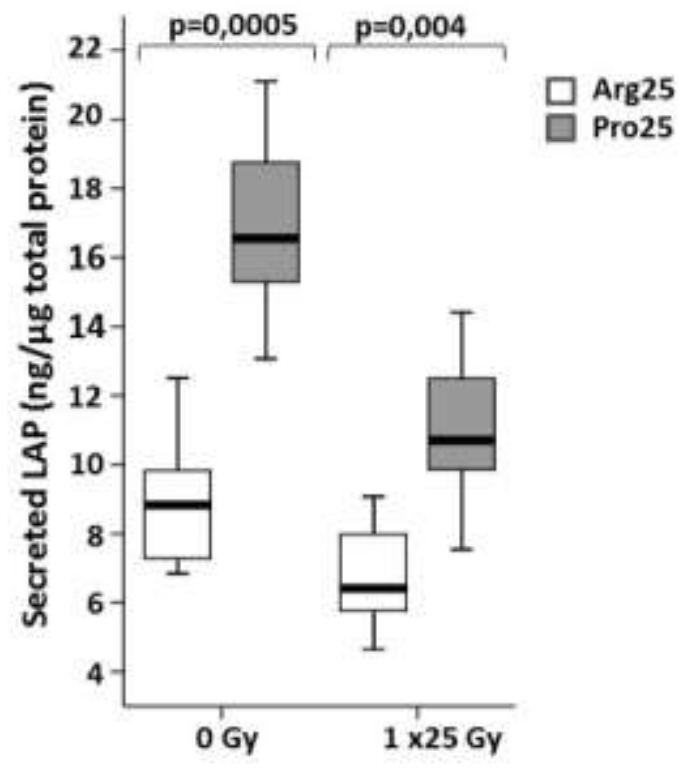

B

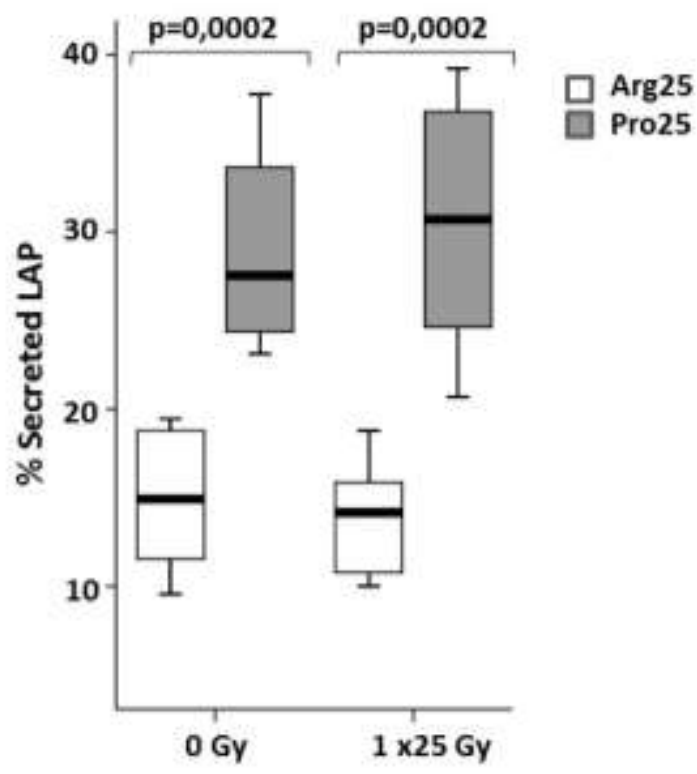

Fig. 17 Impact of Arg25Pro on secretion of LAP.

Two experimental conditions, i.e. sham-irradiation and a single shot with $25 \mathrm{~Gy}$ each with eight independent replications, were investigated both for the Arg25- and the Pro25-transfected T-REx HEK 293 cells. Panel A displays the amounts of LAP secreted from the cells into the culture media. Panel B shows the ratio of LAP found in the cell culture supernatant with respect to intracellular LAP (for the latter see Fig. 16). Experimental conditions and statistical analysis were identical to those described in Fig. 16.

\subsection{Arg25Pro polymorphism: Impact on activation of TGF $\beta 1$}

Acidification represents one major mechanism for activation of TGF $\beta 1$ from its latent complex (1.3.4). The hypothesis was tested whether the Arg25Pro polymorphism may modulate $\mathrm{pH}$-dependent activation of TGF $\beta 1$.

In culture supernatants of cells transfected with either Arg25 or Pro25 a linear curve fit for TGF $\beta 1$ in dependence on the $\mathrm{pH}$ value was obtained. Under physiological conditions, ( $\mathrm{pH} \sim 7.4$ ) similarly low amounts of activated TGF $\beta 1$ were observed for both alleles (Fig. 
18 A). Increasing acidification suggests more TGF $\beta 1$ activated in presence of the Pro25 in comparison to the Arg25 allele. In linear regression with adjustment for $\mathrm{pH}$ this allelic effect turned out statistically significant ( $p=0.0004$ for Fig. $18 \mathrm{~A}$ ). As higher secretion of LAP in case of Pro25 was demonstrated (Fig. 17) the obtained data for active TGF $\beta 1$ were normalized to secreted LAP amount. Upon normalization to LAP, a steeper slope of TGF $\beta 1$ activation with increasing acidification was noticed in culture supernatants derived from constructs with Arg25 compared with Pro25 (Fig. $18 \mathrm{~B}, \mathrm{p}=0.000009$ ). The latter suggests TGF $\beta 1$ produced with Arg25 could easier be activated, however, not compensating completely the higher secretion rate of constructs with Pro25 (Fig. 17). 
A

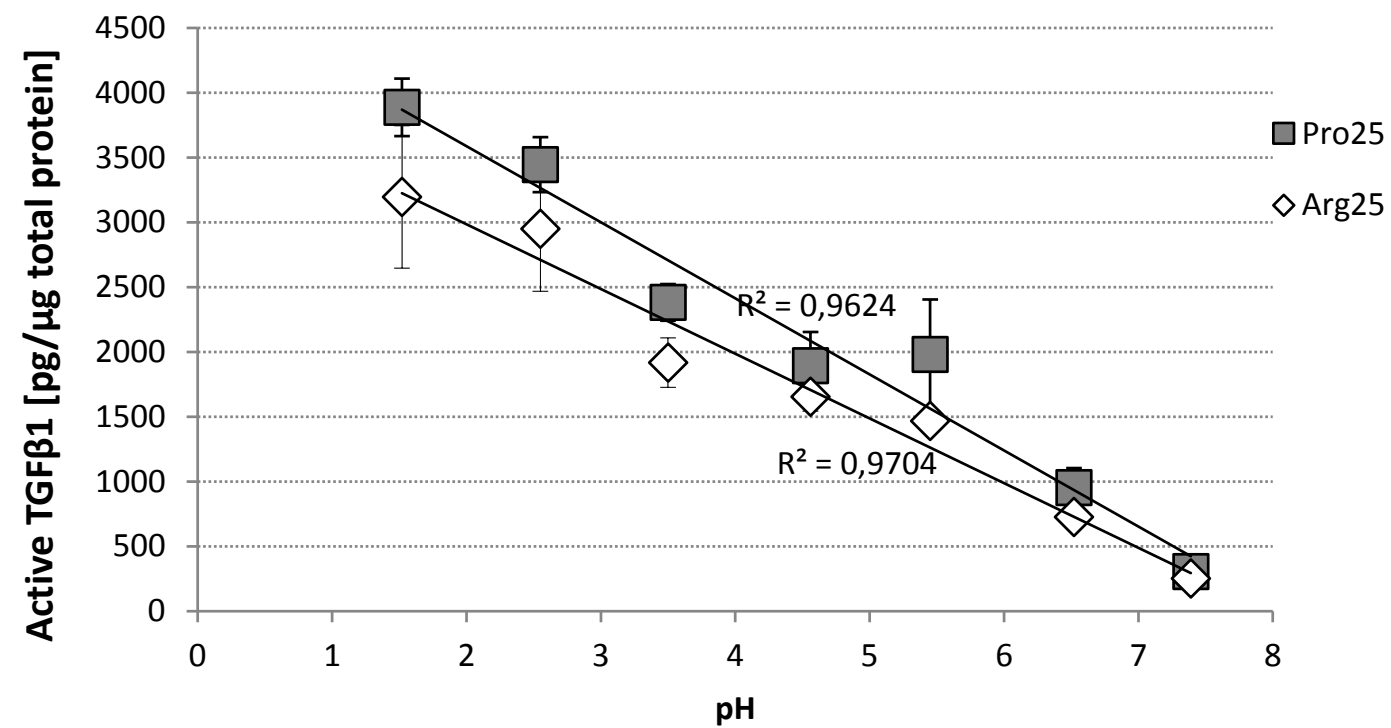

B

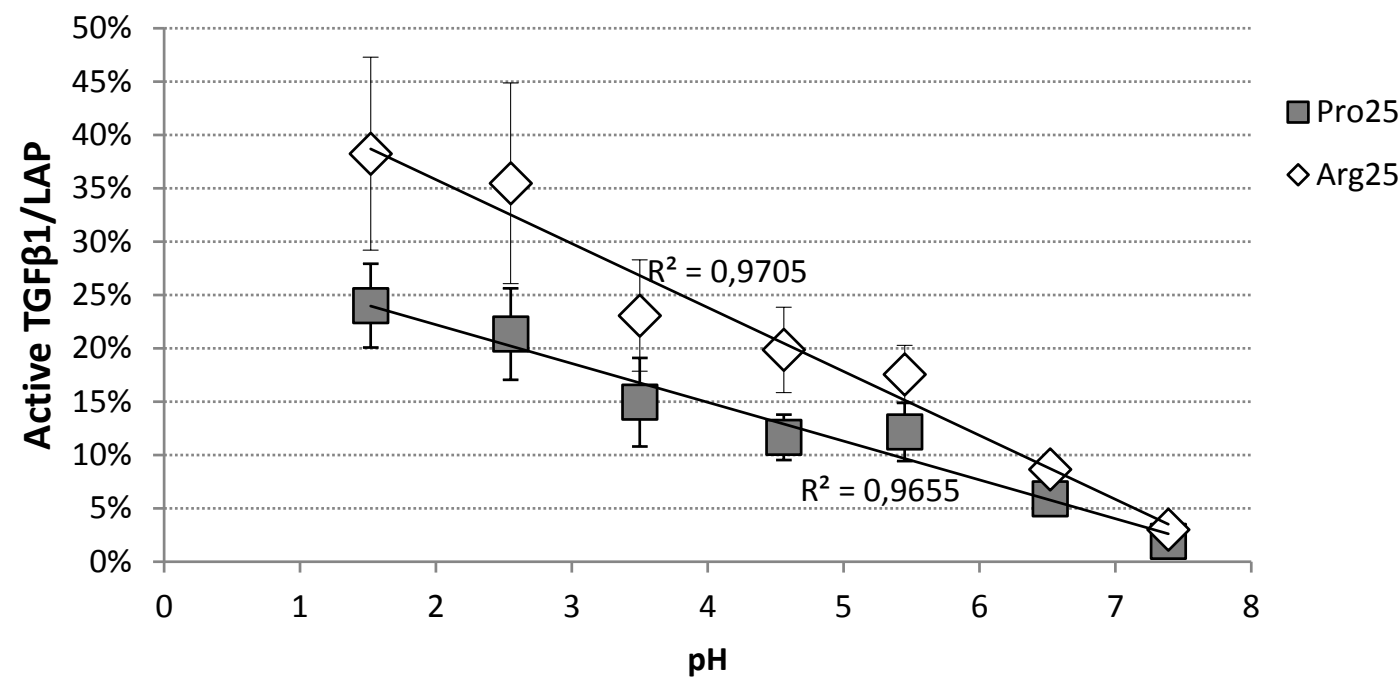

Fig. $18 \mathrm{pH}$-dependent activation of TGFß1 in relation to total protein (A) and LAP (B).

Culturing of T-Rex HEK 293 cells was identical to that described in Fig. 17. The cell culture supernatants were treated with acid $(1 \mathrm{~N} \mathrm{HCl})$ to adjust to $\mathrm{pH}$-values of 7.4, 6.5, 5.5, 4, 3.5, 2.5, and 1.5. Following $10 \mathrm{~min}$ incubation at RT, the samples were neutralized (by $1 \mathrm{~N} \mathrm{NaOH}$ with the same volumes as used for acidification) and TGF $\beta 1$ was immediately quantified by ELISA. The graph depicts the amount of TGF $\beta 1$ relative to the total protein content in dependence on the $\mathrm{pH}$ value. The shown data refer to three independent experiments of which the respective mean values with standard deviation are depicted. Within each experiment, each sample was assayed in duplicate. The interpolated regression line is based on a presumed linear relationship between $\mathrm{pH}$ and measured TGF $\beta 1$ with respective $\mathrm{r}^{2}$ values indicated. 


\subsection{Arg25Pro polymorphism: Impact on simulated RCT}

In order to evaluate if the observed impact of Arg25Pro polymorphism on LAP secretion (Fig. 17) can also apply in clinical situation, RCT in stably transfected T-REx HEK 293 cells was simulated. Therefore, the cells carrying either Arg25 or Pro25 were subjected to 3 x 5 Gy irradiation in presence of 5-FU $(3 \mu \mathrm{M})$.

Here, under baseline conditions, a statistically significant difference for the amounts of secreted LAP protein from cells transfected with either Arg25 or Pro25 was not observed. However, it should be noted that the cells in this experimental series were cultured for a total of $120 \mathrm{~h}$ until harvesting in contrast to $48 \mathrm{~h}$ for which Arg25 and Pro25 differed substantially (see Fig. 17). Upon $120 \mathrm{~h}$ without any cytotoxic treatment acidification of the culturing media and cell overgrowth as manually inspected by microscopy was observed. Whereas this problem was barely avoidable when simulating RCT for several days it could explain absence of statistical difference between the two variants. In fact, when the cells were treated with 5-FU and irradiated the effect of Pro25 again was elucidated. With the latter treatment, cell proliferation was lowered resulting in less cell overgrowing in the culturing plates.

Regarding active TGF $\beta 1$ no effect of Arg25Pro was observed using the identical samples neither under baseline nor RCT conditions (data not shown). 


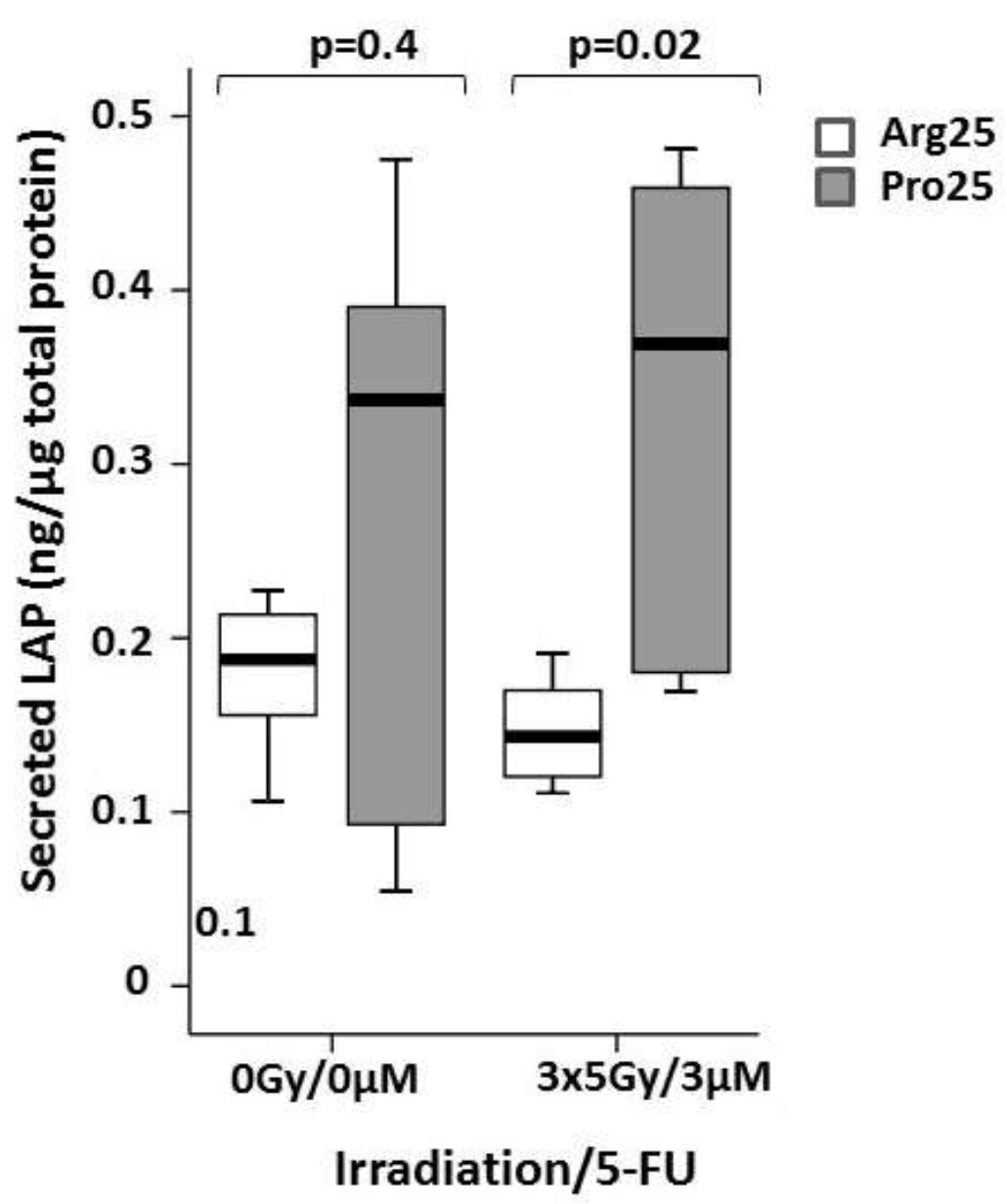

Fig. 19 Impact of Arg25Pro on secretion of LAP when simulating RCT.

Stably transfected T-REx HEK 293 cells were plated at $5 \times 10^{5}$ per well and cultured for a total time of $120 \mathrm{~h}$ at $37^{\circ} \mathrm{C}$. First, upon plating cells were allowed to grow for $48 \mathrm{~h}$ before fresh medium was supplied. For the wells simulating RCT, 5-FU was added to a final concentration of $3 \mu \mathrm{M}$. Following $1 \mathrm{~h}$ incubation, the cells were irradiated with one shot of $5 \mathrm{~Gy}$ or sham-irradiated, respectively. The irradiation was repeated two more times every $24 \mathrm{~h}$. After the last irradiation the cells were incubated for additional $24 \mathrm{~h}$, culture supernatants and cell pellets were then harvested. Quantification of LAP was performed by ELISA and referred to total protein contents as ascertained by BCA assay with each sample determined in duplicate. The shown data refer to six independent experimental series for each allele and each condition. Statistical difference between the two alleles was assessed by Mann-Whitney U test.

In a linear regression analysis the effect of the Arg25Pro polymorphism was adjusted for irradiation and 5-FU exposure in accordance with the clinical situation. This analysis corroborated the relevance of Arg25Pro and demonstrated no major impact of RCT simulation on the fraction of secreted LAP. 
Tab. 31 Linear regression analysis for the fraction of secreted LAP.

The impact of Arg25Pro was adjusted for RCT. The data refer to those used in the Fig. 19. This analysis was applicable as compatibility of data with normal distribution was given (all $\mathrm{p} \geq 0.01$ according to ShapiroWilk test).

\begin{tabular}{lcl}
\hline Variable & Standardized coefficient $(95 \%$ confidence interval) & p value \\
\hline Arg25Pro & $0.51(0.25-0.76)$ & 0.0002 \\
$3 x 5$ Gy & $-0.12(-0.37-0.14)$ & 0.4 \\
$3 \mu \mathrm{M} 5-\mathrm{FU}$ & $0.16(-0.09-0.42)$ & 0.2 \\
\hline
\end{tabular}

\subsection{Prediction of signal peptide cleavage}

Modifications in signal peptide sequences can potentially change the cleavage site position resulting in inefficient signal peptide processing (Palzkill et al. 1994), and thus, may affect the TGF $\beta 1$ synthesis (Faria et al. 2007, Jiang et al. 2002).

In order to predict the cleavage site in dependence on both variants of the Arg25Pro polymorphism, the SignalP tool (version 4.1), which is available in the internet (http://www.cbs.dtu.dk/services/SignalP/), was applied. A markedly distinct pattern for cleavage sites in presence of Arg25 or Pro25 was predicted (Fig. 20). In case of Arg25, the cleavage site position appeared equivocal with two major hits suggested between either the codons Glu24/Arg25 or the codons Glu29/Leu30 (Fig. 20A). In contrast, when Pro25 is present one distinct cleavage site position between the codons Glu29 and Leu30 was presumed (Fig. 20B). 

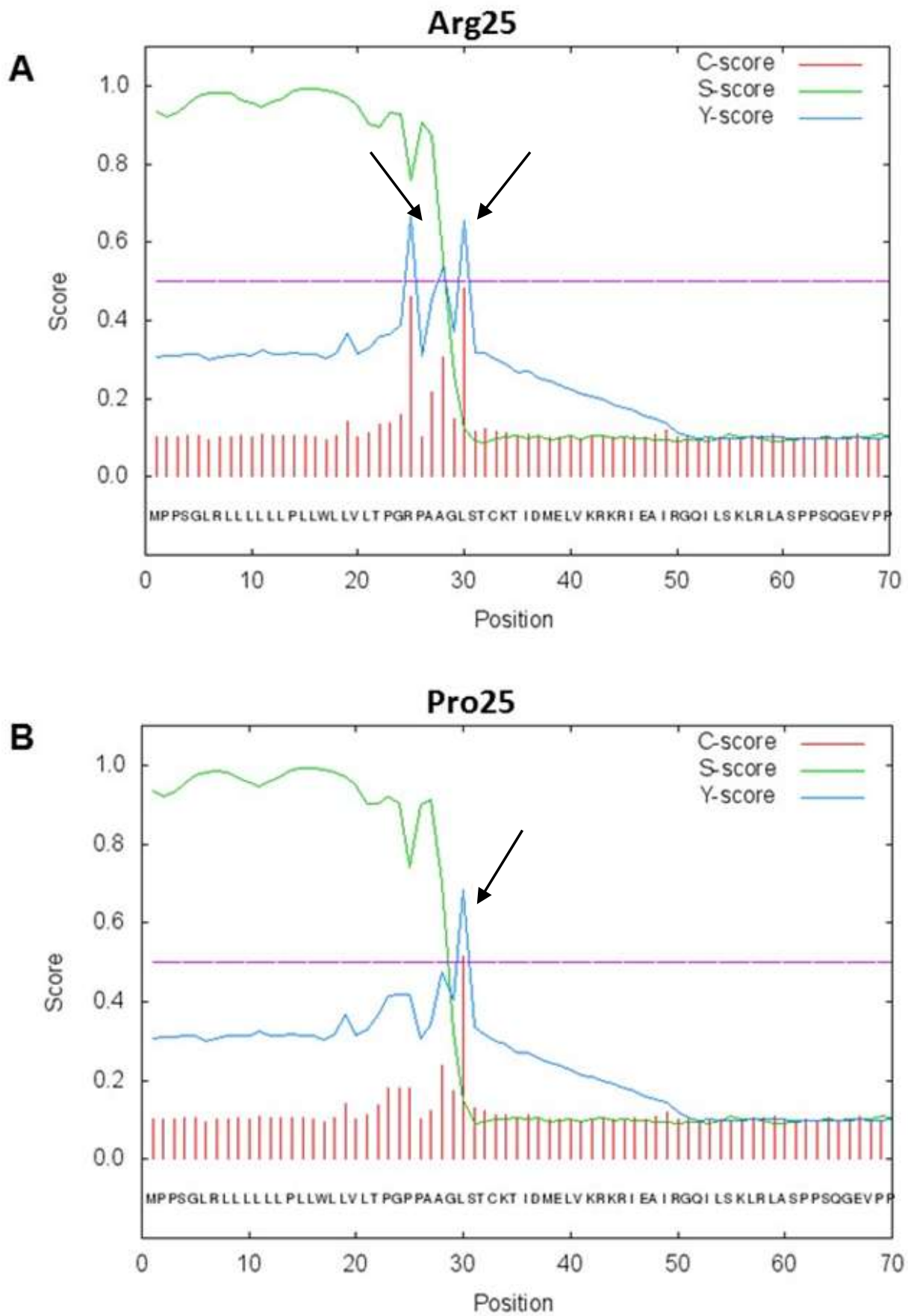

Fig. 20 In silico prediction of signal peptide cleavage site of the TGF $\beta 1$ precursor.

The upper panel (A) displays cleavage site prediction for Arg25, the lower (B) for Pro25. The x-axis exhibits the amino acid sequence with the respective codon position indicated. The $y$-axis represents score values ranging from 0 (minimal) to 1.0 (maximum). The $\mathrm{C}$-score estimates the most likely position of the first amino acid in the mature protein (position +1 ). The $S$-score is a signal peptide score, which recognizes signal peptide and is high at all positions before the cleavage site. The Y-score denotes the combined cleavage site score and is calculated by a geometric average of the $\mathrm{C}$-score and the slope of the S-score. Maximal Y-score represents the predicted cleavage site (Emanuelsson et al. 2007). The predicted cleavage sites are marked in both graphs by arrows in black. 


\section{Discussion}

The starting point of the present work was based on a clinical finding which showed a reproducible impact of the Arg25Pro polymorphisms in the TGFB1 gene on acute toxicity in patients with rectal cancer receiving N-RCT (Schirmer et al. 2012). All carriers of the Pro25 variant experienced high grade acute organ toxicity (HGAOT). The purpose of this work was to investigate possible functional roles of the Pro25 in comparison to the Arg25 allele and by that to explain molecular mechanisms behind the observed clinical association.

Due to the location of Arg25Pro in the signal peptide the hypotheses of affecting translation, secretion or activation of TGF $\beta 1$ were analyzed by means of stably transfected T-REX HEK 293 cells overexpressing either Arg25 or Pro25. Whereas no effect of Arg25Pro on intracellular protein expression of LAP-TGF $\beta 1$ under baseline conditions was observed (Fig. 16) a major alteration in secretion rate of the inactive TGF $\beta 1$ in complex with LAP was detected (Fig. 17). A minor modification toward sensitivity of activating by acidification was also noticed.

\subsection{Pro25 variant results in higher secretion rate}

A major effect on the secretion rate of the inactive LAP-TGF $\beta 1$ complex was noted being about two times higher for stably transfected cells with Pro25 than with Arg25. This was consistently seen in all conducted experimental series with a plenty of independent replications performed over several months. An artificial difference between cells with either Arg25 or Pro25 constructs is much improbable for several reasons: First, clones were selected with comparable intracellular mRNA (Fig. 9) and protein (Fig. 10) expression. Intracellularly, the amounts of TGF $\beta 1$ and LAP should be much similar since co-translated within the same open reading frame. Second, both intracellular and extracellular amounts of TGF $\beta 1$-LAP complex were normalized to total protein contents. Third and most important, for each experimental series culture supernatants and cell lysates were matched and thus the ratio of extracellular to intracellular LAP reflecting the secretion rate controls for confounding by differential transfection efficacy.

The Arg25Pro polymorphism was barely investigated with respect to functionality in literature so far. One report addressed effects of Arg25Pro and another frequent polymorphism in close vicinity, i.e. Leu10Pro, on expression and secretion of TGF $\beta 1$ using allele-specific genetic constructs (Mohren and Weiskirchen 2009). They stated Pro25 and Pro10 might be related to 
reduced TGF $\beta 1$ expression rather than altering its secretion. This is contradictory to my findings. Technical discrepancies may account for that. Whereas in the cited publication transient transfection was applied, I used stable transfection. The latter one allows measurements over extended time frames and transfection efficacy could better be controlled. Interestingly, a former report (Dunning et al. 2003) also using transient transfection indicated an increased secretion rate for the Pro10 allele in sharp contrast to the study by Mohren and Weiskirchen (2009). In my experimental series, transiently transfected and expressed TGF $\beta 1$ did also not reveal a distinct intracellular distribution pattern dependent on Arg25Pro as ascertained by Western blotting (Fig. 13, Fig. 14) and immunocytochemistry (Fig. 15). These discrepant findings highlight the necessity of transfection control, which is much less achievable in case of transient transfection also due to rapid dynamics. Furthermore, the host cells used by Mohren and Weiskirchen (2009) were different from the T-REx HEK 293 cells which I used, therefore cell type-specific effects could not completely be excluded. Another study investigated a potential impact of Arg25Pro on the amount of secreted TGF $\beta 1$ in isolated human leucocytes (Awad et al. 1998). However, the samples sizes were pretty low (25 carriers of $\operatorname{Arg} 25 / \operatorname{Arg} 25$ and 9 of $\operatorname{Arg} 25 / \operatorname{Pro} 25)$ for the purpose to prove or to deny an association. Furthermore, in that study no control for other potentially confounding genetic variation was performed. According to data comprising a sample size twice as high as that from Awad et al. 1998) published from our working group no significant modulation of TGF $\beta 1$ plasma concentrations by Arg25Pro was observed (Schirmer et al. 2011).

The two-fold higher fraction of secreted LAP-TGF $\beta 1$ in presence of Pro25 in contrast to Arg25 was true both under baseline conditions as well as when simulating RCT (Fig. 17B). As this secretion rate was not altered by any of the administered RCT simulations (i.e. 1 x $25 \mathrm{~Gy}$, 3 x 8.3Gy, 3 x 5Gy with and without 5-FU used as radiosensitizer), the secretory mechanisms may not much be affected by RCT. As RCT is a major activator of latent TGF $\beta 1$ it could be assumed that higher secretion rates of TGF $\beta 1$ might result in extended levels of active TGF $\beta 1$ when patients are exposed to RCT. Besides affecting the rate of secretion it is also conceivable that Arg25Pro might change the composition of the secreted protein (by altering the cleavage site of the signal peptide), which may affect subsequent activation of latent TGF $\beta 1$. 


\subsection{Increased sensitivity toward $\mathrm{pH}$ activation of TGF $\beta 1$ in constructs with Arg25}

TGF $\beta 1$ is secreted by most cultured cells as a part of the latent complex and low $\mathrm{pH}$ was suggested as one of the possible mechanisms for TGF $\beta 1$ activation from its latent complex (Lyons et al. 1988). Mild acid treatment ( $\mathrm{pH} 4.5$ ) activates $20-30 \%$ of latent TGF $\beta 1$, whereby extreme $\mathrm{pH}$ (1.5) results in significant activation of TGF $\beta 1$ (Lyons et al. 1988). Thus, stepwise increases of acidification were used to test the propensity of the latent TGF $\beta 1$ complex toward activation. In case of Pro25 more active TGF $\beta 1$ was detected (Fig. 18A). However, acidification-induced increase in relative amounts of active TGF $\beta 1$ normalized to secreted LAP was more pronounced for Arg25 (Fig. 18B). The latter effect might in part compensate for the enhanced secretion rate in case of Pro25 (Fig. 17), however, still leaving higher active TGF $\beta 1$ amounts under acidifying conditions. In this respect, Fig. 18A could be regarded as a combined result of opposing effects of Pro25 on secretion rate (Fig. 17) and sensitivity of the latent complex toward activation (Fig. 18B). In summary, these data indicate higher concentrations of active TGF $\beta 1$ in inflamed and acidified tissue in patients harboring the Pro25 allele. In leucocytes, which represent a major source of TGF $\beta 1$, the primary control of TGF $\beta 1$ function, is not on the expression level but on secretion and activation in line with the effects I observed for the Pro25 in contrast to the Arg25 allele (Assoian et al. 1987, Grotendorst et al. 1989).

\subsection{Arg25Pro polymorphism may affect cleavage of signal peptide}

The Arg25Pro polymorphism is located within the 29 amino acid-comprising signal peptide of the TGF $\beta 1$ precursor. As stated in detail in the Introduction section (1.3.2), the signal peptide directs the TGF $\beta 1$ precursor to the rough ER (Gentry et al. 1988, ten Dijke and Arthur 2007). During or immediately after translocation of the protein to the ER lumen cleavage of the signal peptide is catalyzed by signal peptidases (Andrews et al. 1988 (Lemberg and Martoglio 2002). Following cleavage, the signal peptide initially accumulates in the ER membrane, and later degrades (Zimmermann 2009).

Signal peptide sequences comprise usually 16-30 amino acids whereby three distinct regions could be distinguished: a positively charged $\mathrm{N}$-terminal region, a central hydrophobic core, and a polar C-terminal region (Randall and Hardy 1989, Zimmermann 2009). The N-aminoterminal region consists of 5-8 amino acids, and is represented by the presence of basic residues. The central hydrophobic core contains 8-12 nonpolar amino acids and has a tendency to from alpha-helices. The C-terminal region (or cleavage region), which is usually 6 amino acids long, 
comprises a signal peptidase recognition site (Jain et al. 1994). Amino acids like proline, glycine or serine are often found in the cleavage region. If any substitution or deletion is present in this region cleavage may occur less efficiently (Jain et al. 1994). Proper cleavage requires small and neutral residues at -3 and -1 relative to the cleavage site (Nielsen et al. 1997). In this regard, the Arg25Pro polymorphism in the TGF $\beta 1$ precursor corresponding to position -5 may modulate rather than abolish cleavage in accordance with the bioinformatic analysis (Fig. 20). It represents an exchange of arginine (polar positively charged basic amino acid) by proline (non-polar hydrophobic amino acid).

\subsection{Mechanistic suggestion for clinically observed radiotoxicity}

Based on my findings, increased acute radiotoxicity in presence of Pro25 reported by Schirmer et al. (2012) might be explained by enhanced secretion of LAP-TGF $\beta 1$. This higher secretion may lead to higher concentrations of TGF $\beta 1$ upon activation (see schematically drawn in

Fig. 21). Even in case of Arg25 the LAP-TGF $\beta 1$ complex appeared to be more sensitive to activation, there was still a net effect of more active TGF $\beta 1$ upon acidification for Pro25 due to the two-fold higher secretion rate of the LAP-TGF $\beta 1$ complex. Upon activating stimuli, these higher amounts of active TGF $\beta 1$ in case of Pro25 might explain the observed clinical association. Such stimuli typically present during radiotherapy comprise radiation (BarcellosHoff and Dix 1996) or inflammation accompanied by tissue acidification (Lyons et al. 1988).

TGF $\beta 1$ is known to act as a major orchestrator of inflammatory conditions (Sanjabi et al. 2009). At inflammatory sites, TGF $\beta 1$ produced particulary by leucocytes and acting both in autocrine/paracrine manner a well as a chemoattracant for invading leucocytes and other cells participating in immune response (Letterio and Roberts 1998). Though TGF $\beta 1$ over years was prevalently regarded as an immunosuppressive cytokine there is as well increasing evidence that this pleiotropic cytokine can, under certain circumstances, promote inflammatory reactions (Wan and Flavell 2008). Intriguingly, when the canonical TGF $\beta 1$ pathway was inhibited by a small molecule acute radiation-provoked inflammatory reactions were mitigated in mice (Flechsig et al. 2012). Thus, this finding supports the hypothesis that under conditions of radiotherapy TGF $\beta 1$ might act as an enhancer of radiotoxic side-effects. Regarding humans, clinical trials assessing antibodies, anti-sense nucleotides and small molecules targeting TGF $\beta$ in malignancies were launched (Buijs et al. 2012). As far as I am aware, no substance for TGF $\beta$ targeting has been approved for clinical use yet (July 2014). 
Mechanistically, high concentrations of TGF $\beta 1$ in inflammatory leasions stimulate monocytes to synthesize and secrete other growth factors like TNF $\alpha$ and IL-1. Involvement of fibroblasts and endothelial cells in inflammatory response contributes to initiation of cell proliferation and matrix synthesis. Thus, repeating application of stimuli activating TGF $\beta 1$ like fractionated radiotherapy over weeks might result in sustained liberation of growth-promoting and matrixinducing factors (Wahl et al. 1989). Morover, in presence of IL-6 TGF $\beta 1$ initiates the differentiation of $\mathrm{T}$ helper 17 (Th17) cells (Sanjabi et al. 2009). High amounts of IL-17 produuced by Th17 cells can induce further inflammation by activating matrix metalloproteases, which can cause collagen degradation. Moreover, IL17 promotes neutrophils recruitment further assisting in pro-inflammatory responses (Veldhoen and Stockinger 2006). Interestingly, when testing expression of proteins mechanistically linked to fibrosis only increased TGF $\beta 1$ was also associated with acute kidney allograft recection upon transplantation (Eikmans et al. 2002, Shihab et al. 1995) corroborating a role of this cytokine in acute inflammatory conditions.

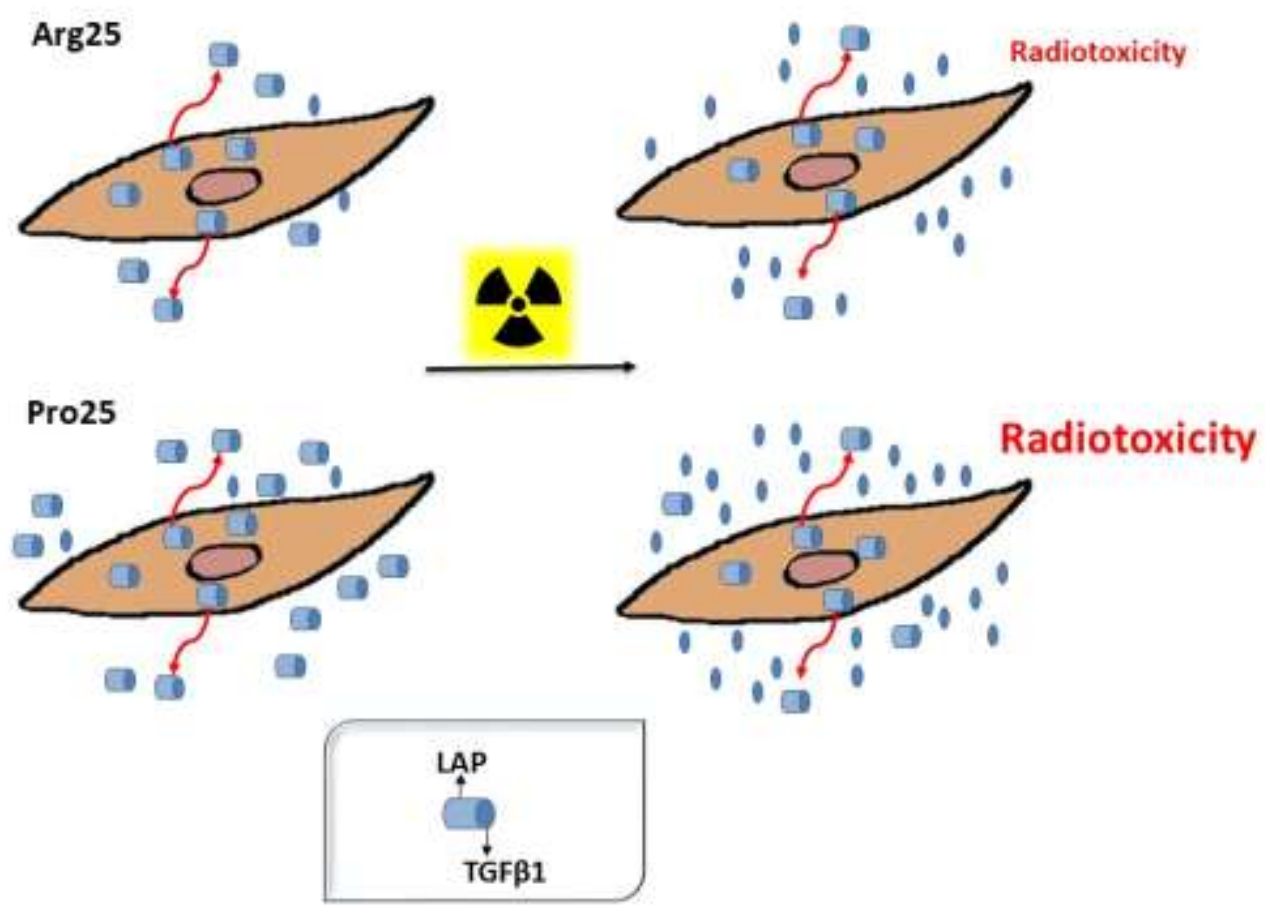

Fig. 21 Suggested link between LAP-TGFß1 secretion rate and acute radiotoxicity dependent on Arg25Pro. 


\subsection{Limitations}

When considering the results of my work, certain limitations are needed to be taken into account.

First, the role of LTBPs, which constitute optional binding proteins for LAP-TGF $\beta 1$, was not considered. LTPBs, albeit not essential, enhance proper assembly and secretion of LAP-TGF $\beta 1$. It is thus conceivable that LTBPs might modulate the observed effect of the Arg25Pro polymorphism on LAP-TGFß1 secretion.

Moreover, with respect to the clinical settings, treatment courses which patients receive over weeks could not be reflected by the experimental procedure though two different applications of radiation, i.e. 1 x 25 Gy or 3 x 5 Gy, were employed. A more extended experimental procedure was not easily feasible. With the purpose of minimizing interventions during incubation, longer incubation times were not possible due to overgrowing of non-irradiated cells. Thus, with the obtained data an extrapolation on the clinical setting used at the University Medicine in Göttingen for treatment of rectal cancer, i.e. 28 x1.8 Gy, is limited.

Finally, the effects observed in stably transfected T-REx HEK 293 might be cell contextspecific, and thus possibly not easily transferable to other cell types. Assessment of the relevance of the Arg25Pro polymorphism in cells regarded as crucial for normal tissue reactions of radiotherapy, e.g. immune cells and fibroblasts, is pending. In particular, the ability of a model cell line to reflect processes in tissues with heterogeneous cell types is limited.

\subsection{Perspectives}

Based on the findings from my thesis, further investigations could be directed to extend mechanistic and clinical views regarding the relevance of the Arg25Pro polymorphism.

The observed alteration in LAP-TGF $\beta 1$ secretion rate may be due to different signal peptide cleavage for Arg25 in contrast to Pro25. Therefore, the hypothesis suggested by in silico analysis (Fig. 20) could be experimentally proven by mass spectrometry of LAP-TGF $\beta 1$ secreted by the generated cell constructs.

Mice models engineered as knock-in for either Arg25 or Pro25 might allow comprehensive investigations in the context of a macroorganism. Interestingly, human and mouse LAP-TGF $\beta 1$ have an identical length of 390 amino acid residues with $90 \%$ sequence identity. Regarding the signal peptide, only one out of 29 residues differs between these two species (leucine at codon 
16 on human and proline in mouse). Besides to study entire tissue reactions in animal models, they also will allow to simulate an entire course of radiotherapy administered to patients.

Clinically, further trials in prospective fashion should be launched to confirm the actual relevance of the Arg25Pro polymorphism. If confirmed, this polymorphism might become a biomarker for individual treatment stratification. For the patients who carry the Pro 25 risk allele and necessitate the intended radiotherapy intensified care might be offered. This might include prophylactic procedures (like anti-inflammatory drugs) during RCT to decrease treatmentrelated side effects. If deeper insights into processes related to the signal peptide cleavage will be available specific pharmacological interventions might become conceivable. Monoclonal TGF $\beta$ antibodies are already tested in clinical trials to prevent tumor metastasis. It remains to be evaluated if they apply to control better radiation-induced side effects by blocking TGF $\beta$ receptors thereby counteracting excessive secretion of LAP-TGF $\beta 1$ in patients with Pro25.

Beyond the relation to radiotherapy, the Arg25Pro polymorphism might be of relevance also for other clinical entities where inflammatory processes occur, e.g. kidney fibrosis, liver cirrhosis or heart failure. Thus, this polymorphism could be checked as a potential biomarker for these conditions as well. 


\section{Summary}

In radiochemotherapy administered for rectal cancer, all patients harboring the Pro25 allele in the signal peptide of TGF $\beta 1$ experienced a higher grade of acute treatment toxicity. Pro25 features an allelic frequency of about $10 \%$ in the Caucasian population and replaces an arginine residue. The functional role of this Arg25Pro polymorphism is still not clarified. Therefore, the aim of my work was to determine the possible molecular mechanisms driving the reported clinical association.

In order to investigate allele-specific effects of the Arg25Pro polymorphism stable trasnfection to overexpress either Arg25 or Pro25 was carried out. As host cells, T-REx HEK 293 cells were used. The transfected cells were characterized on genome level by specific PCRs, for mRNA expression by quantitative real time PCR, and for protein expression by Western blotting. Transient transfection with FLAG tag-containing TGF $\beta 1$ constructs was employed to localize subcellular TGF $\beta 1$ distribution visualized by immunocytochemistry. Quantitative expression was determined by ELISA directed to either an epitope of the LAP or the mature TGF $\beta 1$ both for intracellular and secreted amounts. Clinically administered radiochemotherapy was simulated on the stably transfected cells.

A major effect of the Arg25Pro polymorphism was observed on the secretion rate of the inactive LAP-TGF $\beta 1$ complex. Under baseline conditions without irradiation, the stably transfected cells carrying Pro 25 secreted two times higher amounts of LAP-TGF $\beta 1$ than the cells harboring Arg25 as assesd by ELISA ( $\mathrm{p}=0.0002)$. This increased level of secreted TGF $\beta 1$ in presence of Pro25 was confirmed by Western blotting. Radiation did not result in changes of the fraction of secreted LAP-TGF $\beta 1$ compared to non-irradiated cells. Intracellular amounts of LAP-TGF $\beta 1$ and active TGF $\beta 1$ were not affected by the Arg25Pro polymorphism. FLAG epitope staining upon transient transfection indicated perinuclear localization of TGF $\beta 1$ suggesting its association with ER or Golgi apparatus. There were no apparent distribution distinctions dependent on the Arg25Pro polymorphism.

Stepwise acidification was used to test the hypothesis whether the Arg25Pro polymorphism may modulate activation of TGF $\beta 1$. Increasing proton concentrations revealed more activated TGF $\beta 1$ normalized to the inactive LAP-TGF $\beta 1$ in case of Arg25 in comparison with Pro25. This allelic effect was still evident when adjusted for $\mathrm{pH}$ in linear regression analysis. Though secreted TGF $\beta 1$ from Arg25-containing constructs appeared more sensitive toward activation, there was a net effect of more active TGF $\beta 1$ by $\mathrm{pH}$-dependent activation for Pro25. This was 
due to substantially higher amounts of secreted and thus potentially activatable LAP-TGF $\beta 1$ molecules.

Altered secretion rate in dependence on the Arg25Pro polymorphism might be due to distinct cleavage sites patterns. Thus, prediction of the cleavages site position was conducted in silico. For Pro25 one cleavage site position between the codons Glu29/Leu30 and for Arg25 two sites, i.e. at Glu24/Arg25 and at Glu29/Leu30, were predicted.

In conclusion, the data of my thesis indicate that an increased secretion rate in case of Pro25 might contribute to the clinically reported association of this allele with acute radiotoxicity. Distinct patterns of signal peptide cleavage for the Arg25 and the Pro25 allele may lead to higher secretion rates of LAP-TGF $\beta 1$. As ionizing radiation and tissue acidification are major activators of LAP-TGF $\beta 1$, increased active TGF $\beta 1$ in irradiated tissue might result for carriers of Pro25 possibly explaining the radiotherapy-related toxicity. Pharmacological interference to target elevated TGF $\beta 1$ secretion, activation or subsequent signaling might offer strategies to prevent patients at particular risk for radiation injuries. Such approaches might also be beneficial for other conditions linked to altered TGF $\beta 1$ signaling like chronic inflammations. 


\section{References}

Andreassen CN, Alsner J, Overgaard M, Overgaard J (2003): Prediction of normal tissue radiosensitivity from polymorphisms in candidate genes. Radiother Oncol 69 (2), 127-135

Andreassen CN, Alsner J, Overgaard M, Sorensen FB, Overgaard J (2006): Risk of radiationinduced subcutaneous fibrosis in relation to single nucleotide polymorphisms in TGFB1, SOD2, XRCC1, XRCC3, APEX and ATM--a study based on DNA from formalin fixed paraffin embedded tissue samples. Int J Radiat Biol 82 (8), 577-586

Andrews DW, Perara E, Lesser C, Lingappa VR (1988): Sequences beyond the cleavage site influence signal peptide function. J Biol Chem $\underline{263}$ (30), 15791-15798

Annes JP, Munger JS, Rifkin DB (2003): Making sense of latent TGFbeta activation. J Cell Sci $\underline{116}(\mathrm{Pt} 2), 217-224$

Annes JP, Chen Y, Munger JS, Rifkin DB (2004): Integrin alphaVbeta6-mediated activation of latent TGF-beta requires the latent TGF-beta binding protein-1. J Cell Biol 165 (5), 723-734

Anscher MS, Marks LB, Shafman TD, Clough R, Huang H, Tisch A, Munley M, Herndon JE, Garst J, Crawford J et al. (2003): Risk of long-term complications after TFG-beta1-guided veryhigh-dose thoracic radiotherapy. Int J Radiat Oncol Biol Phys $\underline{56}$ (4), 988-995

Arestrom I, Zuber B, Bengtsson T, Ahlborg N (2012): Measurement of human latent Transforming Growth Factor-beta1 using a latency associated protein-reactive ELISA. $J$ Immunol Methods $\underline{379}$ (1-2), 23-29

Assoian RK, Fleurdelys BE, Stevenson HC, Miller PJ, Madtes DK, Raines EW, Ross R,Sporn MB (1987): Expression and secretion of type beta transforming growth factor by activated human macrophages. Proc Natl Acad Sci U S A $\underline{84}$ (17), 6020-6024

August P, Suthanthiran M (2003): Transforming growth factor beta and progression of renal disease. Kidney Int Suppl (87), S99-104

Awad MR, El-Gamel A, Hasleton P, Turner DM, Sinnott PJ, Hutchinson IV (1998): Genotypic variation in the transforming growth factor-betal gene: association with transforming growth factor-beta1 production, fibrotic lung disease, and graft fibrosis after lung transplantation. Transplantation 66 (8), 1014-1020

Barcellos-Hoff MH, Dix TA (1996): Redox-mediated activation of latent transforming growth factor-beta 1. Mol Endocrinol 10 (9), 1077-1083 
Barnett GC, Elliott RM, Alsner J, Andreassen CN, Abdelhay O, Burnet NG, Chang-Claude J, Coles CE, Gutierrez-Enriquez S, Fuentes-Raspall MJ et al. (2012): Individual patient data metaanalysis shows no association between the SNP rs1800469 in TGFB and late radiotherapy toxicity. Radiother Oncol 105 (3), 289-295

Berndt SI, Huang WY, Chatterjee N, Yeager M, Welch R, Chanock SJ, Weissfeld JL, Schoen RE,Hayes RB (2007): Transforming growth factor beta 1 (TGFB1) gene polymorphisms and risk of advanced colorectal adenoma. Carcinogenesis 28 (9), 1965-1970

Blobe GC, Schiemann WP, Lodish HF (2000): Role of transforming growth factor beta in human disease. $N$ Engl J Med $\underline{342}$ (18), 1350-1358

Border WA, Noble NA (1993): Cytokines in kidney disease: the role of transforming growth factor-beta. Am J Kidney Dis 22 (1), 105-113

Border WA, Noble NA (1994): Transforming growth factor beta in tissue fibrosis. $N$ Engl $J$ Med $\underline{331}$ (19), 1286-1292

Border WA, Noble NA (1995): Fibrosis linked to TGF-beta in yet another disease. J Clin Invest $\underline{96}(2), 655-656$

Bottinger EP, Bitzer M (2002): TGF-beta signaling in renal disease. J Am Soc Nephrol 13 (10), $2600-2610$

Bouquet F, Pal A, Pilones KA, Demaria S, Hann B, Akhurst RJ, Babb JS, Lonning SM, DeWyngaert JK, Formenti SC et al. (2011): TGFbeta1 inhibition increases the radiosensitivity of breast cancer cells in vitro and promotes tumor control by radiation in vivo. Clin Cancer Res $\underline{17}$ (21), 6754-6765

Branton MH, Kopp JB (1999): TGF-beta and fibrosis. Microbes Infect 1 (15), 1349-1365

Buijs JT, Stayrook KR, Guise TA (2012): The role of TGF-beta in bone metastasis: novel therapeutic perspectives. Bonekey Rep $\underline{1}, 96$

Cambien F, Ricard S, Troesch A, Mallet C, Generenaz L, Evans A, Arveiler D, Luc G, Ruidavets JB, Poirier O (1996): Polymorphisms of the transforming growth factor-beta 1 gene in relation to myocardial infarction and blood pressure. The Etude Cas-Temoin de l'Infarctus du Myocarde (ECTIM) Study. Hypertension 28 (5), 881-887

Chubet RG, Brizzard BL (1996): Vectors for expression and secretion of FLAG epitope-tagged proteins in mammalian cells. Biotechniques 20 (1), 136-141 
Dallas SL, Park-Snyder S, Miyazono K, Twardzik D, Mundy GR, Bonewald LF (1994): Characterization and autoregulation of latent transforming growth factor beta (TGF beta) complexes in osteoblast-like cell lines. Production of a latent complex lacking the latent TGF beta-binding protein. J Biol Chem $\underline{269}$ (9), 6815-6821

De Jaeger K, Seppenwoolde Y, Kampinga HH, Boersma LJ, Belderbos JS, Lebesque JV (2004): Significance of plasma transforming growth factor-beta levels in radiotherapy for non-smallcell lung cancer. Int J Radiat Oncol Biol Phys $\underline{58}$ (5), 1378-1387

Dennler S, Goumans MJ, ten Dijke P (2002): Transforming growth factor beta signal transduction. J Leukoc Biol 71 (5), 731-740

Densem CG, Hutchinson IV, Yonan N, Brooks NH (2004): Donor and recipient-transforming growth factor-beta 1 polymorphism and cardiac transplant-related coronary artery disease. Transpl Immunol 13 (3), 211-217

Derynck R, Akhurst RJ, Balmain A (2001): TGF-beta signaling in tumor suppression and cancer progression. Nat Genet 29 (2), 117-129

Drabsch Y, ten Dijke P (2011): TGF-beta signaling in breast cancer cell invasion and bone metastasis. J Mammary Gland Biol Neoplasia 16 (2), 97-108

Dubois CM, Laprise MH, Blanchette F, Gentry LE, Leduc R (1995): Processing of transforming growth factor beta 1 precursor by human furin convertase. J Biol Chem $\underline{270}$ (18), 10618-10624

Dunning AM, Ellis PD, McBride S, Kirschenlohr HL, Healey CS, Kemp PR, Luben RN, Chang-Claude J, Mannermaa A, Kataja V et al. (2003): A transforming growth factorbeta1 signal peptide variant increases secretion in vitro and is associated with increased incidence of invasive breast cancer. Cancer Res $\underline{63}$ (10), 2610-2615

Eikmans M, Sijpkens YW, Baelde HJ, de Heer E, Paul LC, Bruijn JA (2002): High transforming growth factor-beta and extracellular matrix mRNA response in renal allografts during early acute rejection is associated with absence of chronic rejection. Transplantation $\underline{73}$ (4), 573-579

Emanuelsson O, Brunak S, von Heijne G, Nielsen H (2007): Locating proteins in the cell using TargetP, SignalP and related tools. Nat Protoc $\underline{2}$ (4), 953-971

Faria PC, Saba K, Neves AF, Cordeiro ER, Marangoni K, Freitas DG, Goulart LR (2007): Transforming growth factor-beta 1 gene polymorphisms and expression in the blood of prostate cancer patients. Cancer Invest $\underline{25}$ (8), 726-732

Flechsig P, Dadrich M, Bickelhaupt S, Jenne J, Hauser K, Timke C, Peschke P, Hahn EW, Grone HJ, Yingling J et al. (2012): LY2109761 attenuates radiation-induced pulmonary murine 
fibrosis via reversal of TGF-beta and BMP-associated proinflammatory and proangiogenic signals. Clin Cancer Res $\underline{18}$ (13), 3616-3627

Fukasawa H, Yamamoto T, Suzuki H, Togawa A, Ohashi N, Fujigaki Y, Uchida C, Aoki M, Hosono M, Kitagawa M et al. (2004): Treatment with anti-TGF-beta antibody ameliorates chronic progressive nephritis by inhibiting Smad/TGF-beta signaling. Kidney Int 65 (1), 63-74

Gentry LE, Lioubin MN, Purchio AF, Marquardt H (1988): Molecular events in the processing of recombinant type 1 pre-pro-transforming growth factor beta to the mature polypeptide. $\mathrm{Mol}$ Cell Biol $\underline{8}$ (10), 4162-4168

Gordon KJ, Blobe GC (2008): Role of transforming growth factor-beta superfamily signaling pathways in human disease. Biochim Biophys Acta 1782 (4), 197-228

Grainger DJ (2007): TGF-beta and atherosclerosis in man. Cardiovasc Res $\underline{74}$ (2), 213-222

Grainger DJ, Kemp PR, Liu AC, Lawn RM, Metcalfe JC (1994): Activation of transforming growth factor-beta is inhibited in transgenic apolipoprotein(a) mice. Nature $\underline{370}$ (6489), 460462

Grainger DJ, Heathcote K, Chiano M, Snieder H, Kemp PR, Metcalfe JC, Carter ND, Spector TD (1999): Genetic control of the circulating concentration of transforming growth factor type beta1. Hum Mol Genet $\underline{8}$ (1), 93-97

Gressner OA, Weiskirchen R, Gressner AM (2007): Evolving concepts of liver fibrogenesis provide new diagnostic and therapeutic options. Comp Hepatol $\underline{6}, 7$

Grotendorst GR, Smale G, Pencev D (1989): Production of transforming growth factor beta by human peripheral blood monocytes and neutrophils. J Cell Physiol $\underline{140}$ (2), 396-402

Guirado D, Ruiz de Almodovar JM (2003): Prediction of normal tissue response and individualization of doses in radiotherapy. Phys Med Biol 48 (19), 3213-3223

Hansson GK, Robertson AK (2004): TGF-beta in atherosclerosis. Arterioscler Thromb Vasc Biol 24 (6), E137-138

Higuchi R, Fockler C, Dollinger G, Watson R (1993): Kinetic PCR analysis: real-time monitoring of DNA amplification reactions. Biotechnology (N Y) 11 (9), 1026-1030

Ho AY, Atencio DP, Peters S, Stock RG, Formenti SC, Cesaretti JA, Green S, Haffty B, Drumea K, Leitzin L et al. (2006): Genetic predictors of adverse radiotherapy effects: the GenePARE project. Int J Radiat Oncol Biol Phys $\underline{65}$ (3), 646-655 
Hold GL, Untiveros P, Saunders KA,El-Omar EM (2009): Role of host genetics in fibrosis. Fibrogenesis Tissue Repair $\underline{2}$ (1), 6

Hyytiainen M, Penttinen C, Keski-Oja J (2004): Latent TGF-beta binding proteins: extracellular matrix association and roles in TGF-beta activation. Crit Rev Clin Lab Sci 41 (3), 233-264

Jain RG, Rusch SL, Kendall DA (1994): Signal peptide cleavage regions. Functional limits on length and topological implications. J Biol Chem $\underline{269}$ (23), 16305-16310

Jakowlew SB (2006): Transforming growth factor-beta in cancer and metastasis. Cancer Metastasis Rev 25 (3), 435-457

Janssens K, ten Dijke P, Janssens S,Van Hul W (2005): Transforming growth factor-beta1 to the bone. Endocr Rev 26 (6), 743-774

Javelaud D, Mauviel A (2004): Mammalian transforming growth factor-betas: Smad signaling and physio-pathological roles. Int J Biochem Cell Biol $\underline{36}$ (7), 1161-1165

Jenkins G (2008): The role of proteases in transforming growth factor-beta activation. Int $J$ Biochem Cell Biol $\underline{40}$ (6-7), 1068-1078

Jiang M, Lamminen T, Pakarinen P, Hellman J, Manna P, Herrera RJ, Huhtaniemi I (2002): A novel Ala(-3)Thr mutation in the signal peptide of human luteinizing hormone beta-subunit: potentiation of the inositol phosphate signalling pathway and attenuation of the adenylate cyclase pathway by recombinant variant hormone. Mol Hum Reprod $\underline{8}$ (3), 201-212

Jobling MF, Mott JD, Finnegan MT, Jurukovski V, Erickson AC, Walian PJ, Taylor SE, Ledbetter S, Lawrence CM, Rifkin DB et al. (2006): Isoform-specific activation of latent transforming growth factor beta (LTGF-beta) by reactive oxygen species. Radiat Res 166 (6), 839-848

Kanzaki T, Shiina R, Saito Y, Oohashi H, Morisaki N (1998): Role of latent TGF-beta 1 binding protein in vascular remodeling. Biochem Biophys Res Commun 246 (1), 26-30

Karathanasi V, Tosios KI, Nikitakis NG, Piperi E, Koutlas I, Trimis G, Sklavounou A (2013): TGF-beta1, Smad-2/-3, Smad-1/-5/-8, and Smad-4 signaling factors are expressed in ameloblastomas, adenomatoid odontogenic tumors, and calcifying cystic odontogenic tumors: an immunohistochemical study. J Oral Pathol Med $\underline{42}$ (5), 415-423

Khalil MS, El Nahas AM, Blakemore AI (2005): Transforming growth factor-beta1 SNPs: genetic and phenotypic correlations in progressive kidney insufficiency. Nephron Exp Nephrol $\underline{101}(2), \mathrm{e} 31-41$ 
Khalil N (1999): TGF-beta: from latent to active. Microbes Infect 1 (15), 1255-1263

Kim SJ, Angel P, Lafyatis R, Hattori K, Kim KY, Sporn MB, Karin M,Roberts AB (1990): Autoinduction of transforming growth factor beta 1 is mediated by the AP-1 complex. Mol Cell Biol $\underline{10}$ (4), 1492-1497

Kitamura M, Suto TS (1997): TGF-beta and glomerulonephritis: anti-inflammatory versus prosclerotic actions. Nephrol Dial Transplant 12 (4), 669-679

Koli K, Saharinen J, Hyytiainen M, Penttinen C, Keski-Oja J (2001): Latency, activation, and binding proteins of TGF-beta. Microsc Res Tech $\underline{52}$ (4), 354-362

Kubiczkova L, Sedlarikova L, Hajek R, Sevcikova S (2012): TGF-beta - an excellent servant but a bad master. J Transl Med $\underline{10}, 183$

Lan HY, Chung AC (2012): TGF-beta/Smad signaling in kidney disease. Semin Nephrol 32 (3), 236-243

Leask A, Abraham DJ (2004): TGF-beta signaling and the fibrotic response. FASEB J $\underline{18}$ (7), 816-827

Lemberg MK, Martoglio B (2002): Requirements for signal peptide peptidase-catalyzed intramembrane proteolysis. Mol Cell $\underline{10}$ (4), 735-744

Letterio JJ, Roberts AB (1998): Regulation of immune responses by TGF-beta. Annu Rev Immunol $\underline{16}, 137-161$

Loeffler I, Wolf G (2014): Transforming growth factor-beta and the progression of renal disease. Nephrol Dial Transplant 29 (Suppl 1), i37-i45

Lutgens E, Gijbels M, Smook M, Heeringa P, Gotwals P, Koteliansky VE, Daemen MJ (2002): Transforming growth factor-beta mediates balance between inflammation and fibrosis during plaque progression. Arterioscler Thromb Vasc Biol 22 (6), 975-982

Lyons RM, Keski-Oja J, Moses HL (1988): Proteolytic activation of latent transforming growth factor-beta from fibroblast-conditioned medium. J Cell Biol 106 (5), 1659-1665

Maeda S, Dean DD, Gomez R, Schwartz Z, Boyan BD (2002): The first stage of transforming growth factor beta1 activation is release of the large latent complex from the extracellular matrix of growth plate chondrocytes by matrix vesicle stromelysin-1 (MMP-3). Calcif Tissue Int $\underline{70}$ (1), 54-65 
Mallat Z, Tedgui A (2002): The role of transforming growth factor beta in atherosclerosis: novel insights and future perspectives. Curr Opin Lipidol $\underline{13}$ (5), 523-529

Mallat Z, Gojova A, Marchiol-Fournigault C, Esposito B, Kamate C, Merval R, Fradelizi D, Tedgui A (2001): Inhibition of transforming growth factor-beta signaling accelerates atherosclerosis and induces an unstable plaque phenotype in mice. Circ Res $\underline{89}$ (10), 930-934

Marín-García J (2011). Signaling in the heart. E-published by Springer

Martin M, Lefaix J, Delanian S (2000): TGF-beta1 and radiation fibrosis: a master switch and a specific therapeutic target? Int J Radiat Oncol Biol Phys 47 (2), 277-290

Massague J (1990): The transforming growth factor-beta family. Annu Rev Cell Biol $\underline{6}$ 597-641

Massague J (1998): TGF-beta signal transduction. Annu Rev Biochem 67 753-791

Massague J (2008): TGFbeta in Cancer. Cell 134 (2), 215-230

Massague J, Wotton D (2000): Transcriptional control by the TGF-beta/Smad signaling system. EMBO J 19 (8), 1745-1754

Massague J, Gomis RR (2006): The logic of TGFbeta signaling. FEBS Lett 580 (12), 28112820

Massague J, Blain SW, Lo RS (2000): TGFbeta signaling in growth control, cancer, and heritable disorders. Cell 103 (2), 295-309

Mehta JL, Attramadal H (2007): The TGFbeta superfamily in cardiovascular biology. Cardiovasc Res $\underline{74}$ (2), 181-183

Miyazono K, Olofsson A, Colosetti P, Heldin CH (1991): A role of the latent TGF-beta 1binding protein in the assembly and secretion of TGF-beta 1. EMBO J $\underline{10}$ (5), 1091-1101

Mohren S, Weiskirchen R (2009): Non-synonymous gene polymorphisms in the secretory signal peptide of human TGF-beta1 affect cellular synthesis but not secretion of TGF-beta1. Biochem Biophys Res Commun $\underline{379}$ (4), 1015-1020

Mu D, Cambier S, Fjellbirkeland L, Baron JL, Munger JS, Kawakatsu H, Sheppard D, Broaddus VC, Nishimura SL (2002): The integrin alpha(v)beta8 mediates epithelial homeostasis through MT1-MMP-dependent activation of TGF-beta1. J Cell Biol 157 (3), 493-507 
Munger JS, Sheppard D (2011): Cross talk among TGF-beta signaling pathways, integrins, and the extracellular matrix. Cold Spring Harb Perspect Biol $\underline{3}$ (11), a005017

Munger JS, Harpel JG, Gleizes PE, Mazzieri R, Nunes I, Rifkin DB (1997): Latent transforming growth factor-beta: structural features and mechanisms of activation. Kidney Int 51 (5), 13761382

Munger JS, Huang X, Kawakatsu H, Griffiths MJ, Dalton SL, Wu J, Pittet JF, Kaminski N, Garat C, Matthay MA et al. (1999): The integrin alpha v beta 6 binds and activates latent TGF beta 1: a mechanism for regulating pulmonary inflammation and fibrosis. Cell $\underline{96}$ (3), 319-328

Murakami K, Takemura T, Hino S,Yoshioka K (1997): Urinary transforming growth factorbeta in patients with glomerular diseases. Pediatr Nephrol 11 (3), 334-336

Murphy-Ullrich JE, Poczatek M (2000): Activation of latent TGF-beta by thrombospondin-1: mechanisms and physiology. Cytokine Growth Factor Rev 11 (1-2), 59-69

Nagata H, Hatano E, Tada M, Murata M, Kitamura K, Asechi H, Narita M, Yanagida A, Tamaki N, Yagi S et al. (2009): Inhibition of c-Jun NH2-terminal kinase switches Smad3 signaling from oncogenesis to tumor- suppression in rat hepatocellular carcinoma. Hepatology 49 (6), 19441953

Nielsen H, Engelbrecht J, Brunak S, von Heijne G (1997): Identification of prokaryotic and eukaryotic signal peptides and prediction of their cleavage sites. Protein Eng 10 (1), 1-6

Ogawa E, Ruan J, Connett JE, Anthonisen NR, Pare PD, Sandford AJ (2007): Transforming growth factor-betal polymorphisms, airway responsiveness and lung function decline in smokers. Respir Med 101 (5), 938-943

Palzkill T, Le QQ, Wong A, Botstein D (1994): Selection of functional signal peptide cleavage sites from a library of random sequences. J Bacteriol $176(3), 563-568$

Parsons CJ, Takashima M, Rippe RA (2007): Molecular mechanisms of hepatic fibrogenesis. $J$ Gastroenterol Hepatol 22 (Suppl 1), S79-84

Peters CA, Stock RG, Cesaretti JA, Atencio DP, Peters S, Burri RJ, Stone NN, Ostrer H, Rosenstein BS (2008): TGFB1 single nucleotide polymorphisms are associated with adverse quality of life in prostate cancer patients treated with radiotherapy. Int J Radiat Oncol Biol Phys $\underline{70}(3), 752-759$ 
Pohlers D, Brenmoehl J, Loffler I, Muller CK, Leipner C, Schultze-Mosgau S, Stallmach A, Kinne RW, Wolf G (2009): TGF-beta and fibrosis in different organs - molecular pathway imprints. Biochim Biophys Acta 1792 (8), 746-756

Presser LD, McRae S, Waris G (2013): Activation of TGF-beta1 promoter by hepatitis C virusinduced AP-1 and Sp1: role of TGF-beta1 in hepatic stellate cell activation and invasion. PLoS One $\underline{8}(2)$, e56367

Raabe A, Derda K, Reuther S, Szymczak S, Borgmann K, Hoeller U, Ziegler A, Petersen C,Dikomey E (2012): Association of single nucleotide polymorphisms in the genes ATM, GSTP1, SOD2, TGFB1, XPD and XRCC1 with risk of severe erythema after breast conserving radiotherapy. Radiat Oncol $\underline{7}, 65$

Randall LL, Hardy SJ (1989): Unity in function in the absence of consensus in sequence: role of leader peptides in export. Science 243 (4895), 1156-1159

Rosenstein BS (2011): Identification of SNPs associated with susceptibility for development of adverse reactions to radiotherapy. Pharmacogenomics 12 (2), 267-275

Ruiz-Ortega M, Rodriguez-Vita J, Sanchez-Lopez E, Carvajal G, Egido J (2007): TGF-beta signaling in vascular fibrosis. Cardiovasc Res $\underline{74}$ (2), 196-206

Saharinen J, Hyytiainen M, Taipale J, Keski-Oja J (1999): Latent transforming growth factorbeta binding proteins (LTBPs)--structural extracellular matrix proteins for targeting TGF-beta action. Cytokine Growth Factor Rev $\underline{10}$ (2), 99-117

Sanjabi S, Zenewicz LA, Kamanaka M, Flavell RA (2009): Anti-inflammatory and proinflammatory roles of TGF-beta, IL-10, and IL-22 in immunity and autoimmunity. Curr Opin Pharmacol $\underline{9}$ (4), 447-453

Schirmer MA, Brockmoller J, Rave-Frank M, Virsik P, Wilken B, Kuhnle E, Campean R, Hoffmann AO, Muller K, Goetze RG et al. (2011): A putatively functional haplotype in the gene encoding transforming growth factor beta- 1 as a potential biomarker for radiosensitivity. Int J Radiat Oncol Biol Phys 79 (3), 866-874

Schirmer MA, Mergler CP, Rave-Frank M, Herrmann MK, Hennies S, Gaedcke J, Conradi LC, Jo P, Beissbarth T, Hess CF et al. (2012): Acute toxicity of radiochemotherapy in rectal cancer patients: a risk particularly for carriers of the TGFB1 Pro25 variant. Int J Radiat Oncol Biol Phys $\underline{83}$ (1), 149-157

Sheppard D (2005): Integrin-mediated activation of latent transforming growth factor beta. Cancer Metastasis Rev 24 (3), 395-402 
Shi Y, Massague J (2003): Mechanisms of TGF-beta signaling from cell membrane to the nucleus. Cell $\underline{113}$ (6), 685-700

Shihab FS, Yamamoto T, Nast CC, Cohen AH, Noble NA, Gold LI, Border WA (1995): Transforming growth factor-beta and matrix protein expression in acute and chronic rejection of human renal allografts. J Am Soc Nephrol $\underline{6}$ (2), 286-294

Stoll C, Mengsteab S, Stoll D, Riediger D, Gressner AM, Weiskirchen R (2004): Analysis of polymorphic TGFB1 codons 10, 25, and 263 in a German patient group with non-syndromic cleft lip, alveolus, and palate compared with healthy adults. BMC Med Genet $\underline{5}, 15$

Taipale J, Saharinen J, Keski-Oja J (1998): Extracellular matrix-associated transforming growth factor-beta: role in cancer cell growth and invasion. Adv Cancer Res $\underline{75}, 87-134$

Tang Y, McKinnon ML, Leong LM, Rusholme SA, Wang S, Akhurst RJ (2003): Genetic modifiers interact with maternal determinants in vascular development of Tgfb1(-/-) mice. Hum Mol Genet $\underline{12}$ (13), 1579-1589

ten Dijke P, Arthur HM (2007): Extracellular control of TGFbeta signalling in vascular development and disease. Nat Rev Mol Cell Biol $\underline{8}$ (11), 857-869

Terpe K (2003): Overview of tag protein fusions: from molecular and biochemical fundamentals to commercial systems. Appl Microbiol Biotechnol $\underline{60}$ (5), 523-533

Toma I, McCaffrey TA (2012): Transforming growth factor-beta and atherosclerosis: interwoven atherogenic and atheroprotective aspects. Cell Tissue Res $\underline{347}$ (1), 155-175

Trachtman H, Fervenza FC, Gipson DS, Heering P, Jayne DR, Peters H, Rota S, Remuzzi G, Rump LC, Sellin LK et al. (2011): A phase 1, single-dose study of fresolimumab, an anti-TGFbeta antibody, in treatment-resistant primary focal segmental glomerulosclerosis. Kidney Int $\underline{79}$ (11), 1236-1243

Tucker SL, Geara FB, Peters LJ, Brock WA (1996): How much could the radiotherapy dose be altered for individual patients based on a predictive assay of normal-tissue radiosensitivity? Radiother Oncol $\underline{38}$ (2), 103-113

Unsold C, Hyytiainen M, Bruckner-Tuderman L, Keski-Oja J (2001): Latent TGF-beta binding protein LTBP-1 contains three potential extracellular matrix interacting domains. J Cell Sci 114 (Pt 1), 187-197

van de Wetering J, Weimar CH, Balk AH, Roodnat JI, Holweg CT, Baan CC, van Domburg RT, Weimar W (2006): The impact of transforming growth factor-betal gene polymorphism on end-stage renal failure after heart transplantation. Transplantation $\underline{82}$ (12), 1744-1748 
Veldhoen M, Stockinger B (2006): TGFbeta1, a "Jack of all trades": the link with proinflammatory IL-17-producing T cells. Trends Immunol 27 (8), 358-361

Verrecchia F, Mauviel A (2007): Transforming growth factor-beta and fibrosis. World J Gastroenterol $\underline{13}$ (22), 3056-3062

Wahl SM, Wong H, McCartney-Francis N (1989): Role of growth factors in inflammation and repair. J Cell Biochem $\underline{40}$ (2), 193-199

Wan YY, Flavell RA (2008): TGF-beta and regulatory T cell in immunity and autoimmunity. J Clin Immunol $\underline{28}$ (6), 647-659

Wells RG (2000): Fibrogenesis. V. TGF-beta signaling pathways. Am J Physiol Gastrointest Liver Physiol 279 (5), G845-850

Wolff HA, Daldrup B, Jung K, Overbeck T, Hennies S, Matthias C, Hess CF, Roedel RM, Christiansen H (2011): High-grade acute organ toxicity as positive prognostic factor in adjuvant radiation and chemotherapy for locally advanced head and neck cancer. Radiology 258 (3), 864871

Zhang L, Yang M, Bi N, Ji W, Wu C, Tan W, Zhao L, Yu D, Lin D, Wang L (2010): Association of TGF-beta1 and XPD polymorphisms with severe acute radiation-induced esophageal toxicity in locally advanced lung cancer patients treated with radiotherapy. Radiother Oncol 97 (1), 1925

Zhao L, Sheldon K, Chen M, Yin MS, Hayman JA, Kalemkerian GP, Arenberg D, Lyons SE, Curtis JL, Davis M et al. (2008): The predictive role of plasma TGF-beta1 during radiation therapy for radiation-induced lung toxicity deserves further study in patients with non-small cell lung cancer. Lung Cancer $\underline{59}$ (2), 232-239

Zhu ML, Wang M, Shi TY, Li QX, Xi P, Xia KQ, Zheng L,Wei QY (2013): No association between TGFB1 polymorphisms and late radiotherapy toxicity: a meta-analysis. PLoS One $\underline{8}$ (10), e76964

Zimmermann R (2009): Protein transport into the endoplasmic reticulum. E-published by Landes Bioscience 


\section{List of publications}

Filonenko K, Bokelmann K, Saadatmand AR, Brockmöller J, Schirmer MA (2013): Molecular mechanisms for the Arg25Pro polymorphism predisposing to acute toxicity of radiochemotherapy. Br J Clin Pharmacol $\underline{75}$ (Suppl.1), 15

Filonenko K, Brockmöller J, Schirmer M (2013): The TGFB1 Arg25Pro polymorphism and acute toxicity of radiotherapy: Studying the mechanism behind. Drug Metab Drug Interact 28 (3), A45.

Filonenko K, Adreeva ZB, Malik JA, Pasynkova TA (2010): Selection criteria for creation a prognostic model of asthma control achievement. Ukr J Asthma and allergology 1-2, 67-68.

Filonenko K, Chumak YY, Pobedonna TA (2010): Efficacy and safety of specific immunotherapy in patients with bronchial asthma. Book of abstracts of the 17th International students' congress of medical sciences, Groningen, the Netherlands $\underline{1}, 303$.

Filonenko K., Gavrylov A., Pobedonna T. (2010): Specific immunotherapy as a method of asthma control achievement. Eur J Med Res 15, 208.

Filonenko K, Pobedonna TA. (2010): Prognostication - modern direction in asthma study. $U k r$. Med Almanac 10, 21-22.

Filonenko K, Bugaeva OV, Romanenko IM, Afonin SL. (2007): Elimination therapy in multimodality therapy for urticaria. Ukr Med Almanac $\underline{6}$ : 243-46. 


\section{Acknowledgment}

This dissertation would not have been possible without constant support and encouragement of many important people.

First and foremost, I am deeply indebted to Prof. Dr. Jürgen Brockmöller, who gave me the possibility to work in the Institute of Clinical Pharmacology and supported my thesis work.

I would like to express my thanks to Deutsche Forschungsgemeinschaft (DFG) for financial support, which allowed me to undertake this research.

I am extremely thankful to my mentor and doctoral advisor, Dr. Markus Schirmer, who gave me an opportunity to join his group, who was understanding, had always positive attitude and a lot of valuable advices. I want to thank him for the constant support and patience, motivation and enthusiasm, insightful suggestions and guidance throughout my work. I thank him very much for the valuable help and all the corrections of my thesis.

I acknowledge my gratitude to PD Dr. Mladen Tzvetkov for his comments and suggestions, which were essential for the completion of this work.

I would also like to thank M. Sc. Margret Rave-Fränk, Juliane Kasten-Krapp and Alexandra Bitter from the Department of Radiotherapy and Radiation Oncology, University medical center Göttingen for their cooperation, help and allowance to perform the irradiation of my cells with their equipment.

My special thanks goes to my colleagues from the Institure of Clinical Pharmacology Dr. Kristin Bokelmann, Claudia Lüske, Nawar Dalila, S. Mohammad Hasheminasab, Tina Seitz, Karoline Jobst and Sina Tadjerpisheh for their great support, helpful suggestions and advices. 


\section{Curriculum Vitae}

I was born on 21 September 1987 in Lugansk, Ukraine. In 2003, I graduated from the Lugansk Lyceum of Foreign Languages. I studied medicine at the Lugansk State Medical University, Ukraine from 2003, and successfully graduated in 2009. In the same year I started residency and in parallel my master thesis in Internal Medicine at the Lugansk State Medical University. During university and residency time I participated in the research projects at the departments of Normal Physiology and Internal Medicine. In 2009, I took part in the short term training in internal medicine at Wroclaw Medical University, Poland under supervision of Dr. W Wojciech Barg.

In 2011 I passed final examinations and got thequalification "Internist", and defended my master thesis.

In August 2011, I joined the group of Dr. Markus Schirmer in the Institute of Clinical Pharmacology, University medical center Göttingen under supervision of Prof. Dr. Jürgen Brockmöller. 